\title{
High-speed photography and digital optical measurement techniques for geomaterials: Fundamentals and applications
}

\author{
H.Z. Xing ${ }^{1}$, Q.B. Zhang*1, C.H. Braithwaite ${ }^{2}$, B. Pan $^{3}$ and J. Zhao ${ }^{1}$ \\ ${ }^{1}$ Department of Civil Engineering, Monash University, Clayton, VIC 3800, Australia \\ ${ }^{2}$ Cavendish Laboratory, JJ Thomson Avenue, Cambridge, CB3 OHE, United Kingdom \\ ${ }^{3}$ Institute of Solid Mechanics, Beihang University, Beijing 100191, China \\ * To whom correspondence should be addressed. \\ Email: qianbing.zhang@alumni.epfl.ch \\ Telephone and fax number: +61 399054385 \\ Address: Department of Civil Engineering, Monash University, VIC 3800, Australia.
}

\begin{abstract}
Geomaterials (i.e., rock, sand, soil and concrete) are increasingly being encountered and used in extreme environments, in terms of the pressure magnitude and the loading rate. Advancing the understanding of the mechanical response of materials to impact loading relies heavily on having suitable high-speed diagnostics. One such diagnostic is high-speed photography, which combined with a variety of digital optical measurement techniques can provide detailed insights into phenomena including fracture, impact, fragmentation and penetration in geological materials. This review begins with a brief history of high-speed imaging. Section 2 discusses of the current state-of-the-art of high-speed cameras, which includes a comparison between Charge-Coupled Device (CCD) and Complementary Metal-Oxide-Semiconductor (CMOS) sensors. The application of high-speed photography to geomechanical experiments is summarized in Section 3. Section 4 is concerned with digital optical measurement techniques including photoelastic coating, Moiré, caustics, holographic interferometry (HI), particle image velocimetry (PIV), digital image correlation (DIC) and infrared thermography (IRT), in combination with highspeed photography to capture transient phenomena. The last section provides a brief summary and discussion of future directions in the field.
\end{abstract}

Keywords: High-speed photography; digital optical measurement; dynamic loading; high strain rate; fracturing. 


\section{CONTENTS}

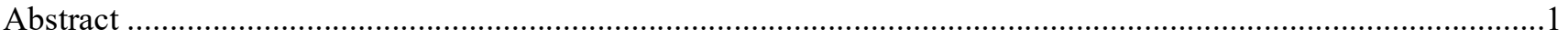

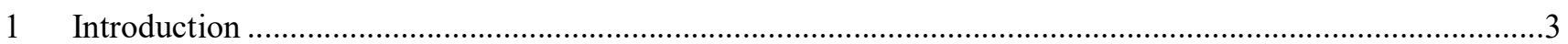

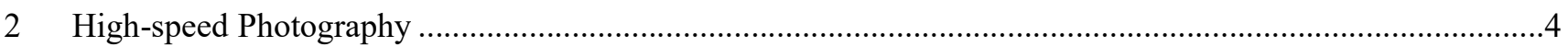

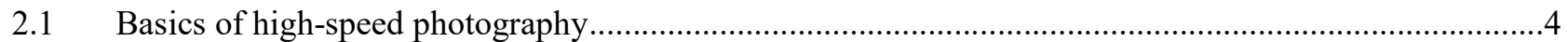

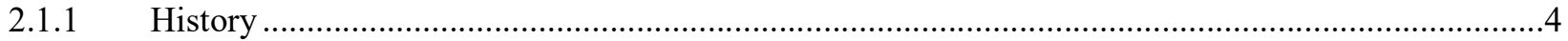

2.1.2 Frame rate and exposure time

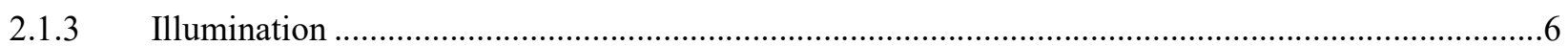

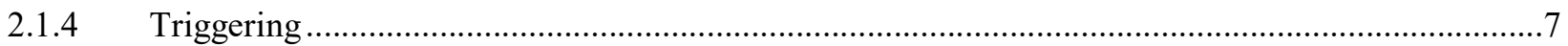

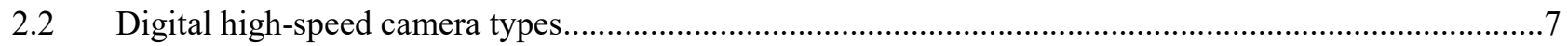

3 Recent Applications of high-speed photography to geomaterials ...........................................................

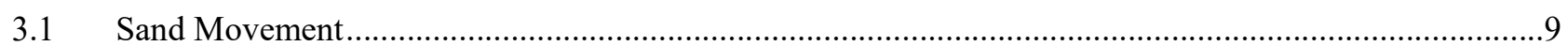

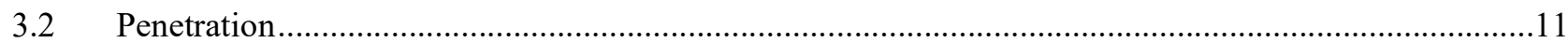

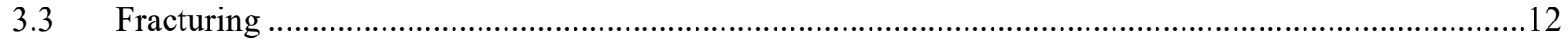



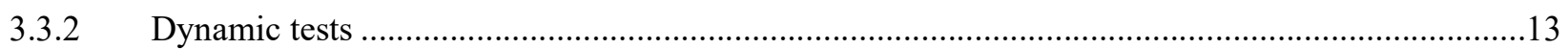

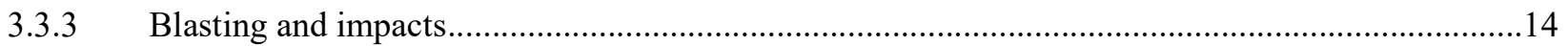

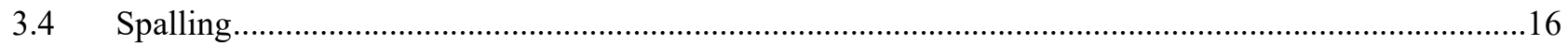



4 High-speed Digital Optical Measurement Techniques and their applications to geomaterials .......................19

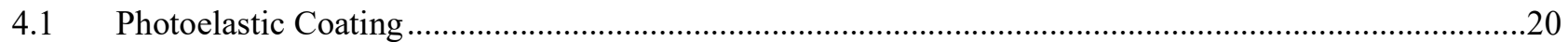

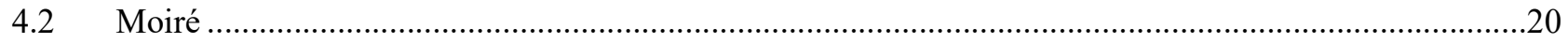



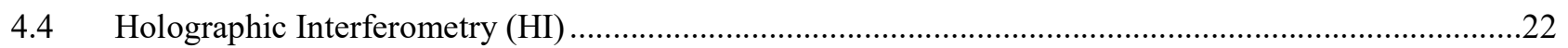



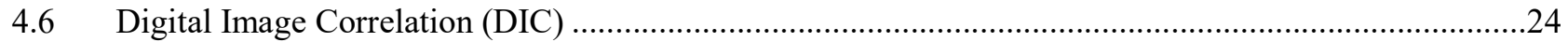



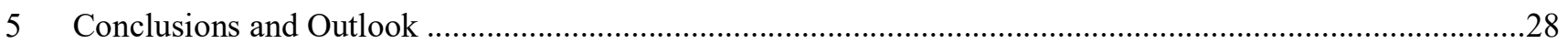

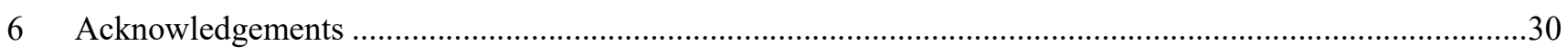

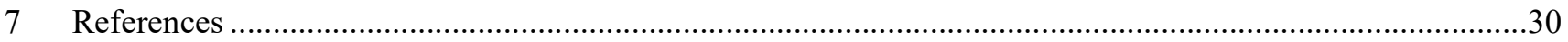




\section{INTRODUCTION}

Geomaterials can be defined as "Processed or unprocessed soils, rocks or minerals used in the construction of buildings or structures, including man-made construction materials manufactured from soils, rocks or minerals (Fookes 1991)". Therefore, in addition to rock and soil, some man-made materials including concrete and bricks can also be considered as geomaterials. A complete review of the behaviour and testing methods of geomaterials under quasi-static loading is given by (Mayne et al. 2009). The behaviour of geomaterials under dynamic loading is a topic of extensive research interest owing to the importance to industry, various environmental concerns and society as a whole (Braithwaite 2009; Zhang 2014b; Zhang et al. 2017; Zhang and Zhao 2014b; Zhou and Zhao 2011). Dynamic loading events can be natural in origin, for example, earthquakes, meteorite impact and volcanic eruptions. Alternatively the loading can be man-made such as mining, tunnelling, weapon penetration and hydraulic fracturing. Therefore, a deep insight into the behaviour of geomaterials subjected to dynamic loading is essential to prevent or alleviate the threat of natural disaster to human life, and on the other hand, to improve the development of natural resources and inform best practice in civil engineering and construction (Forquin 2017). However, due to the difficulties associated with measuring and recording events with short durations, particularly those unable to be observed adequately by the naked eye, the dynamic properties of geomaterials were not well understood for a long period.

High-speed photography is particularly useful in geomechanical tests under dynamic loading owing to the scales and frame rates involved. The definition of high-speed photography varies in different sources. One classical definition divides the historic implementations of high-speed photography into four categories, which vary according to framing rate and the technologies used (Peres 2013). From low to high frame rate, these categories are: (a) high-speed, 50 to 500 frames per second (fps), using intermittent film motion and mechanical shuttering; (b) very high-speed, 500 to $100,000 \mathrm{fps}$, using continuously moving film, image compensation, and digital video systems; (c) ultra-high-speed, 100,000 to 10 million fps (Mfps), using stationary film with moving image systems and electronically with image converter cameras; and (d) super high-speed, in excess of $10 \mathrm{Mfps}$, where film has been largely superseded by electronic imaging and recording. Modern high-speed systems are invariably electronic in nature. However, as well as temporal resolution, to gain a full appreciation of the capabilities of an imaging system it is necessary to consider the spatial resolution. As (Fuller 1994) states, a more comprehensive description of high-speed imaging can be proposed as: "recording optical or electro-optical information with adequately short exposures and fast enough framing rates for an event to be evaluated with a temporal and dimensional resolution which satisfies the experimenter". Therefore, the definition of "high-speed photography" covers all of the imaging systems discussed in this review.

The following conferences provides a good platform for dissemination of the state of the art in high-speed imaging:

- The British Association for High-speed Photography (AHSP) founded in 1954 organizes activities and annual conferences to discuss the latest development.

- DYMAT Technical Meeting in 2013 was on the topic of 'High speed imaging for dynamic testing of materials and structures'.

- The Society for Experimental Mechanics (SEM) organized a panel on Imaging at High Strain Rates in 2013 annual conference. In 2014, a "High Rate Image" panel was organized for the fourth year in a row.

- The Society of Photo Instrumentation Engineers (SPIE) has held many conferences on photonics subjects and published the Proceedings of the International Congresses on High-speed Photography and Photonics since 1954. The latest one is the 31st International Congress in 2016.

In general, with high-speed photography, the scene is captured using a high framing rate to record motion, which can later be played back at a reduced rate for analysis. However, in some cases, the analysis may still be observation 
based, but digitizing the images either by scanning or electronic capturing allow for quantitative measurements. Nowadays, the utility of high-speed photography has been greatly improved in combination with optical measurement techniques and computer calculation. A detailed background and description of some representative optical measurement techniques can be found in (Rastogi 2015; Sharpe 2008). Using digital image processing techniques such as particle image velocimetry (PIV) and digital image correlation (DIC), it is possible to examine material deformation, through the visualization of displacement, strain or stress field at the microsecond $(\mu \mathrm{s})$ timescale. This can be achieved with a wide range of measurement sensitivities and resolutions as well as being a non-contact diagnostic with the relatively simple setup. In terms of high-speed photographic technology, (Ray 2006) and (Honour 2009) present comprehensive summary of the principles and applications. Reviews of optical techniques combined with high-speed photography are given in (Field et al. 2009; Field et al. 2004). A systematic description of a full-field optical method for solid mechanics is available (Rastogi and Hack 2012). The applications of high-speed photography and digital optical measurement have been recently reviewed in the areas including fluid mechanics (Dear and Field 1988; Versluis 2013), bubbles and drops (Lauterborn and Hentschel 1985; Thoroddsen et al. 2008), glass and ceramics (Walley 2014), ballistics (Settles 2006), and phoniatrics (Hertegård et al. 2003). However, it would be of considerable benefit to the geomechanical community to have a summary of the conducted research in this field, as current efforts to implement high-speed imaging are complicated by material related issues which have been solved by other researchers.

This review concentrates on the application and performance evaluation of high-speed photography and combined digital optical measurement techniques in geomaterial experiments. The current introduction is followed by a discussion of some fundamentals of high-speed photography, including the historical development and a discussion of camera types and currently available CCD and CMOS-based systems. In Section 3, applications of high-speed photography to granular flow, penetration, crack fracturing, spalling and fragmentation are reviewed. In each subsection, the definition and the significance of the topic are presented before a description of typical experimental setups (particularly the camera setup), as well as sequences of example images and quantitative results. Section 4 reviews seven combined digital optical measurement techniques in geomaterials, including photoelasticity, Moiré, caustic, holographic interferometry (HI), infrared thermography (IRT), PIV and DIC. The fundamental principle of each optical method is given, and the development and the original use of these methods are described. By showing sequences of typical images, an evaluation of the efficacy of each method as related to geomaterials is provided. Finally, a brief summary and future directions are presented.

\section{High-SPEED PHOTOGRAPHY}

\subsection{BASICS OF HIGH-SPEED PHOTOGRAPHY}

\subsubsection{History}

High-speed imaging technology relied initially on having highly light sensitive emulsions, but in general these were unavailable in the early years of photography. The goal of high-speed photography in the early days was sufficient speed to record a street scene without the people being blurred. It is often stated that the first instance of what we would now call high-speed photography was to settle a hotly debated issue "is there a moment in a horse's gait when all four hooves are off the ground at once?" in 1872 (NMAH 2001). The photographer, Eadweard Muybridge, was a pioneer of scientific research in motion analysis. He devised a camera system consisting of 12 (later 24) individual cameras capturing images on photographic glass plates and triggered by the horse's legs via tripwires in 1878. The photographs were taken in succession one twenty-fifth of a second apart, with the shutter speeds calculated to be less than 1/2000 s. This famous sequence was named Sallie Gardner at a Gallop (Muybridge 1878), as shown in Fig. 1. In 1888, George Eastman invented photographic film and the Kodak cameras that housed it, 
making photography a process much more widely available (Eastman 1888). In 1892 the British Scientist Boys suggested an original design of rotating mirrors (Boys 1892), which could be used for a high-speed imaging system, and this principle is still in use today. One of the early drivers for faster framing with cameras came from the desire to reproduce motion smoothly, and thus it requires a number of frames per second to be taken. A $16 \mathrm{~mm}$ cine highspeed camera was developed by the Kodak in the 1930s, which eventually reached up to $5000 \mathrm{fps}$ (Bourne 2013). Another great pioneer, Edgerton, invented the electronic flash stroboscope, which allowed illumination to provide the "high-speed" nature rather than the imaging system, and took many iconic photographs, e.g. the corona formed by the water impacting into the milk (Edgerton and Killian 1954).

Fig. 1. Sallie Gardner at a Gallop (Muybridge 1878) (The photographs were taken at a distance of around $70 \mathrm{~cm}$ corresponding to a time interval of approximately $0.04 \mathrm{~s}$.)

The main development motivation for high-speed imaging came, as with much high-rate scientific research, in the wake of the Manhattan project and nuclear weapons research during the cold war. Coupled with a desire to study ballistics in greater depth (Fuller 2005), it gave birth to the modern understanding of high-speed photography. In the 1950 s, rotating mirror technology was applied to high-speed imaging of thermonuclear weapons (Bowden and McOnie 1967; Coleman 1959) with the technology eventually capable of recording at $1 \mathrm{Mfps}$. Afterwards, a series of rotating mirror, streak cameras and rotating prism cameras sprang up (Courtney-Pratt 1973; Courtney-Pratt 1986). For applications where fewer images were required at a higher rate, the image converter camera was developed by Courtney-Pratt in 1949 (Courtney-Pratt 1949) using a method of converting light to charged particles and then back again, which allowed for the "image" to be steered using charged plates to fall on spatially separated areas of the recording medium. In the 1980s, there were no marked advances in high-speed cameras, since the film-based highspeed camera approached the theoretical maximum performance possible due to physical limitations (Huston 1978). In contrast, the high-speed digital photography underwent its fast development due to a great breakthrough in photosensitive media, resulting in the photosensitive emulsions replaced gradually by electronic semiconductor devices (CCD or CMOS).

\subsubsection{Frame rate and exposure time}

The frame rate, refers to the number of frames taken per second. The reciprocal function of the frame rate is approximately the interframe time (depending on whether the exposure time is included in the calculations or not), simply the time between frames, and essentially defines the temporal resolution of the system. Fig. 2 is a schematic representation of the definitions of frame rate, interframe time, exposure time, and illumination time in a series of successive frames. It illustrates two different high-speed photography methods, firstly a long illumination and short exposures controlled by the camera, and secondly a long camera exposure illuminated by short bursts of illumination.

Fig. 2. Illustration of interframe time, exposure time and illumination time. A: a long illumination and short exposures controlled by the camera, and B: a long camera exposure illuminated by short bursts of illumination (after (Versluis 2013)).

The optimum frame rate for the observation $f$ can be estimated from:

$$
f=N \cdot u / l
$$

where $N$ represents the required number of samples, a minimum value of 2, but a typical value of 5-10 would be more appropriate, $u$ is a typical velocity, and $l$ is a typical length scale. Taking the split Hopkinson pressure bar (SHPB) test as an example, a typical wave propagation velocity in the geomaterial sample is several kilometres per second (i.e., millimetres per microsecond). Thus, millimetre sized samples require microsecond interframe times or approximately a frame rate of Mfps. According to Eq. (1), the required frame rates for some common experimental setups are listed in Table 1.

Table 1 Some common high strain-rate tests of geomaterials and their required frame rates. 


\begin{tabular}{ll}
\hline Application & Frame Rate (kfps) \\
\hline Blast effect & $5-50$ \\
Projectile penetrating & $25-75$ \\
Shock tube work & $25-100$ \\
Hopkinson bar test & $100-1,000$ \\
High rate fracture & $300-1,000$ \\
Explosive detonation initiation & 1,000 \\
\hline
\end{tabular}

For rotating mirror cameras, the frame rate is a function of the rotational speed of the mirror and the angular density of the image capture devices. In a gated intensified camera, the time between frames is randomly programmable, and may not necessarily be the same for each frame. One way for film-based high-speed cameras to increase the frame rate is to subdivide the photograph area or reduce the film size, making it possible to take more photographs per second without increasing the accelerations and the stress in the film and/or the moving parts. However, this can reduce the information obtained in each frame (Courtney-Pratt 1957). Similar techniques of image splitting are common across many digital high-speed systems as well.

The exposure time is the time for which light is collected for an image. In order to build up a sequence of still images (i.e., without motion blur) showing the change in a scene with time, the exposure time is typically shorter than the interframe time. One criterion for the necessary exposure time is the time taken for an object to move its own length rather than the object's speed (Ray 2006). Therefore, normally the smaller the object is, like sand, the shorter the exposure time is likely to be in many situations. The impact of a steel ball into very fine loose sand is well defined by short exposure time (Lohse et al. 2004). Standard shutter time for digital high-speed cameras is often around $1 \mu \mathrm{s}$, but can also be as short as hundreds of nanoseconds (ns), however, such options are often export controlled. Specialized double-frame PIV cameras are capable of having exposure times of $200 \mathrm{~ns}$, while an intensified CCD camera can have an exposure time as short as $250 \mathrm{ps}$ owing to the fast electronic gating of the image intensifier which converts photons imaged onto a photocathode to electrons (after (Versluis 2013)). The short-pulse laser illumination developed by the Oxford Laser Company (Oxfordlasers) can enhance camera performance by reducing the effective exposure time to $1 / 40,000,000$ of a second ( $25 \mathrm{~ns}$ ).

\subsubsection{Illumination}

The difficulties encountered in lighting high-speed photography can often be the limiting factor in the quality of the data obtained, rather than the camera itself (Courtney-Pratt 1957). Since the number of photons impinging on the detector is strongly restricted in a short exposure time, a good deal of photons is required to begin with. This problem is becoming acute when colour images are captured, as the need for three colour filters generally increases the light required by at least a factor of 2 .

Various types of lighting available for high-speed photography are summarized in Table 2. Nowadays, lightemitting diodes (LEDs) are becoming more popular as a lighting source in high-speed photography, replacing the older technologies of traditional filament-based flash units. It is possible to vary the output intensity, synchronize with the camera, trigger externally or provide a pulsed output. Moreover, LEDs offer continuous light output in addition to flashes, which can be done at short intervals owing the LEDs not requiring a preheat time. However, if one uses LED lights, a high quality DC power supply is essential to avoid flickering. Another light option is laser pulse, in which a typical high frequency pulsed laser can offer shutter speeds ranging from $30 \mathrm{~ns}$ to $250 \mathrm{~ns}$ at frequencies up to around $50 \mathrm{kHz}$ without the need for an image intensifier. Both LED and laser systems share an advantage over conventional lighting that they are "cold light" and do not generate high temperatures which could affect some sample types, for example plastics. Laser illumination has the unique advantage of single wavelength illumination, and this aids with imaging processes which emit light, such as burning. It also allows for interferometric, holography, or PIV measurements to be made through focusing of the beam on a thin sheet. 
Table 2 Types of lighting available for high-speed photography (after (Fuller 2009))

\begin{tabular}{ll}
\hline Source & Typical duration (s) \\
\hline Sunlight & continuous \\
Tungsten filament lamps & continuous \\
Continuous Arc sources and gas & continuous \\
discharge lamps & \\
Flash bulbs & $0.5-5 \times 10^{-3}$ \\
Electronic flash & $10^{-3}-10^{-6}$ \\
Argon bomb & $10^{-6}-10^{-7}$ \\
Electrical spark & $10^{-6}-10^{-9}$ \\
X-ray flash & $10^{-7}-10^{-9}$ \\
Pulsed laser & $10^{-6}-10^{-12}$ \\
Super radiant light sources & $10^{-9}$ \\
LED & continuous or up to $5 \times 10^{-7}$ \\
\hline
\end{tabular}

\subsubsection{Triggering}

For high-speed imaging, triggering can determine the success or failure of the recording of interest due to the limited number of frames captured within an extremely short time. Triggering is also essential, since other measurements like strain gauges and acoustic emission recordings need to have a common zero to aid post-experimental analysis. There are several triggering methods commonly used, such as manually (i.e., pushing a button), through triggering a computer interface, and by a signal from a delay/pulse generator. Generally a generator takes a variety of inputs (e.g. optical, acoustical and magnetic signals) that can be transferred into an electrical trigger pulse. The transistortransistor logic (TTL) signal is widely used for high-speed camera. It should be noted that the transportation of trigger signal needs time, which can be considerable in relation to the framing time in ultra-high-speed imaging, and causes a delayed trigger. Programmable delays on selected input and output triggers are usually accurate to a few nanoseconds. Some camera systems will introduce an unavoidable delay of their own, for example, rotating prism cameras need a period of time to accelerate up to a wanted framing rate before recording. If standard flash lamps are used, the warm-up time will also need to be incorporated into a delay sequence to avoid dark photos. When continuous recording is available (i.e., images are recorded to a buffer which is continuously overwritten), further triggering options become available. If the start of an event is important or an event before triggering is of interest, one may adopt pre-triggered acquisition where the trigger tells the camera to keep the frames recorded before a certain point. In many cases, when the record length (often more than a second), the triggering becomes easy, a short event can be easily timed within the record time even with manual triggering.

\subsection{DigITAL HIGH-SPEED CAMERA TYPES}

CMOS and CCD technologies were developed roughly at the same time (in 1963 and 1969, respectively). The main difference is how the value of the electric charge of each cell in the image is read. In CCD architecture, after each exposure, the charges in every row of pixel are moved into the buffer device successively and then are guided to the amplifier on the edge of the CCD. Finally, an output is generated from an analogue to digital converter (ADC) in sequence. In most CMOS devices, there are several transistors at each pixel that amplify and move the charge using more traditional wires. Therefore, the CCD architecture allows high-quality and low-noise images, but CMOS enables parallel and partial readout of subareas of the sensor at high rates. As the CMOS architecture tends to be utilised in consumer devices and therefore receives more development, the line between CCD and CMOS image quality has become more blurred. A classic work on the pros and cons of CCD versus CMOS was written by (Litwiller 2001).

There are three main typical types of high-speed CCD sensor cameras: rotating mirror, intensified CCD (ICCD) and in-situ storage image sensor (ISIS) CCD cameras. The rotating mirror system was first designed for streak photography but was thought impossible to be adapted for 2D imaging (Sultanoff 1950) until Miller succeeded in 
doing so using a smart optical configuration, known as the Miller principle (Miller 1949). Having multiple fixed focusing elements behind which sits a photosensitive medium which is exposed to light in a sequential fashion via the action of the mirror rotation. Typical frame rates are in Mfps and resolutions are 2 to 8 megapixels per image. The maximum speed and resolution can be achieved simultaneously. The disadvantages include: the movable mechanical device inside increases its complexity and fragility (Field 1983), the number of frames is limited, undesired measurement errors of the multi-sensor system might be introduced by manufacturing differences of each CCD (Kirugulige and Tippur 2009; Moulart et al. 2011), alignment issues could also cause individual frames to be spatially shifted from each other, and the weight and sizes to some extent restrict portability. Typical applications of such high-speed camera include detonics (Held 1987), mechanical experiments (Sarva et al. 2007), plasma observations (Turchi et al. 1991), crack propagation (Xu et al. 2003) and terminal ballistics (Draxler 2005). Representative models are the Cordin 560 and 580 (Company 2012a; Company 2012b).

In the early 1990s, the ICCD cameras based on the micro channel plate (MCP) image intensifiers were developed (Wiza 1979). The main function of the MCP image intensifier is the multiplication of the incoming photons, i.e. the amplification of the incoming light signal. It enables the ICCD camera to take images at extremely low light conditions and/or at extremely short exposure times down to $200 \mathrm{ps}$, when the integral of the photon flux over the exposure time is very small. In this technique, a beam splitter is used to divide the incoming light that is then directed onto multiple detectors. ICCD systems typically use at least 8 channels of MCP-CCD sensors to acquire 8 frames in sequence at the speed up to $200 \mathrm{Mfps}$, with more recent systems yielding up to 24 frames with rates over 1 billion fps with $1 \mathrm{~ns}$ exposure time. However, the presence of light intensifiers consistently increases the level of noise in images (Tiwari et al. 2007). For instance, the significant spatial correlation in the noise between two stationary images of the same scene was found in using IMACON 200 (Pierron et al. 2011a). As the number of frames is relatively low, in ICCD cameras accurate triggering of the system is critical. Typical applications for this kind of high-speed camera are terminal ballistics (Grogan et al. 2007), detonics (Sollier et al. 2012), plasma (Kekić and Dojčinović 2003), mechanical experiments (Sharma et al. 2002), combustion (Starikovskaia et al. 2004), electrical discharge (Descoeudres et al. 2005), and cine X-ray (Li and Jia 2005). Typical representatives of this kind of camera are IMACON200 camera, Invisible Vision Ultra 12/24 or SIM series of Specialized Imaging.

In so-called ISIS-CCD cameras, each single CCD pixel has memory integrated onto the detector itself (Etoh and Mutoh 2005; Etoh et al. 2003; Etoh et al. 2007). Each photodiode is followed by a string of storage sites to maximise the number of fps. When each image is recorded, the electrons are transferred from the photodiode to the storage unit, and then from one storage unit to the next one through 100 linear locations until they reach the CCD drain. Commercial cameras using this technology currently reach a maximum speed of $5 \mathrm{Mfps}$, which is potentially capable of achieving $100 \mathrm{Mfps}$ (Lazovsky et al. 2005). The main shortcomings are threefold. First, mounting the on-board memory takes up a lot of space of the pixel. As a result, the photo-active area of each pixel is small, but the low fill factors (i.e., the ratio of a pixel's light sensitive area to its total area) distort images, especially in the case of high spatial frequencies (Reu 2011); Second, the power consumption is comparatively high, and the heat generated can potentially degrade imaging performance or even damage the sensor; Finally, the exposure time depends on its imaging speed (Kondo et al. 2012). In other words, one cannot shorten the exposure time at low or intermediate frame rates, which may cause motion blur. This type of imaging system is mainly used for the events between $50 \mu$ s and $2 \mathrm{~ms}$, such as applications of SHPB (Foster et al. 2015; Nagao et al. 2014) and target impact studies with light-gas gun (Ohtani et al. 2006). Representative cameras are Shimadzu HPV (Company) and Kirana (Crooks et al. 2013).

Compared with CCD, CMOS sensors can record a great number of frames. In a CCD camera, this can be only achieved by installing more CCD chips. Furthermore, the energy consumption of CCD sensors is proportional to the recording speed, and hence a CCD operating at $10 \mathrm{Mfps}$ consumes about $100 \mathrm{~W}$ of power on a chip. Since CMOS-based cameras heavily rely on the sensitivity of a single sensor rather than the mechanical system or the 
number of chips, the key to improving performance is upgrading the pixel structure and associated circuitry. Improvements can be made through parallelism and a pipelined architecture, as well as improvements in faster electronics and memory, and optimizing image processing algorithms. The early CMOS-based camera in highspeed photography was developed by (Etoh 1992). The Photron Fastcam with 16 parallel readouts can be used for full-frame imaging $(256 \times 256$ pixels $)$ at $4,500 \mathrm{fps}$ or $64 \times 64$ pixels at $40,500 \mathrm{fps}$ (Etoh 1992). To achieve the high readout speed, the parallel unit is applied to read the signal from the pixel to the memory region in parallel corresponding to the number of pixel output wires in each column (Tochigi et al. 2013). The frame rate achievable is up to $10 \mathrm{Mfps}$ with a resolution 50,000 pixels, compared to CCD based systems. However, FTCMOS sensor cameras have limitations on wide or full-field measurements due to the low spatial resolution and the small fill factor. Four pixels share one output wire to obtain higher fill factors of the FTCOMS sensor. Currently, a number of commercial companies (e.g., Photron, Vision Research, DEL Imaging, iX Cameras, NAC, Weinberger, Shimadzu and LaVision) are expending much effort towards developing CMOS-based high-speed cameras.

Fig. 3 shows the performance of currently available CMOS and CCD-based digital cameras. There is a large gap between the frame rate/record length of the CMOS-based cameras and that of the CCD-based cameras. The CMOSbased cameras normally have a frame rate limitation of around Mfps (except Kirana and Shimadzu HPV) with a relatively small resolution. However, the number of frames easily exceed 50,000. In terms of CCD-based cameras, the frame rate can be more than $100 \mathrm{Mfps}$ with a large resolution but less than 100 images can be captured. Meanwhile, the maximum resolution for CMOS-based camera decreases with the increase of frame rate, but not for CCD-based cameras. The high frame rate of CMOS-based camera relies on the high detector sensitivity and fast data transfer rate of a single detector. The maximum throughput of this design is stationery, which means a higher frame rate needs to sacrifice the resolution per image and vice versa. The design of CCD-based camera follows that of the original film-based rotating mirror or beam splitter device, where the image is relayed onto a number of distinct detectors or spatially separated areas on a single detector. As a result, the resolution and frame rate are independent. The gap in the middle zone is series of intermediate-rate experiments that are currently not adequately covered by a high-speed camera.

Fig. 3. Survey of current HS cameras based on CMOS and CCD technologies (the maximum resolution is proportional to the area of the representative rectangle of each camera), courtesy of Dr. Reu. (Reu and Miller 2008)

\section{RECENT APPLICATIONS OF HIGH-SPEED PHOTOGRAPHY TO GEOMATERIALS}

\subsection{SAND Movement}

In nature, sand movements are mostly driven by wind or water. The motion of wind-blown grains occurs via three major modes: saltation, suspension, and creep (Bagnold 1941; Bagnold 2012). Saltation refers to the sand propelled by the wind in short hops above the surface of the sand bed. It has received much attention because saltating grains account for 50-75\% of the total aeolian transport, and saltation acts as the key link in transferring momentum between the moving air and the underlying bed (Bagnold 1941). The parameters of saltating sand, including the velocity, angle (direction), length and height of the trajectory are the basic physical characteristics. The most common application of high-speed imaging in such experiments is to record the movement of sand and then image processing or statistical methods are used to determine the trajectory parameters and to reconstruct the trajectory process. A typical experimental setup is schematically shown in Fig. 4(a). A continuous laser beam was transformed into a thin light plane by using light-sheet optics to illuminate a narrow vertical-center plane aligned with the flow 
direction to visualize the moving particles. The sand was moved by the free-stream wind whose velocity was measured by a Pitot-static probe. Afterwards, the consecutive images containing velocity information of particles are processed with a particle tracking velocimetry (PTV) method (Maas et al. 1993). (Wang et al. 2008) used an Ultima-APX high-speed digital camera (Photron) to record the sand grain/bed collision process. The resolution was $1024 \times 512$ frame rate at $2000 \mathrm{fps}$. The light source is a PICL-NEX twin cold lighting system. After modulation, the light was transported by fibre to generate a thin sheet. The results showed that the kinetic energy restitution coefficient and the collision angle are the relevant parameters for understanding the process of a grain impacting and rebounding, as shown in Fig. 4(b). (Wang et al. 2009) employed a PCO-1200hs high-speed digital camera (PCO AG) which was set at a resolution of $1280 \times 1024$ at $500 \mathrm{fps}$ to record the sand creep movement in a horizontal plane. Unlike the view from the side, which can record particle images with a black background, the camera imaged from above the sand bed on a section in the middle and towards the rear (with respect to the flow direction) making it possible to record the creep of sand grains and their maintained positions. A light sheet is not applicable but a volume illumination mode was employed, which is usually used for three-dimensional (3D) velocity measurements (Willert and Gharib 1992) and a micro-PIV measurement (Meinhart et al. 2000). Since the images contain fixed grains, the traditional PTV algorithm is hard to use. Therefore, an unsigned image subtraction method was adopted to form a new image queue from original images, in which each subsequent image was subtracted from the one before, leaving an image of creeping grains. In another experiment, (Zhang et al. 2014c) used an Ultima-APX camera (Photron) to record the movement of the illuminated saltating sand on a sand bed. The resolution was set at $1024 \times 512$ pixels at 2,000 fps. The imaging zone was arranged at the rear of the sand bed parallel to the flow direction, $0.7 \mathrm{~m}$ from the leading edge and centrally aligned in the spanwise direction. The saltating trajectory was reconstructed by an overlapping particle tracking algorithm and the kinetic parameters of saltating grains were abstracted by differential schemes. Moreover, the acceleration of saltating sand grains was obtained directly from the reconstructed trajectory, and the climbing stage of the saltating trajectory represents a critical process of energy transfer while the sand grains travel through air. (Zhang et al. 2007) used a high-speed CMOS camera (FastcamAPX) to capture consecutive particle images with a resolution of $1024 \times 512$ pixels at $2000 \mathrm{fps}$. The instantaneous velocity fields of saltating particles were determined by high-speed photography in combination with the PTV method. Ensemble-averaged data were estimated, including the resultant velocity, mass concentration and streamwise mass flux distribution. Their results demonstrate that the resultant particle velocity has an approximate log-linear profile with vertical height. Both the particle concentration and streamwise mass flux decay dramatically in the near surface region, then decline mildly beyond this region. (Jiang et al. 2015) captured the movement of the saltating sand in a wind tunnel by using a Phantom V310 camera at 5,000 fps with the resolution of $600 \times 800$ pixel. The imaging zone was at the middle of the sand bed, towards the downwind end. Movement parameters were derived from a digital recording of the trajectory. However, it is still difficult to reconstruct an accurate and quick particle trajectory from images. More detailed sand saltating experiments are referred to (Ilstad et al. 2004a; Yang et al. 2009a; Zou et al. 2001). Water moves sand in two ways: one is by water flow and the other is by raindrop impact. (Ilstad et al. 2004a) examined the subaqueous debris flows (Locat and Lee 2005) through a set of laboratory experiments examining the behaviour within the flow and its dependence on the sand/clay ratio at a fixed water content. In another experiment, the pore-fluid pressure and total stress were measured (Ilstad et al. 2004b). In both experiments, the high-speed camera was employed to record data of the velocity field for different positions inside the debris flow. Through particle tracking, the mobility of subaqueous debris flows is obtained. When sand is impacted by a rain drop, part of its momentum is transferred to the sediment grains, which leads to so-called "rain splash" (i.e., large grains are ejected into arched trajectories away from impact sites). It is generally accepted that rain splash transport increases with a land surface slope (Moeyersons and De Ploey 1976) and grains on an inclined surface commonly go through a downslope drift. This drift motion has received considerable attention in hillslope geomorphology and erosional processes on agricultural lands (De Ploey and Savat 1968; Ellison 1944; Van Dijk et al. 2002). Furbish investigated the details of the momentum transfer from drops to grains which leads to downslope 
drift at 500 fps of drops impacting sand targets under controlled conditions in the laboratory (Furbish et al. 2007), as shown in Fig 4(c).

Fig. 4. (a) Layout of the wind tunnel during the experiment (Jiang et al. 2015), (b) a sequence of sand saltation (A to E) and the composite trajectory image (F) (Wang et al. 2008), and (c) sequence images of grains ejected from grain ridge following drop impact. The high-speed images showed that grains ejected from the top of the ridge have the highest initial velocity and launch angles, whereas grains from the middle and bottom parts of ridge have lower ejected velocities and launch angles following grain-to-grain collisions. (Furbish et al. 2007).

\subsection{Penetration}

Penetration takes place when a projectile enters a target without passing through it, however perforation occurs when the projectile completely passes through the target. The degree of penetration resistance is a significant parameter to understand in protective engineering. On the one hand, it is hard to simulate penetration accurately by simulation software. On the other hand, computational codes require sensible levels of experimental validation. This complication also extends to theoretical analysis, though many empirical theories of penetration have been established over the years, usually with the assistance of high-speed photography. The applications of high-speed photography to these experiments are generally to measure the penetrator prior to impacting, and to examine the interaction between a projectile and geomaterial during penetration.

(True 1975) used a high-speed camera to investigate the penetration of projectiles into seafloor soils at rates up to 5000 fps. Qualitative information on soil deformation patterns was obtained, and the penetrator velocity determined by scaling distances and calculating the film speed. The camera was also used to observe projectile instability at $1000 \mathrm{fps}$ and to provide data (e.g., flight stability and penetration depth) on the projectile impact velocity at $48 \mathrm{fps}$. Penetration experiments in various sizes of sand have been performed to evaluate the penetrating processes or determine the penetration resistance (Allen et al. 1957; Braslau 1970; Cole 2010; Culp and Hooper 1961). (Cintala et al. 1999) used a high-speed photography method that was illuminated by a stroboscopic laser to measure ejecta velocities during the impacts of aluminium projectiles into the coarse-grained sand. Their studies show that the impact velocity had a slight effect on the functional relationship between the scaled, radial launch position and either the speed or the angle of ejection. (Borg et al. 2013) designed a vertically mounted compressed air gun with a $4.5 \mathrm{~mm}$ diameter launch tube, which then was used to launch a projectile at the velocity ranging of $30 \sim 200 \mathrm{~m} / \mathrm{s}$ into a tank $(35 \mathrm{~cm} \times 25 \mathrm{~cm} \times 18 \mathrm{~cm})$ filled with Ottawa sand. Images were collected with a Photron RS camera at a minimum frame rate of $3000 \mathrm{fps}$, and illuminated by two halogens lamps. Owing to the long record time (around 2 seconds) and the large field of view $(30 \mathrm{~cm} \times 61 \mathrm{~cm}$ ) with a resolution of $512 \times 1,024$ pixels (approximately 3 pixels per grain of sand), the entire penetration event was recorded, and typical images are shown in Fig. 5(a). It can be seen that a cavity was formed around the contact between the nose of the projectile and sand, but there was little interaction between the sides of the projectile and the sand. (Collins et al. 2011) changed the point of view to record the projectile exiting through the end of the specimen, as shown in Fig. 5(b), though the main diagnostic of this study was flash x-rays. High-speed photography suggested that the displacement ahead of the rod formed at early impacting stages, but kept a steady-state in the rest of the event.

Fig. 5. (a) Images of sphere traveling at $141 \mathrm{~m} / \mathrm{s}$ (Borg et al. 2013), (b) a sequence of high-speed images, showing a flat-ended projectile exiting the back of the sample, along with a volume of sand (Collins et al. 2011).

The development of transparent materials provides an alternative method to visualize the internal deformation under penetration. (Chen et al. 2014b) employed a conical nose projectile accelerating into a transparent soil (fused quartz saturated in a matched refractive index pore fluid made of mineral oil) target at an impact velocity of $13.6 \mathrm{~m} / \mathrm{s}$, shown in Fig. 6(a). The whole penetration event was recorded with the NAC HX5 camera at $4000 \mathrm{fps}$ and a spatial resolution of $1280 \times 960$ pixels was corresponded to a field view of $217 \times 163 \mathrm{~mm}$. It was found that the splash created by the air accompanying the projectile displaced oil on the top of the target (approximately $25 \mathrm{~mm}$ ), and 
that the projectile impacted the surface of the saturated soil. A cone-like cavity was created in the target material during the penetration event. (Guzman et al. 2015) visualized the penetration of a spherical projectile into the centre of a saturated granular target made of fused quartz waste at speeds of 60,100 and $150 \mathrm{~m} / \mathrm{s}$, as shown in Fig. 6(b). The transparent sand was made of fused quartz waste product with pore fluid made of sucrose. The penetration process was recorded by a NAC HX-5 camera at 10,000 fps. The opaque zone appeared circular during initial penetration and transitioned into the shape of an elongated cone in shots with higher initial velocities.

Fig. 6 (a) High-speed visualization of a cone projectile penetrating into the transparent soil and at projectile velocity of 13.6 $\mathrm{m} / \mathrm{s}$. (Chen et al. 2014b) (b) Progressive snapshots of penetration into transparent sucrose saturated granular fused quartz shot at the centre of the target. (Guzman et al. 2015)

(Borvik et al. 2007) applied high-speed imaging to examine the ballistic perforation resistance of high-strength concrete slabs. The projectiles were not visibly damaged or deformed as a result of the penetration process as ascertained by a series of images. The measured initial versus residual projectile velocity curve for concrete is given. (Seah et al. 2011) conducted the penetration tests on Iddefjord granite with a dimension of $0.6 \mathrm{~m} \times 0.6 \mathrm{~m} \times 0.1 \mathrm{~m}$ by using ogive-nose projectiles made of Arne tool steel. High-speed images were used to determine the impact velocity, the first sign of cone plugging and the fractured conical plug, as shown in Fig. 7.

Fig. 7. High-speed images at various time intervals showing the responses at the front and rear sides of a granite target plate when impacted by an ogive-nose projectile at $V_{s}=279 \mathrm{~m} / \mathrm{s}$ (Seah et al. 2011).

\subsection{Fracturing}

Fracturing includes the process of crack initiation, propagation, interaction, and eventual coalescence. Fracturing in rock is one of the most popular research focuses in geomechanics as a large number of engineering designs and implementations such as rock slope stability assessments, tunnel support design, and fluid flow prediction can benefit from a greater understanding of fracture. However, the crack velocity in the geomaterials easily exceeds $1000 \mathrm{~m} / \mathrm{s}$ not only in dynamic experiments but also in quasi-static experiments. If the nature of a crack is determined solely by the examination of fractographic features, the signs of shearing obfuscate the pre-existing tensile cracking (Einstein and Meyer 1999) and the true identity of tensile cracks cannot be identified, which can be obtained in the sequence of images captured by high-speed cameras. Perhaps the most important technique for crack speed measurements is high-speed imaging (Ravi-Chandar 2004).

\subsubsection{Static tests}

(Wong and Einstein 2006) used a high-speed camera to observe the fracturing behaviour of prismatic specimens containing single flaws and found that tensile wing cracks (TWCs) were in most cases the first cracks to appear in fracture propagation from the existing flaws independent of aperture and material. (Wong and Einstein 2009b) summarized the fundamentals of their experimental techniques using a high-speed camera, video capturing operation for examining crack behaviour. (Wong and Einstein 2009a) studied the cracking and coalescence behaviour in prismatic laboratory-moulded gypsum and Carrara marble specimens containing two parallel preexisting open flaws by using uniaxial compression tests. A Phantom V5.0 camera was used to monitor specimen from the front face, and the camera was triggered manually to capture images when the $\operatorname{crack}(\mathrm{s})$ coalesced or specimen failure occurred. The frame rate and image resolution settings varied among specimens ranging from 1000 fps to 24000 fps. The typical fracturing process is shown in Fig. 8. (Song et al. 2015; Song et al. 2014) conducted uniaxial and biaxial loading and unloading tests on marble with single and double pre-existing cracks inclined at $45^{\circ}$. A Photron Fastcam SA5 was employed to record the process of the crack initiation, propagation, coalescence and final failure. 
Fig. 8. The cracking and coalescence process in a gypsum specimen at a frame rate of 24,096 fps. (Left image: Tensile wing cracks initiated from the two pre-existing flaws. Middle image: Additional cracks initiated from the flaw tips. Right image: A coalescent shear crack developed to link up the two inner flaw tips.) (Wong and Einstein 2009a).

\subsubsection{Dynamic tests}

The testing principle of drop-weight machines is use of gravitational potential energy, through controlling a hammer with known height and weight. Due to some limitations of the testing machines (refer to subsection 2.1 in (Zhang and Zhao 2014b) for details), only a few studies have been conducted using drop-weight machines to investigate the characteristics of fragmentation (Whittles et al. 2006) and fracture (Islam and Bindiganavile 2012). The fracture behaviours of plain concrete, fibre reinforced concrete, and plain concrete with conventional reinforcement, were studied with a three-point bending specimen impacted by a drop-weight machine by (Mindess and Bentur 1985). High-speed photographs were taken at $500 \mathrm{fps}$, which facilitated monitoring of crack opening during the fracture event.

The SHPB is regarded as the most successful loading technique corresponding to strain rates of $10^{1}-10^{4} \mathrm{~s}^{-1}$ (Lindholm 1964; Zhang and Zhao 2014b). The crack initiation, propagation, and coalescence processes of geomaterials under dynamic loading have been well investigated by various types of SHPB tests. The first application of high-speed photography technology in the SHPB tests on geomaterials was made (Perkins and Green 1968) on Solenhofen limestone with dynamic compression at strain rate $10 \mathrm{~s}^{-1}$. A Calumet View Camera was used with high-speed Polaroid, the IOX12.7 cm sheet film, to obtain a conveniently large format without enlargement. The lens shutter was operated in the bulb condition. A General Radio Strobe served as a short duration $(0.8 \mu \mathrm{s})$ and high-intensity light source. (Cai et al. 2007) used a high-speed camera to visualize the initiation of failure and subsequent deformation of the Meuse/Haute-Marne argillite specimens at frame rates from 15,000 to 20,000 fps. The direct compression specimens were found to deform and fail uniformly around the circumference of the specimen, by a radial cracking process, as shown in Fig. 9. (Kimberley and Ramesh 2011) performed compression SHPB experiments on ordinary chondrite and a Hadland DRS Ultra-8 camera was used to record the dynamic failure process. Two high-intensity flash sources were used to illuminate the specimen and diagnostics were triggered by a strain gauge. The interframe time was $1 \mu$ s with $200 \mathrm{~ns}$ exposure time, but only eight frames in total were captured. A shared triggering signal was used to synchronize the high-speed camera with the loading pulse, and thus the stresses of the specimen corresponding to the specific times was known. The crack growth speeds were estimated from images by comparing with the scale ruler. (Luo et al. 2015) used a Cordin 550-62 camera to record the dynamic compressive behaviour of dry Mason sand under confinement using SHPB and observed sand deformation and failure processes such as rotation, slippage, fracture, and compaction.

Fig. 9. Initiation of fracture of Haute-Marne argillite specimens under compression test (Cai et al. 2007).

The failure processes are varied when a confining pressure is applied. (Hu et al. 2011) used a DRS Hadland Ultra 8 camera to perform real-time visualization of the failure processes in the aluminium nitride during loading under a modified Hopkinson bar with and without confining stresses. Direct visualization of the confined failure process was obtained through the use of a one-dimensional confinement technique. The camera was capable of capturing up to 8 frames with an exposure time as low as $10 \mathrm{~ns}$ and a framing rate up to $100 \mathrm{Mfps}$. Two Photogenic Powerlight 2500DR flashes were used to provide illumination, and were triggered by an independent strain gauge on the incident bar. Fig. 10 shows that the axial cracks propagated at speeds of several hundred meters per second under uniaxial dynamic compression, but no axial cracking was observed in the bi-axial confined specimens. It was demonstrated that the application of a biaxial confining stress could re-orient the principal direction of crack growth during compression, producing diffuse shear-dominated cracks.

Fig. 10. Influence of confinement on the failure process in aluminium nitride(reproduced from (Ramesh et al. 2015) and original source (Hu et al. 2011)). Photographs taken every $2 \mu \mathrm{s}$ with exposure times of $500 \mathrm{~ns}$ and white regions in the specimen indicate damaged regions. Left: Unconfined uniaxial dynamic compressive loading in the horizontal direction, red arrows show the WC 
platens and blue arrows show damage regions and crack propagation. Right: Failure during planar confinement (in the vertical direction) and dynamic compressive loading (in the horizontal direction), blue arrows show damage regions and red arrows indicate crack propagation.

The Brazilian disc (BD) test is an ISRM suggested method to obtain the tensile strength of rocks (ISRM 1978; Li and Wong 2013). (Zhang and Zhao 2013a) conducted SHPB BD tests on Fangshan marble using Photron Fastcam SA1.1, a macro-lens (Kenko PRO 300 2.0× objective lens), a set of extension tube (Kenko 12, 20 and $36 \mathrm{~mm}$ ), and a ring-shaped flash light (Pallite VIII $120 \mathrm{~V}$ ). As shown in Fig. 11, the resolution of the zone of camera (ZOC) was $448 \times 192$ pixels at $60,000 \mathrm{fps}$, and the zone of camera (ZOI) was selected as $420 \times 150$ pixels for further DIC calculation. The main crack orientation was parallel to the impact direction and axial crack divided the specimen into at least two pieces. There were two kinds of obviously observed failure, i.e., shear failure and tensile failure, and the extent of two shear failure zones at contact points of the disk depended on loading rate. (Wong et al. 2014) observed the dynamic cracking processes of Carrara marble aided by a Phantom V310 camera at 100,000 fps with the resolution of $72 \times 288$ pixels. There were some distinct differences in the white patch geometry and initiation load under quasi-static and dynamic loading. (Zhou et al. 2014) conducted Brazilian tests under a compressive prestress which was in the same direction as the loading direction By analysing the photographs of specimen failure taken by a high-speed camera, they revealed that the type II failure pattern (central cracking with crushed wedges) should be classified as type I (diametrical split). High-speed photography also showed that the damage zones were formed at the bar/specimen contact areas first when the impact stress increased quickly. As a result, the type III failure patterns appeared. Without the help of the high-speed camera, the original fracture patterns could only be found by checking the fragments of failed specimens and were not able to reveal the real phenomena such as cracks initiating from the damage zone rather than the specimen centre. Reducing this failure at the bar/specimen interface is a good argument for using curved anvils.

Fig. 11. High-speed images of dynamic Brazilian disc test of marble at $60,000 \mathrm{fps}$ with the resolution of $448 \times 192$ pixels (ZOC: zone of camera, ZOI: zone of interest) (Zhang and Zhao 2013a).

Two of ISRM suggested fracture toughness measurement methods, the short rod (SR) and notched semi-circular bending (NSCB) methods, were further used to determine the dynamic fracturing behaviour of rocks (Chen et al. 2009; Dai et al. 2010; Zhang and Zhao 2013a; Zhang et al. 2000). A high-speed framing camera was employed to show the motion of the SR specimen and the fragments of Fangshan gabbro and Fangshan marble (Zhang et al. 2000). The frame rate was set at $350 \mathrm{fps}$, and thus the interval of two neighbouring images was around $2.857 \mathrm{~ms}$, as shown in Fig. 12(a). One of the most classic direct uses of high-speed imaging in quantitative analysis of geomaterials is to determine crack propagation velocity. As shown in Fig. 12(b), crack initiation time and propagation velocity can easily be determined by a sequence of images and the crack velocity of Fangshan marble was approximately $680 \mathrm{~m} / \mathrm{s}$ (Zhang and Zhao 2013a). The resolution of ZOC was $256 \times 144$ pixels at $125,000 \mathrm{fps}$, and ZOI was selected as $150 \times 95$ pixels for further DIC calculation. (Zhang and Zhao 2014a) took high-speed photographs of the gabbro until the NSCB specimen was split into two almost equal fragments, and each flying fragment had both rotational and translational motion. The translational velocity was calculated by the subsequent translational movement of the centre of mass and the time from the corresponding photographs, and the angular velocity was estimated by the change in rotational angle with respect to time.

Fig. 12. (a) Photographs of dynamic gabbro fracture process of SR specimen by SHPB test. The time intervals between the neighbouring images were all $2.857 \mathrm{~ms}$ (Zhang et al. 2000). (b) Crack propagating process on a marble in a NSCB test (The development of white belt indicated by a dashed arrow, and the observable moving crack-tip is indicated by a solid arrow in the images.) (Zhang and Zhao 2013b).

\subsubsection{Blasting and impacts}

As early as the 1960s, (Bieniawski 1967a; Bieniawski 1967b; Bieniawski 1968) used a high-speed camera at 1.6 Mfps to study crack propagation in rocks, as shown in Fig 13. The fracture velocity of Norite rock was plotted in 
two parts: stable fracture propagation and unstable fracture propagation. It was observed that fracture propagation started with a lower crack velocity and then until the limit of stable fracture propagation (beyond which unstable propagation and bifurcation occurs) the elastic energy released by crack extension was not sufficient to maintain fracture. At a later stage, when the elastic energy released was able to maintain fracture, the crack velocity increased rapidly to a limit where it maintained a constant value, namely, the terminal fracture velocity. The experiment confirmed that the terminal velocity was a phenomenon characteristic of brittle fracture. Once the terminal fracture velocity was reached, the phenomenon of crack forking (bifurcation or branching) took place, that is, additional cracks were formed at an angle to the original crack.

Fig. 13. Selected images of rock fracture propagation induced by charge explosion and obtained by an ultra-high-speed camera at 1.5 Mfps (modified after (Bieniawski 1968)).

When underground caverns and tunnels are excavated by drilling and blasting, the formation of a flat excavation surface and damage to the walls have to be controlled to reduce the overbreak. As a result, the technique of smooth blasting has been developed (Persson et al. 1993). However, it is hard to investigate the fracture mechanism of rock in smooth blasting because the blast wave from one hole generates a closed crack in an adjacent hole which is subsequently developed by the blast in the next hole, thus creating a fracture surface. One use of high-speed photography in sealed charge experiments is that numerical models can be verified by comparing with experimental results. However, the rock is opaque, so sealed charge experiments were normally conducted with Polymethyl methacrylate (PMMA) to simulate the fracturing behaviour. In laboratory experiments, the fracture patterns in PMMA are qualitatively very similar to the fracture patterns in rock but different in scale which is believed to be useful in investigating the fracturing mechanism (Kutter and Fairhurst 1971). (Rossmanith et al. 1996) used a 3D cube-type laboratory models fabricated from PMMA, transparent enough to be observed, to undertake dynamic loading from explosives (Rossmanith et al. 1996). Fig. 14 shows the fracture structures, which were captured by a Cranz-Schardin-type multiple-spark gap camera at $5000 \mathrm{fps}$. By recording the dynamic evolution of blast-induced fractures, a qualitative description of 3D fracture propagation caused by the detonation of explosives for three model geometries was obtained. The descriptions of blast-induced fractures under controlled conditions in the laboratory could be used to validate numerical codes. To clarify the effect of rock pressure on crack generation during tunnel blasting, Jung et al. conducted the blasting tests not only on PMMA plates but also on marble plates and sandstone blocks under the assumption that the borehole on the expected fracture line in the tunnel was under initial rock pressure (Jung et al. 2001). A colour 35-mm film Model 124 Framing Camera by Cordin, was used to examine the crack initiation and propagation processes in three different materials due to blasting, at a frame rate of $2 \times 10^{5} \mathrm{fps}$.

Fig. 14. The final fracture structure in a sealed-charge experiment depicted in two directions (Left image: parallel to the borehole axis. Right image: perpendicular to this axis. ' $E$ ' marks the position of the explosive charge and ' $D$ ' is the detonation wire.) (Rossmanith et al. 1996).

At higher strain rates, experiments are normally carried out in gas guns. In this series of experiments by (Willmott and Field 2006), samples of natural diamond were set into PMMA and then subjected to shock loading from a flyer plate. A DRS 501 image converter camera was used at $10 \mathrm{Mfps}$ to observe crack growth and measure velocities. Typical images in Fig. 15 show that the fracture of diamond is strongly related to the presence of initial flaws in the specimens. Velocities in excess of $10 \mathrm{~km} \mathrm{~s}^{-1}$ were recorded for the cracks and it was speculated that this was due to multiple initiation sites and crack coalescence.

Fig. 15. Four examples of high-speed images showing fracture in diamond, with propagating cracks denoted by arrows. The white arrows show the edge of the dark, vertical shock front in the PMMA matrix. Each frame is labelled with the time in microseconds after shock wave arrival. Cracks can be seen growing in each sequence (Willmott and Field 2006). 


\subsection{Spalling}

For some protective structures, like shelters, plates protecting against explosions and collisions and many others, it is important that pieces are not ejected from the rear of the material through tensile failure or spalling. Spalling is a process that can be carried out in controlled laboratory conditions (Klepaczko and Brara 2001) and refers to a specific form of fracture, which occurs when a compressive wave reaches a free surface and is reflected as a rarefaction wave. In particular though interactions with other waves, the rarefaction passing back through the material can "pull" the material to the extent where the tensile strength is exceeded causing a failure surface to develop. (Klepaczko and Brara 2001) observed the spalling process of wet and dry concrete by using a coupled fast video system consisting of six CCD fast cameras in Fig. 16(a). Each camera produced a high-resolution image $(800 \times 590$ pixels) at frame rate up to $1 \mathrm{Mfps}$, and the sequence of spalling images allowed independent determination of the ejection velocity of the fragments. It was found that at such loading rate (up to $5000 \mathrm{GPa} / \mathrm{s}$ ), dynamic strength exceeds the quasi-static value up to 10 times. It is demonstrated that the high rate sensitivity of the fracture stress should be taken into account by the cumulative fracture criterion based on the rate dependent process of material separation. (Brara et al. 2001; Brara and Klepaczko 2006) conducted a series of spalling experiments and numerical simulations on concrete specimens to determine dynamic strength and fragmentation processes, as shown in Fig. 16(b). (Cho et al. 2003) also measured the fractured planes in dynamic tension tests on Inada granite and Tage tuff to investigate the strain-rate dependence of the tensile strength. (Schuler et al. 2006) studied the behaviour of cylindrical concrete specimens positioned at the end of the incident bar in a SHPB system to initiate spalling. It was designed to measure the tensile strength and the specific fracture energy. The velocities of the fragments were related to the fracture energy and were measured using a high-speed camera. (Kubota et al. 2008) conducted tests on Kimachi sandstone with dimensions of $60 \mathrm{~mm}$ diameter and $300 \mathrm{~mm}$ length. The tensile wave was generated by an explosive charge coupled to the sample via a water buffer section, which was able to be varied in length to alter the amplitude of the loading pulse in different experiments, as shown in Fig. 16(c). The position of the crack was determined by a model 124 framing-type Cordin camera. The experimental results showed that the distance from the free end to the fracture position varied even when the loading condition was same. It was suggested that this was because the shock wave reduced the strength in the whole damage zone (containing the fracture cross section) rather than just in the fracture cross section. An alternative explanation would simply be that the tensile strength of the inhomogeneous rock specimen is not constant along the length, or from sample to sample. (Pierron and Forquin 2012) used an ISIS CCD camera (Shimadzu HPV-1) with a spatial resolution of $312 \times 260$ pixels to record images of a grid bonded onto a concrete specimen to allow for a virtual field method to identify the mechanical properties of concrete during spalling. Because the fill factors of ISIS-CCD sensor are very low, only $13 \%$ in the 312 pixel direction, but $76 \%$ in the 260 pixel direction, the camera was rotated so that the specimen movement occurred along the vertical direction of the camera along which the fill factor was higher.

Fig. 16. (a) Schematic of typical spalling test by SHPB with a high-speed photography system (Klepaczko and Brara 2001), (b) Captured fracture process with two spalls under loading from the left side of concrete specimen (Brara et al. 2001), (c) the spalling test on Kimachi sandstone ( $a$ is the initiation of the explosion and $b$ is $240 \mathrm{~ms}$ after the explosion.) (Kubota et al. 2008).

\subsection{FRAGMENTATION}

Fragmentation is a spatially and temporally discrete process governed by flaws (inherent and random), material properties (e.g., toughness, hardness) and structure (e.g., grain orientation and size) (Grady and Benson 1983). The dynamic fracture and fragmentation of geomaterials are of interest in particular for mining engineers (Grady and Kipp 1979; Levy and Molinari 2010; Shockey et al. 1974). The reasons for fragmentation can be easily understood both from the viewpoint of mechanics that the tensile stress exceeds the tensile strength, and in the viewpoint of energy that dynamic loading provides the body with kinetic energy, allowing for the creation of fracture surfaces (Meyers 1994). 
Research into fragmentation of geomaterials with the aid of high-speed imaging dates back to the 1950s. (Hino 1956) proposed the fundamental principle of rock failure in blasting using shock wave theory, and introduced a theory to determine the dynamic tensile strength of rock materials from the velocities of fragments produced by the detonation of an explosive charge. A high-speed photographic and a chronotron meter method were devised to measure the fragment velocities. The dynamic tensile strength of rock evaluated from the velocity measurements was found to be more than twice the static strength. High-speed camera records were obtained for the rock fragments ejected by impact craters at three nominal framing rates $\left(10^{4}, 10^{5}\right.$, and $10^{6} \mathrm{fps}$ ) (Gault et al. 1963). (Arbiter et al. 1969) conducted drop-shatter impact tests on various sand-cements particles and glass spheres with diameters ranging from 150 to $250 \mathrm{~mm}$, and high-speed photography was used to observe the failure patterns of spherical particles. (Wu et al. 2004) compressed 141 spheres dynamically with a double impact test and examined various parameters including material strength, sphere size, and impact energy. A MotionScope ${ }^{\circledR}$ PCI system was used to capture the process of breakage at the frame rate up to 8,000 fps. As shown in Fig. 17, the impact occurred between frames 3 and 4, and a planar crack was initiated in frame 7, which corresponded to 1.5-2 ms after impact. Frames 113 to 115 , corresponding to $53 \mathrm{~ms}$ later, showed some crushed material falling from the contact zone. Since the spheres were not transparent, it was impossible to observe the fractured development inside the sphere.

Fig. 17. Selected frames of a high-speed photographic sequence of impact fracture of a plaster sphere with the diameter $50 \mathrm{~mm}$ by double impact tests, at the frame rate of $2,000 \mathrm{fps}$, the contact force $P($ in $\mathrm{kN})$ as well as the contact velocity $v($ in $\mathrm{m} / \mathrm{s})(\mathrm{Wu}$ et al. 2004)

Ballistic edge-on impact (EOI) is commonly used to investigate, either in real-time or post-mortem, crack patterns under dynamic loading conditions (Hornemann et al. 1984; Strassburger et al. 1994). The inter-frame time needed for the high-speed photography in EOI is a few microseconds with ceramics (Denoual and Cottenot 1998) or glass (Brajer et al. 2003), and few tens of microseconds for rock and concrete slabs. Edge-on impact tests were conducted on Crinoidal limestone and Beaucaire limestone to compare the fragmentation pattern differences (Grange et al. 2008). High-speed photography was used to observe the details of fragmentation. Since some openings were too small, the images did not show all of the cracks that were visible post-experiment in Crinoidal limestone. As seen in Fig. 18(a), a few radial cracks were visible when $t>40 \mu$ s and a few circular-front cracks centred on the impact point were seen to emerge $30 \mu \mathrm{s}$ after impact in Crinoidal limestone. In Beaucaire limestone, radial cracks development stopped $10 \mu \mathrm{s}$ after impact and a second large emerging crack was observed $30 \mu \mathrm{s}$ after impact, as can be seen in Fig. 18(b). The fragmentation distribution could be well described using Weibull statistics.

Fig. 18. Ultra-high-speed camera observations for two fragmentation tests: (a) Crinoidal limestone with a thickness of 8mm, at striking velocity of $200 \mathrm{~m} / \mathrm{s}$ (b) Beaucaire limestone with a thickness of $12 \mathrm{~mm}$, striker velocity at $101 \mathrm{~m} / \mathrm{s}$ (Grange et al. 2008).

The kinetic energy of moving fragments is usually investigated by tracking them using high-speed photography (Blair 1960). Hogan used a Photron APX Ultima camera filming at 8000 fps to capture fragment trajectories of 10 $\mathrm{mm}$ thick gabbro tiles at the rear of targets impacted by railgun-launched projectiles (Hogan et al. 2013a). The sequence of captured images was shown in Fig. 19. A tracking algorithm written in Matlab was used to track ejecta larger than $0.8 \mathrm{~mm}$ which corresponded to the length of two pixels according to the resolution of the camera. As a result, the ejecta size, velocity, mass, and kinetic energy were measured. It was shown that approximately $11 \sim 16 \%$ of the kinetic energy (21J) of the projectile was converted to that of fragments before the perforation occurred. It would increase to around 50\% when the kinetic energy was $305 \mathrm{~J}$. (Hogan et al. 2013b) continued to conduct tests on four kinds of materials, i.e., a fine-grained tonalitic granitoid, gabbro, a fine-grained syenitic granitoid, and a coarse-grained monzonitic granitoid. In that study, the images were contrast enhanced by Matlab to aid the tracking algorithm. Percentiles of the distribution of mass, momentum and kinetic energy were examined with respect to ejecta lengths. Percentile lengths of ejecta decreased with increasing normalized impact energy. Fittings of the nondimensional ejecta lengths provided reasonable collapse for the percentile values. However, it should be noted in 
the distributions that fragments smaller than $0.8 \mathrm{~mm}$ were not visible to the camera. The two-dimensional field was not able to give any reliable information about the rotational kinetic energy or out-of-plane displacement/velocity of the fragments. A consecutive investigation was conducted, in which the dynamic fragmentation of a fine-grained granitoid material was examined (Hogan et al. 2014). Target thicknesses and impact energies ranged from 7 to 40 $\mathrm{mm}$ and 12 to 2,500 J respectively. This time the high-speed camera was aiming at the rear of the target instead of from the side to better understand lateral ejecta field behaviour. After the impact, PIV and image enhancement techniques were used to measure the size and velocity of material ejected laterally which was helpful for predicting mechanisms of ejecta cloud formation.

Fig. 19. Evolution of the debris cloud of gabbro for $21 \mathrm{~J}$ impact at (a) $3.75 \mathrm{~ms}$, (b) $10 \mathrm{~ms}$, and (c) $20 \mathrm{~ms}$ after impact. Frame rate at 8,000 fps. Various fragmentation mechanisms are labelled in the figure, including plate-like fragments spalled from the rear surface and those crushed ahead of the projectile (Hogan et al. 2013a).

(Miguel A et al. 2011) used a Phantom V710 and Photron SA-5 high-speed cameras at 14,000 fps to observe the ejection of a gas-particle mixture in a shock tube apparatus. The samples were drilled volcanic rocks, with the aim of investigating the influence of the fragmentation process on eruption dynamics. Variations in sample porosity and applied pressures (4-20 MPa), were investigated. The high-speed photography recorded the full ejection for 300$400 \mathrm{~ms}$. Typical images at $20 \mathrm{MPa}$ are shown in Fig. 20(a). A systematic change in the particle size with time was not observed, but a diverse range of particle sizes was captured throughout. It can be seen that the higher the initial driving pressure, the fewer large particles $(>8 \mathrm{~mm})$ were generated. No measurable acceleration of the gas-particle mixture was recorded by the high-speed camera. Detailed analyses of the videos at the initial stage revealed that the size of the particles had no relationship to ejection velocities, and it was common that relatively large particles moved at approximately the same velocity as smaller particles. Another study of volcanic eruptions with high-speed photography was conducted by (Fowler et al. 2009). It was hypothesised that fragmentation of magma was the reason why explosive volcanic eruptions differed from a quiet volcanic activity. Photron Fastcam camera was used to capture the sequential fracturing of the rock at 10,000 fps, as shown in Fig. 20(b). The rock cylinder was placed in a transparent tube with high gas pressure. Fragmentation of porous magma was induced by rapid decompression. The photographs indicated that the fragmentation started at the top of the sample and continued downwards. Two types of fractures were observed: the fractures were parallel to the sample surface and dissected the entire sample into discs (layers); and the internal fracturing of an expelled fragment.

Fig. 20. (a) The front of the gas-particle mixture after fragmentation, samples were drilled from volcanic rocks in cylinder $(1=6$ $\mathrm{cm}, \mathrm{d}=2.5 \mathrm{~cm}$ ), frame rate at 14,000 fps. (Miguel A et al. 2011). (b) Individual frames from a sequence of a typical rock fragmentation experiment, frame rate at 10,000 fps. (Fowler et al. 2009): (a Before depressurization of the autoclave (0ms). (b) $0.3 \mathrm{~ms}$ after decompression, the upper part of the sample has fractured. (C) After $1.1 \mathrm{~ms}$, fractures have occurred throughout the sample. (d) By $2.4 \mathrm{~ms}$, the rock has disintegrated (Fowler et al. 2009).

High-speed pulverization of sand (i.e., sand breaking into many sub-particles) usually occurs in the process of penetration in front of the projectile. With the help of high-speed X-Ray imaging, the actual failure process for individual sand particles under dynamic loading was first observed in-situ by (Parab et al. 2014). A modified Hopkinson bar apparatus synchronised with an X-ray phase contrast imaging (PCI) setup was developed to study the damage mechanisms in dry and wet sand particles under dynamic compressive loading. In the tests, a Photron Fastcam SA1.1 camera was used to capture images at 54,321 fps with the resolution of $640 \times 480$ pixels. The captured images are shown in Fig. 21. It can be seen that in the dry sand one of the two sand particles was observed to be pulverized and in that particle, extensive interfacial cracking was also observed. Wet sand was broken into big subparticles followed by pulverization.

Fig. 21. Image sequence for wet sand dynamic compression experiment. Large cracks can be observed in Frame 2. The cracked particle breaks into large sub-particles in Frame 3. White arrows indicate large cracks in the sand particle. The resolution was $640 \times 48$ pixels at the frame rate of 54,321 fps (Parab et al. 2014). 
In Kirk's study (Kirk 2014), an Invisible Vision UHSi 12-24 Camera and an Opteka mirror lens with a $500 \mathrm{~mm}$ focal length was used to take high-speed photographs during the fragmentation process of Lake Quarry Granite rings driven by a small explosive charge in a copper driver tube (i.e. the method is similar to that detailed in (Marquez et al. 2016)). The camera took 12 images in quick succession and then another 12 images after a $10 \mu \mathrm{s}$ delay, as shown in Fig. 22. The delay was due to downloading of the first set of images from the camera into the memory before taking the second set of images. Images were taken every $1 \mu$ s with a $0.5 \mu$ s exposure time and the resolution was $1,082 \times 974$ pixels. The experiments were illuminated by flash lamps. The high-speed photography allowed the crack growth and fracture patterns in the rings to be observed. Although it was useful for interpreting the results from the other diagnostics, it did not give any qualitative results for comparison with fragmentation, something which was accomplished through soft capture of fragments for post-experimental analysis.

Fig. 22. Sequence of expanding ring fragmentation of Lake Quarry Granite driven by impact plate. The ring sample was seen to stretch, fracture radially and move off outwards as fragments at $1 \mathrm{Mfps}$ with the resolution of 1,082×974 pixels (Kirk 2014).

\section{High-speed Digital Optical Measurement Techniques AND THEIR APPLICATIONS TO GEOMATERIALS}

Digital optical measurement techniques are varied in their scope and application, and include such diverse techniques as profilometry (Wyant et al. 1984), optical fibre sensors (Grattan and Meggitt 1995) and optical coherence tomography (Fercher et al. 2003). In this section, we outline some of the most frequently used noncontact full-field optical measurement techniques for dynamic stress, strain or temperature field and their applications in geomaterial experiments combined with high-speed photography. Table 3 gives a summary of these techniques.

Table 3 Summary of digital optical techniques for dynamic stress and deformation analysis (Field et al. 2004)

\begin{tabular}{|c|c|c|c|c|}
\hline Method & $\begin{array}{l}\text { Measured } \\
\text { parameter }\end{array}$ & Sensitivity & Accuracy & $\begin{array}{l}\text { Light } \\
\text { source }\end{array}$ \\
\hline Photoelasticity & $\sigma_{1}-\sigma_{2}$ & Variable & Variable & Incoherent \\
\hline Geometric Moiré & $u x$ or $u y$ & $\begin{array}{l}\text { Grating pitch } \\
p \approx 5-1000 \mu \mathrm{m}\end{array}$ & $\sim p / 10$ & Incoherent \\
\hline $\begin{array}{l}\text { Moiré } \\
\text { interferometry }\end{array}$ & $u x$ or $u y$ & Grating pitch $p \approx \lambda$ & $\sim p / 10$ & Coherent \\
\hline Caustics & $\partial u_{z} / \partial x, \partial u z / \partial y$ & Variable & Variable & Incoherent \\
\hline $\begin{array}{l}\text { Holographic } \\
\text { interferometry }\end{array}$ & $u x, u y$ and $u z$ & $\lambda / 2$ & $\sim \lambda / 50$ & Coherent \\
\hline $\begin{array}{l}\text { Particle image } \\
\text { velocimetry }\end{array}$ & $u x, u y$ and $u z$ & $\sim 1$ pixel of digital image & $\begin{array}{l}\sim 1 / 10 \text { pixel of digital } \\
\text { image }\end{array}$ & Incoherent \\
\hline $\begin{array}{l}\text { Digital image } \\
\text { correlation }\end{array}$ & $u x, u y$ and $u z$ & $\begin{array}{l}\sim 1 / 100,000 \text { of the field of } \\
\text { view }\end{array}$ & $\begin{array}{l}\sim 1 / 100 \text { pixel of digital } \\
\text { image }\end{array}$ & Incoherent \\
\hline
\end{tabular}

These techniques can be classified into interferometric and non- interferometric categories based on the nature of the physical phenomenon involved (Surrel 2003). Interferometric methods include photoelasticity, Moiré interferometry (MI), caustic and holographic interferometry. DIC, PIV and geometric Moiré are non-interferometric techniques. Interferometry requires a coherent light source, and the measurements can be very susceptible to environment disturbances like vibrations (Jacquot 2008). Thus, they are often conducted on a vibration-damped optical table in the laboratory. Moreover, the raw data from the interferometric techniques are often in the form of fringes which require further fringe processing and phase analysis techniques to obtain kinematic information like 
displacement. On the contrary, the non-interferometric techniques do not require coherent lighting. These techniques generally have less strict experimental requirements and determine the deformation through comparing light intensity changes from the specimen surface before and after deformation (Zhu 2015).

\subsection{Photoelastic Coating}

Photoelasticity allows visualisation of the stress distribution in certain transparent materials using the property of stress-induced temporary birefringence. It is one of the oldest and most widely used photomechanics methods and was developed by (Brewster 1816). In 1928, (Tuzi 1928) expanded the method to dynamic photoelasticity, to study a beam subjected to impact loading. This research also promoted the development of new high-speed photography system (Daehnke 1999), and one year later the multiple spark gap camera was developed by (Cranz and Schardin 1929). In terms of the application of photoelasticity in rock mechanics, the pioneering works were done by (Barla 1972; Barla and Boshkov 1969; Riley and Dally 1969). The principle of photoelasticity utilizes the nature of birefringence in which a ray of light passing through a birefringent material experiences two refractive indices. The relative magnitude of the refractive indices in the material directly relates to the state of stresses at that point.

Photoelasticity is mostly applied to determine stresses or check the quality of transparent objects (e.g. glass, plastics and single crystals) (Lagarde 2014). For opaque geomaterials, photoelastic coatings that deform with the material are used. The simplest setup consists of a coating, polarizer and analyser as shown in Fig. 23(a). Stress field visualization is a widely used feature of the photoelastic coating technique. Owing to the need for a suitable coating sheet, darkness, well defined optical paths and a highly skilled operator, applications of this technique in geomaterials are rare, and only a few recent examples exist. Studies on wave and fracture propagation were performed by several researchers with photoelastic coatings previously, where the results obtained were qualitative. The isochromatic-fringe patterns around a crack propagating in a marble specimen dynamically loaded by a steel wedge using a notch technique was investigated by (Daniel and Rowlands 1975). In (Glenn and Jaun 1978), Solenhofen limestone covered by a continuous coating was struck on edge with a steel projectile. In that research an Imacon 700 and an Imacon 790 were employed to examine the area at different levels of magnification. The use of a continuous coating may introduce uncertainty as the coating responded to fracture not only in the specimen, but also the coating itself (Daniel and Rowlands 1975). This problem may be alleviated by using separated birefringent coatings bonded to either side of the expected path of the crack (Zhang and Zhao 2014b). Fourney investigated the velocity of longitudinal stress waves, attenuation coefficients and dynamic elastic modulus in rock cores with dynamic photoelasticity (Fourney et al. 1976). The samples were $25 \mathrm{~mm}$ in diameter, $0.46 \mathrm{~m}$ long and made of Salem limestone, charcoal granite and Berea sandstone. The rods were loaded by a lead azide charge from one end, as seen in Fig. 23(b). A high-speed camera was operated at frame rates from 30,000 to 800,000 fps. The dynamic resolution of the camera was a function of the fringe gradient and fringe velocity and its upper limit corresponded to gradients of 0.8 fringes $/ \mathrm{mm}$ with fringe velocities of $3,000 \mathrm{~m} / \mathrm{s}$. Brittle polyester materials have high photoelasticity sensitivity, elastic modulus and low creep, time edge effect and can be easily manufactured. More references can be found on simulation of the wave propagation or the crack initiation in rock by polyester rather than directly on the rock. Some relevant references are (Fourney et al. 1975; Rossmanith and Fourney 1982; Shukla 1991; Shukla and Damania 1987; Thomson et al. 1969).

Fig. 23. (a) Loaded photoelasticity coating in a plane polari-scope (Younis 2012), and (b) Dynamic isochromatic-fringe pattern for strain-wave propagation in Salem limestone (Fourney et al. 1976).

\subsection{MOIRÉ}

Moiré fringes are formed by the superposition of two gratings, i.e. two arrays of uniformly spaced lines. Its application and modern scientific research into the Moiré phenomenon was not started until the 1850s with pioneering works such as (Rayleigh 1874; Righi 1887). Since then theoretical analysis of the Moiré phenomena has 
proceeded based on geometric or algebraic approaches (Amidror et al. 2000). A detailed review of the Moiré phenomenon can be found in (Patorski 1993). The Moiré fringes are contour maps of the path difference between the gratings, and as such, they have been attractive in experimental solid mechanics for the determination of surface deformation (Post et al. 2000). There are two distinct Moiré techniques: geometric Moiré and Moiré interferometry. The former can be divided into in-plane Moiré and shadow Moiré for out-of-plane displacement. Moiré interferometry only looks at the in-plane displacement. The basic difference between geometric and interferometric Moiré is the frequency of the gratings used (Anastasi 1992), but Moiré interferometry is much more sensitive than geometric Moire. In-plane geometric Moiré has been rarely applied, but shadow Moiré is still used for out-of-plane displacement which exceeds $0.25 \mathrm{~mm}$ across the field of view (Post et al. 2012). The schematic of Moiré interferometry and shadow Moiré is shown in Figs. 24(a-b). A detailed description of the method can be found in reference (Post et al. 2012). Applications of Moiré interferometry include the fracture behaviour or failure mechanism of materials (Arakawa et al. 1991; Epstein and Dadkhah 1993; Nicoletto et al. 1982), mechanical properties of composite structures and alloy materials (Ifju et al. 1995; Knauss et al. 1980; Mollenhauer et al. 2006), and residual stress detection (Min et al. 2006; Nicoletto 1991; Wu et al. 1998). However, Moiré interferometry needs a special high-frequency grating on the specimen surface on which the lasers impinge from a particular direction. If higher sensitivity is required, the pattern needs to be so fine that it becomes almost impossible to obtain adequate resolution and at the same time adequate depth of focus to cover a wide and possibly deep target (Huntley and Field 1989). As a result, it has limited application for measurements of geomaterials. Fig. 24(c) shows the process of wave propagation observed through isochromatic-fringe patterns on bonded Moiré-fringe patterns. Moiré-fringe patterns corresponding to vertical displacements in a marble specimen dynamically loaded on the edge were recorded at a frame rate of 1,004,500 fps with a 400 lines/cm grating (Daniel and Rowlands 1975). (Meng 1994) studied stress wave propagation and dynamic crack extension in a rock plate under explosive loading using a dynamic Moiré method, recorded by a GSJ rotating mirror framing camera, at frame rates ranging from 62.5 to $2,500 \mathrm{kfps}$. The high-speed camera and flash light were triggered by the explosive charge. Based on the dynamic Moiré records, the strain fields in the specimens were analysed, and the variation of the velocity of crack propagation with time and the phenomena of crack branching and crack arresting were investigated.

Fig. 24. Schematic of (a) four-beam Moiré interferometry to record the $N_{x}$ and $N_{y}$ fringe patterns, which depicts the $U$ and $V$ displacement fields, and (b) shadow Moiré, which depicts the W displacement fields (Post et al. 2012), (c) Moiré-fringe patterns corresponding to vertical displacements in a marble specimen dynamically loaded on the edge, at 1,004,500 fps and ruling of 400 lines/cm. (Daniel and Rowlands 1975).

\subsection{Caustics}

A caustic is the envelope of light rays reflected or refracted by a curved surface or object, or the projection of that envelope of rays impinging on another surface (Weinstein 1969). Making measurements by caustics was proposed by (Manogg 1964) and used extensively by (Theocaris and Gdoutos 1972; Yao and Xu 2011; Zehnder and Rosakis 1990). It is mainly used for studies of dynamic fracture of transparent materials, as shown in Fig. 25(a) (Field et al. 2004; Ravi-Chandar 2004). It can equally well apply to an opaque specimen when light rays are reflected from its surface, as shown in Fig. 25(b), and the optical path changes with the deformation of the object surface. The caustics method avoids one of the main drawbacks of the photoelastic method is that can measure in areas of plastic deformation as well as elastic. This makes it a powerful tool in the study of local stress fields and dynamic stress intensity factor (SIF) (Yang et al. 2014). However, the main problems of caustics are the low resolution, the difficult analytical processing and the narrow research scope (Gong et al. 2005).

Fig. 25. The principle of the caustics image refractive caustics for (a) a transparent specimen, and (b) an opaque specimen by reflective caustics (Kiser et al. 2013). 
(Yang et al. 2009c) conducted dynamic caustic tests on a three-point bending rock specimen using a drop-weight machine. The dimension of a rock specimen was $220 \times 50 \times 8 \mathrm{~mm}$ (length $\times$ height $\times$ thickness). The pre-made crack was $10 \mathrm{~mm}$ in length and $0.25 \mathrm{~mm}$ in width. The specimen was polished to a mirror finish after cutting which gives the specimen the ability to operate reflective caustic. The specimen was mounted in a drop hammer with a $250 \mathrm{~mm}$ height and a $30 \mathrm{kN}$ free-falling weight, which was able to provide impacts at different loading speeds. The dynamic SIF was determined by measurements of the transverse diameter of the caustic curve. A photo-electric system consisting of a DDGS-II multi-spark high-speed camera were employed. PMMA is often chosen for the study of crack-defect interaction mechanisms instead of actual geological materials because of its homogeneity, high mechanical strength, high transparency, low density, and easy casting. The wave speed and dynamic fracture behaviour of PMMA are very similar to certain relevant brittle solids at room temperature, and so allows for some read-across to the study of fracturing problems in geological materials under both static and dynamic loading conditions (Ayatollahi et al. 2015; Huang et al. 2009; Xu et al. 2005; Zhang et al. 2014a; Zhang et al. 2014b). (Li et al. 2005) established a dynamic caustics testing system to study the fracture of PMMA under blast loading, as PMMA was assumed to some extent o have similarities with rock. Through a controlled blasting method, the initial crack was close to a mode-I crack. Yang and his co-authors studied the crack propagation mechanism and the influence of closed and open joints in rock blasting by making inferences from PMMA experiments diagnosed by dynamic caustics (Yang et al. 2009b; Yang et al. 2008a), as shown in Fig. 26(a). Recently, (Yang et al. 2016a) studied the dynamic characteristics of propagation of main and secondary cracks by using a digital laser dynamic caustics method in PMMA with pore-existing flaws under explosive loading. A high-speed camera was set up to capture images with an interframe time of $10 \mu \mathrm{s}$, as shown in Fig. 26(b). Thus, crack length propagation at each time was measured to calculate the crack velocity. In another experiment, (Yang et al. 2016b) studied the crack-defect interaction for mode-I running crack using digital dynamic caustics method a with Fastcam-SA5 at 100,000 fps and exposure time of $1 \mu \mathrm{s}$. Three-point-bend loading type was performed on a pre-cracked PMMA by a hammer with $1.5 \mathrm{~kg}$ weight dropping from a height of $550 \mathrm{~mm}$. The crack velocity and dynamic SIF were obtained by the measurement. Yao and his co-authors studied various dynamic fracture phenomena of multi-cracks in PMMA by means of the caustic method with high-speed photography, such as thin plates with three or four-parallel edge cracks (Yao et al. 2002), 44 sheets with two overlapping offset-parallel cracks under tensile loading (Yao et al. 2003), and dynamic interactions between the static and propagating cracks where material initially containing two collinearedge-cracks was subjected to tensile loading (Yao et al. 2005), as shown in Fig. 26(c).

Fig. 26. (a) Caustics surrounding the tip of flaw after blasting (Yang et al. 2009b; Yang et al. 2008a; Yang et al. 2008b) (b) The caustics image of propagation of main cracks and secondary cracks in PMMA with flaws under explosion loads of PMMA model (Yang et al. 2016a), and (c) ;'[Off-focused caustic patterns of dynamic crack propagation in a PMMA specimen subjected to tensile loading with two collinear cracks (Yao et al. 2005).

\subsection{HOLOGRAPHIC INTERFEROMETRY (HI)}

Dynamic holographic interferometry (HI) enables dynamic displacements of optically rough surfaces to be measured with interferometric precision. The associated phenomena were first observed by (Leith and Upatnieks 1963). The early applications of HI were associated with deformation measurements of a lathe, vibration modes of turbine blades or propellers, non-destructive testing of rubber tires, the SIF of cracks, holographic photoelasticity, and mechanical behaviour of materials (Chia et al. 1984; Hariharan and Oreb 1986; Qin 1981; Stetson and Powell 1965; Yu-wen 1979). Later some pioneering work in HI improvement and applications in mechanical engineering and biomechanics were also published (Parker and Jones 1988; Sharma et al. 1993; Tieng and Lai 1992; Trolinger and Hsu 1993). The principle of HI is to obtain an interference pattern between two holograms of the same object, where the first is a reference state and the second is made on the same photographic film after the movement has occurred. During reconstruction, two waves are formed and interfere beyond the hologram. Traditional HI needs wet film chemical processing, which has been gradually replaced by digital speckle techniques. Digital HI was 
developed later ( $\mathrm{Li}$ et al. 2010). A simple schematic of high-speed digital HI is shown in Fig. 27(a). The sensitivity of the displacement measurement by $\mathrm{HI}$ is as high as half of the wavelength of the applied laser. Therefore, the advantage is mainly controlled by the pixel size in the CCD arrays (Rastogi 2000). In terms of disadvantages, the method requires a darkened room with complex vibration isolation, only one or two dynamic states can be recorded, and its measurement range is limited due to the fixed sensitivity, which leads to limited applications of $\mathrm{HI}$ in the dynamic experiments on geomaterials. (Holloway et al. 1978) introduced the application of HI to visualize wave propagation in Westerly granite. To enhance the coherence properties, a pulsed ruby laser was applied as the light source. Detailed Procedures were presented for the formation and reconstruction of the hologram, fringe interpretation, and data reduction and presentation. The elastic-wave velocities and material constants for Westerly granite were obtained from two images with a length scale, as shown in Fig. 27(b). The first holographic interferometric system was set up in China to capture explosive loading tests (Li et al. 1999), and the principles of the quantitative analysis of dynamic displacement fields in 3D were developed. The full-field surface displacement of marble samples was recorded by HI. It was found that when the explosive was detonated on the surface of samples, the Rayleigh wave predominated, and the main components of surface displacement were in the vertical and radial directions. Accumulation of stress was seen at crack tips.

Fig. 27. (a) Optical arrangement for the high-speed digital holographic interferometry (Pedrini et al. 2006), and (b) Typical fringe patterns at $11 \mu \mathrm{s}$ and $16 \mu \mathrm{s}$ after detonation resulting from an explosive point load in a half space of pink Westerly granite (Holloway et al. 1978)

\subsection{Particle Image Velocimetry (PIV)}

PIV is an optical method of flow visualization to obtain instantaneous velocity measurements and related properties in fluids. PIV has its roots in flow-visualization techniques such as particle-streak photography and stroboscopic photography (Adrian 1991). Applications of PIV include aerodynamics (Koschatzky et al. 2011), hydrodynamics (Hall et al. 2005), environmental research (Greated et al. 1992), biomedical research (Lima et al. 2008) and turbulence research (Zhang et al. 1997). PIV has been widely used and achieved remarkable results in measuring flow fields and in static soil deformation tests. Through calculating the distance of individual particles travelling in two images taken with a known time difference, the whole velocity field is obtained.

Due to the ability to track particles, high-speed PIV is employed to measure sand movement, as well as fragmentation and penetration in geomaterials. A laser pulse is mostly used as the illumination for two reasons: (1) particles in the flow can be very small thus requiring short exposure times to avoid blurred images, and (2) only laser light is able to be focussed on a sheet thin enough to image the particles in a plane. Tracer particles for PIV are required to satisfy two conditions: (1) they should be able to follow the flow streamlines without excessive slip, and (2) they should efficiently scatter the illuminating laser light (Prasad 2000). One of the distinguishing features of PIV is that it does not rely on the presence of targets such as grid or speckle (either naturally occurring or artificial). Deformation or movement of the particles themselves is able to provide reference points which are tracked as the experiment proceeds. This feature can alleviate the drawback of having to rely on separate tracers. An assessment of PIV performance in soil was conducted by (White et al. 2003). A very high measurement precision was achieved with a random 'soil' image. A typical setup of the PIV is shown in Fig. 28. The post-processing of recorded images in PIV is analogous to DIC, a powerful optical technique widely used for deformation measurement of solids, which is discussed in subsection 4.6.

Fig. 28. Typical setup of the PIV test (Raffel et al. 2013)

(Borg et al. 2013) collected light images with a Photron RS CMOS camera for general visual assessment and PIV measurements, as shown in Fig. 29(a). The PIV results revealed that the velocity of the sand near the projectile was quite low as compared to that of the projectile. This resulted in a thin layer of high shear near the interface between 
leading edge of the projectile and the sand. (Chen et al. 2014b) also conducted penetration experiments in transparent soil, as shown in Fig. 29(b). The velocity field of the soil target was determined by the PIV method. A NAC HX5 camera was utilised to capture a field view of $217 \times 163 \mathrm{~mm}^{2}$ at $4000 \mathrm{fps}$ with the resolution of $1280 \times 960$ pixels. (Wang et al. 2015) used high-speed PIV to quantitatively analyse a laboratory rockburst simulation. The displacement and strain fields were obtained, and the debris trajectory was described. The high-speed solid particles were equivalent to the tracer particles in the flow field, and the PIV method was able to track the tracer particles in the flow field produced during rockburst. Hence, applications of fluid mechanics type flow field analysis could potentially be used to simulate rockburst. As mentioned previously, (Hogan et al. 2014) conducted PIV on the highspeed photographs of tonalitic granitoid fragments induced by the impact of an aluminium projectile to track the fragments velocity, as shown in Fig. 29(c). Since the illumination source was not a laser, the individual particles could not be defined separately. Consequently, a cell may contain multiple ejected fragments.

Fig. 29. (a) Raw and processed images illustrating the penetration event and velocity vectors $1 \mathrm{~ms}$ after impact. The field of view is approximately $8 \mathrm{~cm} \times 10 \mathrm{~cm}$ and the impact velocity is $35 \mathrm{~m} / \mathrm{s}$ (Borg et al. 2013), (b) Eulerian trajectories from $\mathrm{t}=1 \mathrm{~ms}$ to $\mathrm{t}=5 \mathrm{~ms}, 4000 \mathrm{fps}$ and a spatial resolution of $1280 \times 6960$ pixels, where white rectangular is the exploded view of Eulerian trajectories below the cone tip and black rectangular is the exploded view of Eulerian trajectories along the cone shaft (Chen et al. 2014b), and (c) High-speed image of the target rear with interrogation area for $30 \mathrm{~mm}$ thick target and impact energy of $735 \mathrm{~J}$. Vector field (blue arrows in the online version) contour from PIV measurements with projected ejecta vectors (red colour in the online version) (Hogan et al. 2014).

The NASA Ames Vertical Gun Range (AVGR) developed 3D-PIV to measure 3D ejecta particle positions and velocities. Several tests were conducted on sand in order to gain understanding of gravity-controlled crater excavation (Anderson et al. 2000; Schultz et al. 2000). In 2002, 3D-PIV was successfully applied to the measurement of hypervelocity impact ejecta (Heineck et al. 2002). In 2003, (Anderson et al. 2003) presented a specific experiment in which ejection velocities, angles, and position were defined. The target was located on a platform within the large vacuum chamber. The projectile entered through one of several ports in the chamber $\left(30^{\circ}\right.$ above horizontal in this sketch). The impact created an ejecta curtain that moves across the target surface as the crater grows. A horizontal laser sheet was projected into the vacuum chamber at a given height above the target surface. Two high-speed CCD cameras were located above the chamber to record the ring of illuminated ejecta particles.

\subsection{Digital Image CoRrelation (DIC)}

DIC refers to the class of non-contacting methods that acquire images of an object, store images in digital form and perform image analysis to extract full-field shape, deformation and/or motion measurements (Sutton et al. 2009). The early research was conducted in the 1980s by (Chu et al. 1985; Peters and Ranson 1982; Sutton et al. 1986). Images can be obtained from various optical sources including macro scopes such as high-speed cameras, and microscopes, including scanning electron microscopes (McCormick and Lord 2010). The DIC technique can be applied not only to optical images but also to other datasets such as surface roughness maps and 2D surfaces of structures like tunnels. Basically, DIC techniques can be divided into 2D-DIC for in-plane deformation of nominal planar objects, 3D-DIC for surface 3D deformation of both planar and curved objects, and digital volume correlation (DVC) for internal full-field deformation of opaque solids or biological tissues. It should be mentioned that if the test object has a curved surface, or out-of-plane deformation occurs after loading, the 2D-DIC method is no longer applicable. The 3D-DIC was developed on the basis of the principle of binocular stereovision (Luo et al. 1993).

The principle of DIC is to match the same pixel in two images (2D-DIC) or two image pairs recorded by two synchronized cameras (3D-DIC) recorded before and after deformation. The basic principle and theory of DIC are presented in (Sutton et al. 2009), and a comprehensive review of DIC progress and applications can be found in (Pan 2011; Pan et al. 2009). For simplicity, the matching of the same two pixel points from two images to determine 
the desired displacement is schematically illustrated in Fig. 30. In order to obtain the displacement of a point $P$, a square subset centred at a point $P\left(x_{0}, y_{0}\right)$ is chosen as the reference subset. Then the DIC algorithms search its corresponding subset in the deformed image as the target subset, after which the center point of the target subset is the point $P\left(x_{0}^{\prime}, y_{0}^{\prime}\right)$ in the deformed image. The DIC algorithms are also known as the correlation criterion for evaluation of the degree of similarity between the reference subset and the target subset. Although different definitions of the correlation criteria can be found in the literature, these correlation criteria can be categorized into two groups, namely cross-correlation (CC) and sum of squared difference (SSD) criteria. More information about the correlation criterion can be found in (Giachetti 2000; Tong 2005). Once the displacement of the center of a subset is determined by $\mathbf{u}$ and $\mathbf{v}$ in the horizontal and vertical directions respectively, then another deformed pixel $\left(x_{i}^{\prime}, y_{i}^{\prime}\right)$ can be obtained by the first-order shape function from the pixel $\left(x_{i}, y_{i}\right)$ in the reference subset:

$$
x_{i}^{\prime}=x_{i}+u+\frac{\partial u}{\partial x} \Delta x+\frac{\partial u}{\partial y} \Delta y, y_{i}^{\prime}=y_{i}+v+\frac{\partial v}{\partial x} \Delta x+\frac{\partial v}{\partial y} \Delta y
$$

where $\Delta x$ and $\Delta y$ are the horizontal and vertical distances from the subset center to point respectively. The firstorder shape function allowing translation, rotation, shear, normal strains and their combinations of the subset is most commonly used. However, when apparent non-homogeneous deformation presents, the twelve-parameter second-order shape function capable of depicting more complex local deformation has been demonstrated to provide high accuracy (Lu and Cary 2000; Yu and Pan 2015).

Fig. 30. Schematic of a reference subset before deformation and a target subset after deformation. The center position of the target subset is obtained through searching the peak position of the distribution of the correlation coefficient (Pan et al. 2010).

The various DIC methods can be divided into types according to different algorithms. One is to analyse the strain field in microscopic images ( $\mu$ DIC) by using the traditional continuum DIC method (Huang et al. 2016). The digital volume correlation (DVC) introduced by (Bay et al. 1999) has the ability to describe the individual particle movement by meshing the specimen into the same size. In this method, the rotational degrees of freedom of particles can be taken into consideration. This latter technique has been widely applied in mechanical research such as wood bending (Forsberg et al. 2008), human bone (Zauel et al. 2006) and Argillaceous rock (Lenoir et al. 2007). The final DIC method is the discrete DIC method which reconstructs the particle with the original shape and size, meaning particles have no longer to be in contact, and large discontinuous deformation (fracture) can be defined in the DIC result (Nguyen et al. 2011). Typical uses of high-speed 2D or 3D-DIC include determination of the deformation field characterization of the deformation mechanism of various materials subjected to dynamic loading (Gilat et al. 2009; Koerber et al. 2015; Xiang et al. 2007) or vibration (Beberniss et al. 2012; Beberniss et al. 2011; Siebert and Crompton 2013), and identification of various dynamic parameters (e.g. fracture toughness) based on the computed displacement/strain fields (Garbowski et al. 2012; Pierron et al. 2011b; Sanborn et al. 2014). Since the sensitivity is adjustable, the DIC method can be used across a variety of length scales from massive systems such as glaciers (Haug et al. 2010) to micro- or nanoscale deformation (Berfield et al. 2007). One of the difficult aspects of the application of the high-speed DIC is purely photographic, how to guarantee the best quality images of the event can be recorded. Best quality means the best contrast with the minimal amount of noise (Reu and Miller 2008). With the constant emergence of high spatial resolution and high temporal resolution CMOS-based cameras, the highspeed DIC method is a promising optical measurement technology for dynamic experiments on geomaterials.

High-speed DIC has been commonly employed in materials such as metals or composite materials. (Zhang and Zhao 2013a) presented a detailed experimental procedure for high-speed DIC for the quantitative determination of mechanical properties and full-field strain measurement of rock under dynamic loads. Strain localization and evolution, and the onset of fracture were examined under three loading conditions: NSCB, Brazilian disc (BD), and uniaxial compression (UC). A great number of SHPB tests on geomaterials in conjunction with high-speed DIC 
technology have been conducted. A summary of high-speed DIC applications to rock materials is shown in Table 4. Four strain field images calculated by DIC in different experiments are shown in Fig. 31. Among these four experiments, for BD and NSCB test, DIC provided the strain field, the crack propagation velocity, fracture initiation toughness and fracture propagation toughness. In the UC or UC and shear combined test, the DIC mainly captured the strain field information during the fracture process. Only a few UC tests in SHPB using a high-speed DIC method have been reported and in general the application of DIC in dynamic UC tests is lacking in terms of maturity.

Fig. 31. Dynamic vertical strain fields of a NSCB specimen of Fangshan marble by DIC (Zhang and Zhao 2013a)

It can be seen from Table 4 that 3D-DIC analysis was seldom conducted, except the analysis of the dynamic Brazilian disc test on Kuru granite experiment conducted by (Mardoukhi et al. 2015). In geometries, such as UC where out of plane displacement is a particular problem, it is expected that 3D data would be more reliable than 2D data (Sutton et al. 2008). However, no 3D-DIC has been applied in dynamic UC tests on geomaterials. It can also be seen from Table 4 that most experiments were conducted with CMOS-based digital high-speed cameras. CMOSbased high-speed cameras have sufficient performance for dealing with DIC (Tiwari et al. 2007). However, due to CMOS-based cameras trade-off of temporal resolution and spatial resolution, only a small section of the sample can be seen. As a result, when the frame rate is settled, the field of view is only a part of the specimen.

(Gao et al. 2015) used an ICCD type camera to record the NSCB test on Laurentian granite for DIC analysis. However, as mentioned above, ICCD has the drawbacks of beam splitting or image intensifying, which decreases the dynamic range and increases noise levels. The errors in DIC using an ICCD high-speed camera are described in detail in (Tiwari et al. 2007). (Fourmeau et al. 2014) used a rotating mirror type CCD camera to capture Kuru Granite under BD test, thus avoiding some of the ICCD problems. The errors in DIC from rotating mirror camera images is described by (Kirugulige and Tippur 2009). ISIS-CCD high-speed cameras are also well suited to DIC but have not been applied in dynamic tests on geomaterials yet. Rotating prism high-speed cameras have not been used successfully for 3D-DIC due to the image misalignments caused by the rotating prism (Reu and Miller 2008). Details about distortions in high-speed cameras and their corrections related to image correlation are discussed in (Tiwari V et al. 2007). 


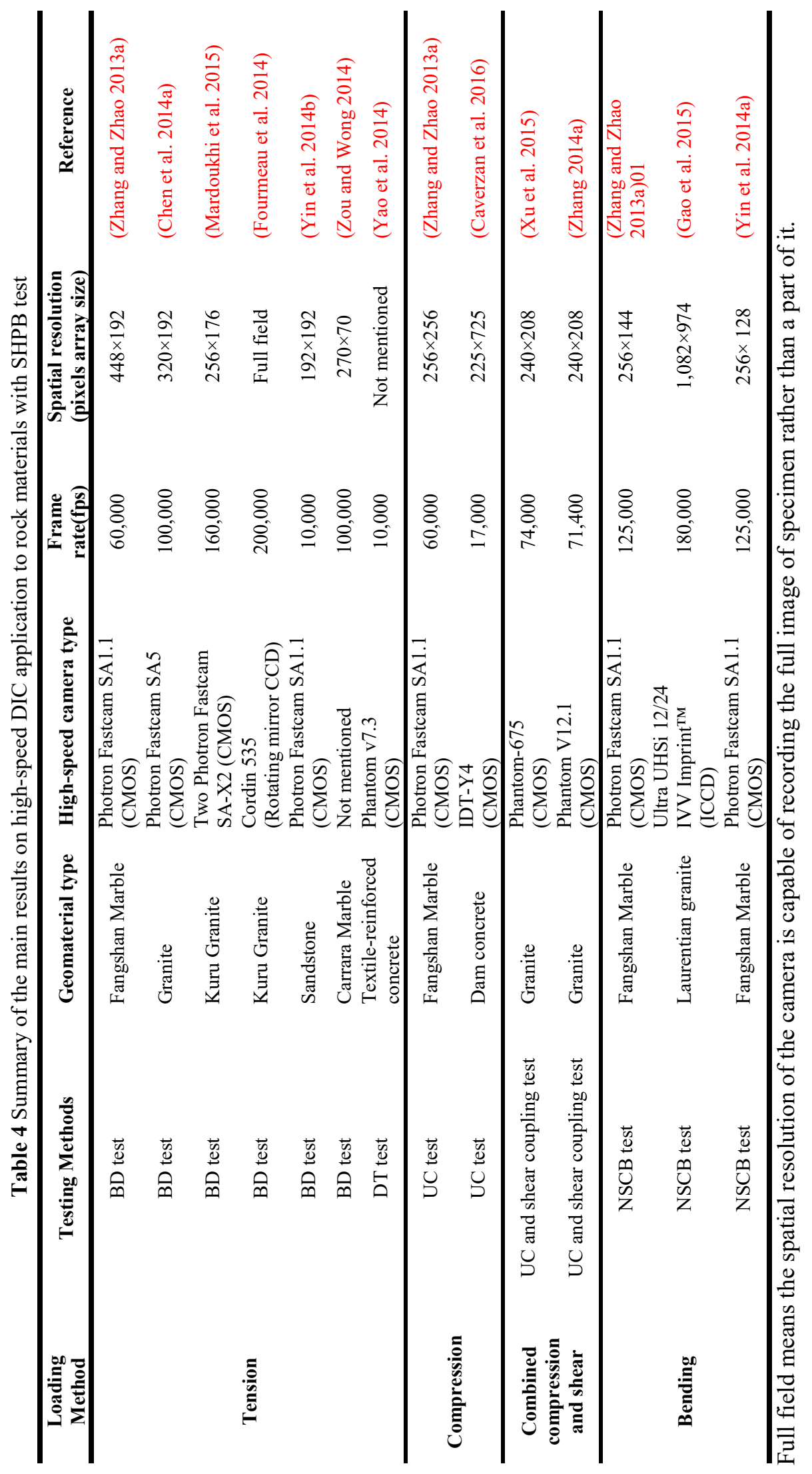


High-speed X-ray photography processed by DIC has become more popular in recent years. This method gives detailed information on local displacements and internal displacements of opaque geomaterials without significantly disrupting or influencing the material behaviour. (Collins et al. 2011) measured the internal flow fields in penetration of sand by long-rod projectiles with three different nose shapes at velocities up to $200 \mathrm{~m} / \mathrm{s}$ as shown in Fig. 32. Impacts on concrete and gelatine were also performed to compare with sand. It was found that loose sand without confining responds in a noticeably different manner both to hydrodynamic materials and inhomogeneous solids. Therefore, sand cannot either be modelled as a fluid or as a conventional solid during ballistic penetration.

Fig. 32. Contour plots of the longitudinal displacements (parallel to the projectile) for penetration of sand by flat-ended rod at $200 \mathrm{~m} / \mathrm{s}$. Colour bar denotes lateral displacement in mm. Time after impact: (a) $150 \mathrm{~ms}$, (b) $250 \mathrm{~ms}$, (c) $350 \mathrm{~ms}$, (d) $450 \mathrm{~ms}$, (e) $550 \mathrm{~ms}$, and (f) $750 \mathrm{~ms}$ (Collins et al. 2011).

\subsection{INFRARED THERMOGRAPHY (IRT)}

Infrared radiation was discovered in 1790 by M. Pitke and rediscovered by Sir William Herschel in 1800 (Bramson 1968). Because the energy emitted by a body is mainly a function (Planck's law) of its surface temperature, IRT is considered as a means of 2D temperature measurement (Meola and Carlomagno 2004). One of the applications is to measure temperature change in dynamic deformation and failure experiments (Costin et al. 1980; Hartley et al. 1987; Marchand and Duffy 1988; Moss and Pond 1975; Zehnder and Rosakis 1991; Zhou et al. 1996). It is noted that these studies were conducted on metallic materials, since these materials are expected to undergo higher temperature changes during high rate deformation (Crump et al. 2011). One of the hurdles of high-speed IRT development is that it can only be recorded by high-speed infrared cameras instead of standard high-speed cameras, and typical IR imaging systems can only run at television rates, $30 \mathrm{~Hz}$. High frame rate IRT is limited to only a few groups which are equipped with bespoke detector systems capable of frame rates up to $1 \mathrm{MHz}$ (Guduru et al. 2001; Trojanowski et al. 1998; Zehnder et al. 2000). Recently, improvements in detector technology have led to the availability of commercial systems to acquire IR images at frame rates in the $\mathrm{kHz}$ range. This acquisition rate meets the requirements of studying the responses of a typical composite material at a strain rate of up to $10^{2} \mathrm{~s}^{-1}$ (Fruehmann et al. 2013). Similar to normal digital high-speed cameras, the frame rate of high-speed infra camera is a compromise between three main parameters: the test duration, the thermal sensitivity and the number of detector elements (Fruehmann et al. 2011). The most advantages of IRT is no pre- or post-processing is needed because quantitative information in temperature is shown directly. Currently, this technique has not been widely applied in the research of rock dynamics due to the lack of adequate knowledge, high expense and difficulty in use (Meola and Carlomagno 2004). Fig. 33 shows transient target thermographs of a marble plate after impact at different impacting velocities (Shi et al. 2007). A thermal infrared imaging system, TVS-8100MKII, was used with a (theoretical) temperature sensitivity of $0.025{ }^{\circ} \mathrm{C}$, the fastest frame rate of $60 \mathrm{fps}$, and the spatial resolution of $0.22 \mathrm{~mm}^{2}$. The geometric features and the radiant characteristics of the IRT in target region were extracted and regressively analysed against both the projectile's impacting velocity and kinetic energy. However, the accuracy of TIR measurements is influenced by many factors, for example, the calibration and evaluation of the emissivity of the target.

Fig. 33. Transient target thermographs of marble plates impacted by split Hopkinson bar at different impacting velocities (modified after (Shi et al. 2007))

\section{CONClusions ANd OUTLOOK}

More than 130 years has passed since the birth of high-speed imaging technology (in 1878), and much progress has been made in the intervening years. High-speed imaging technology has been used for geomaterial research since the 1950s, and various imaging techniques have been applied in conjunction. Research on dynamic properties of geomaterials tends to be slightly behind the pace of the latest high-speed imaging technology as the properties of 
high stiffness, brittleness and heterogeneity in most geomaterials require a higher standard for an imaging system than more homogeneous materials. The basics of high-speed photography, such as the frame rate, the exposure time, and illumination covered in subsection 2.1.2, and a method was described to evaluate the proper frame rate for experiment scale and object velocity. Similarly, the self-length criterion is a good evaluation method to determine the exposure time. It is noted that LEDs have become more and more popular in high-speed imaging illumination, due to their adaptability and cold light. In this review, the currently available digital high-speed cameras were summarized. Fig. 5 clearly shows that the CCD-based high-speed cameras are dominant in terms of the frame rate and spatial resolution, but have a smaller frame number. CMOS-based cameras suffer from the trade-off of temporal and spatial resolution but this is often offset by the long recording time. The development history of the rotating mirror CCD, ICCD and ISIS-CCD and CMOS-based camera was also covered. Some inherent drawbacks of CCDs are likely to see CMOS become the dominant technology in the future. The bottleneck of the frame rate of CMOSbased high-speed cameras is the analog-to-digital converter speed. Triggering is extremely important for use of high-speed cameras. Programmable delay on selected input and output triggers is usually in nanoseconds, and good triggering design is essential for the success of the experiment. Some common dynamic tests for geomaterials and the required frame rates were given and a diagram was modified to illustrate the criteria for suitable frame rate, frame number and magnification for experiments.

In terms of the direct use of high-speed imaging in geomaterials, crack propagation, fragmentation, penetration, spalling and sand movement in different geomaterials were reviewed. In most cases, the digital high-speed cameras were used for qualitative and simple quantitative use. Therefore, it is not necessary to have a very high resolution as long as, for example, cracks or particles can be well defined in a zone of interest. For direct use of high-speed imaging in geomaterials, there is a need for high-speed colour cameras with long recording times and fast framing rates. Though introducing different grids of colour will increase the size of the data and decrease light sensitivity (As a colour filter array in front of the chip blocks approximately two-thirds of the incoming light), it offers the possibility to investigate the dynamic phenomena in geomaterials where different coloured grains are found. Another outlook for the direct use of high-speed cameras in geomaterial research is making comparative studies in an equivalent transparent material, such as the transparent soil mentioned in this review. Transparent soil and rock simulants generated by 3D printing (Jiang et al. 2016; Ju et al. 2014) is another area which gives an excellent opportunity for high-speed cameras to record what happens inside a specimen. This method is in some ways more direct when compared to acoustic emission detection and is easier in terms of experimental setup than real-time XRay computed tomography. The persuasiveness of direct observation will open new perspectives of research in geomechanics.

For optical methods in combination with high-speed imaging, photoelastic coating, Moiré, HI, caustics, PIV, DIC and IRT for geomaterials were reviewed. Advantages and disadvantages of each optical method were discussed. In summary, these combined methods are designed to obtain the wave propagation or stress/strain field at a certain moment. Due to the historic unavailability of electronic cameras and computer technology, photoelastic coatings, Moiré, HI and caustics played an important role in studies on geomaterial mechanics in the early days. However, just as film-based high-speed cameras have been replaced by digital high-speed cameras, the traditional optical methods have been replaced by digital processing methods like DIC and PIV. Another reason is that the principles of traditional optical methods such as photoelastic coating, Moiré, and HI, caustics are developed for transparent materials. To achieve good results, most experiments to investigate rock properties were conducted on transparent materials such as PMMA, epoxy or polyester which have qualitatively similar fracturing properties to rocks. However as the composition is different, it is only possible to make inferences about the behaviour in geomaterials, and the underlying physical mechanisms are generally not explained. With regard to DIC and PIV, a collection of recent literature was reviewed. The DIC and PIV methods are likely to be dominant for high-speed quantitative measurement in geomaterials for the foreseeable future. However, few papers have been dedicated to high-speed 3D-DIC. However, high-speed 3D-DIC inherits advantages from both DIC and stereovision, which is an 
outstanding method to study the fast full-field out-of-plane displacement. A further innovation in DIC is to analyse images obtained by high-speed synchrotron X-ray phase-contrast imaging (Parab et al. 2017). In high loading rate tests on geomaterials, the ability to measure particle movement and fracture propagation during failure can lead to a greater understanding of the micromechanics of failure in rock, soil and concrete etc. Moreover, validation of finite element method (FEM) or theoretical analyses and the bridge between experiment, simulation and theory (e.g., the Virtual Fields Method (Pierron and Grédiac 2012)) has made extraordinary progress (Avril et al. 2008; Hild and Roux 2006). However, the application of these new DIC methods with high-speed imaging in geomaterials still has a long way to go. For example, the stiffness of brittle rock is large, and the strain small, even under dynamic impact and this poses challenges to the resolutions of high-speed cameras. Therefore, the CMOS-based camera with higher spatial and temporal resolution are always in demand. Finally, the gap between CCD and CMOS-based cameras may be filled by an upcoming generation of cameras, eliminating the need, as is sometimes currently the case of making the experiment fit the imaging system, rather than the other way around.

\section{ACKNOWLEDGEMENTS}

This work was supported by the Australian Research Council (LE150100058) and Engineering Seed Funding Scheme of Monash University. The first author would like to acknowledge the financial support by the China Scholarship Council. The authors would like to appreciate the help and support by a number of colleagues who sharing their knowledge and resources during the preparation of this review. Special acknowledgements are given to Mrs Haiying Bian (editorial office of Geomechanics and Geoengineering-An International Journal) and Dr. Philip Reu who provided English editing and survey of current high-speed cameras for this review, respectively.

\section{REFERENCES}

Adrian RJ (1991) Particle-imaging techniques for experimental fluid mechanics Annual Review of Fluid Mechanics 23:261-304

Allen WA, Mayfield EB, Morrison HL (1957) Dynamics of a Projectile Penetrating Sand Journal of Applied Physics 28:370-376 doi:10.1063/1.1722750

Amidror I, Amidror I, Amidror I, Amidror I (2000) The theory of the moiré phenomenon vol 38. vol LSP-BOOK-2000-001. Springer, Boston. doi:10.1007/978-1-84882-181-1

Anastasi RF (1992) An Introduction to Moire Methods with Applications in Composite Materials. Army lab command watertown ma material technology lab,

Anderson J, Schultz P, Heineck J (2000) A new view of ejecta curtains during oblique impacts using 3D particle imaging velocimetry. Paper presented at the Lunar and planetary science and exploration, Washington,

Anderson JL, Schultz PH, Heineck JT (2003) Asymmetry of ejecta flow during oblique impacts using three - dimensional particle image velocimetry Journal of Geophysical Research: Planets 108

Arakawa K, Drinnon Jr R, Kosai M, Kobayashi A (1991) Dynamic fracture analysis by moiré interferometry Experimental Mechanics 31:306309 doi:10.1007/BF02325986

Arbiter N, Harris C, Stamboltzis G (1969) Single fracture of brittle spheres Trans AIME 244:118-133

Avril S et al. (2008) Overview of identification methods of mechanical parameters based on full-field measurements Experimental Mechanics 48:381-402 doi:10.1007/s11340-008-9148-y

Ayatollahi M, Torabi A, Firoozabadi M (2015) Theoretical and experimental investigation of brittle fracture in V-notched PMMA specimens under compressive loading Engineering Fracture Mechanics 135:187-205 doi:10.1016/j.engfracmech.2015.01.005

Bagnold RA (1941) The physics of wind blown sand and desert dunes Methuen, London 265

Bagnold RA (2012) The physics of blown sand and desert dunes. Courier Corporation, New York. doi:10.1007/978-94-009-5682-7

Barla G (1972) Stresses around a single underground opening near a traction-free surface International Journal of Rock Mechanics and Mining Sciences \& Geomechanics Abstracts 9:103-126 doi:10.1016/0148-9062(72)90052-6

Barla G, Boshkov SH (1969) Two-dimensional photoelastic analysis of gravity-loaded rock structures using gelatin mixture models Trans Am Inst Min Metall Engrs 244:99-115

Bay BK, Smith TS, Fyhrie DP, Saad M (1999) Digital volume correlation: three-dimensional strain mapping using X-ray tomography Experimental Mechanics 39:217-226 doi:10.1007/BF02323555

Beberniss T, Eason T, Spottswood S High-speed 3D digital image correlation measurements of long-duration random vibration; recent advancements and noted limitations. In: Proceedings, International Conference on Noise and Vibration Engineering (ISMA), Katholieke Universiteit Leuven, Belgium, 2012. 
Beberniss T, Spottswood M, Eason T (2011) High-speed digital image correlation measurements of random nonlinear dynamic response. In: Experimental and Applied Mechanics, Volume 6. Springer, pp 171-186. doi:10.1007/978-1-4614-0222-0 22

Berfield T, Patel J, Shimmin R, Braun P, Lambros J, Sottos N (2007) Micro-and nanoscale deformation measurement of surface and internal planes via digital image correlation Experimental Mechanics 47:51-62 doi:10.1007/s11340-006-0531-2

Bieniawski ZT Mechanism of brittle fracture of rock: part I - theory of the fracture process. In: International Journal of Rock Mechanics and Mining Sciences \& Geomechanics Abstracts, 1967a. vol 4. Elsevier, pp 395IN11405-11404IN12406. doi:10.1016/0148-9062(67)900307

Bieniawski ZT (1967b) Mechanism of brittle fracture of rock: Part II—experimental studies International Journal of Rock Mechanics and Mining Sciences \& Geomechanics Abstracts 4:407-423 doi:10.1016/0148-9062(67)90031-9

Bieniawski ZT (1968) Fracture dynamics of rock Int J Fract 4:415-430 doi:10.1007/bf00186807

Blair BE (1960) Use of high-speed camera in blasting studies vol 5584. US Dept. of the Interior, Bureau of Mines, USA

Borg J, Morrissey M, Perich C, Vogler T, Chhabildas L (2013) In situ velocity and stress characterization of a projectile penetrating a sand target: experimental measurements and continuum simulations International Journal of Impact Engineering 51:23-35 doi:10.1016/j.ijimpeng.2012.07.009

Borvik T, Gjorv OE, Langseth M (2007) Ballistic perforation resistance of high-strength concrete slabs Concrete International Detroit: American Concrete Institute 29:45

Bourne N (2013) Materials in mechanical extremes: Fundamentals and applications. Cambridge University Press, Cambridge

Bowden F, McOnie M Formation of cavities and microjets in liquids and their role in initiation and growth of explosion. In: Proceedings of the Royal Society of London A: Mathematical, Physical and Engineering Sciences, 1967. vol 1452. The Royal Society, pp 38-50

Boys C (1892) On Electric Spark Photography; or, Photography of Flying Bullets, and so on, by the Light of the Electric Spark Nature 3:415 Braithwaite C (2009) High strain rate properties of geological materials. University of Cambridge

Brajer X, Forquin P, Gy R, Hild F (2003) The role of surface and volume defects in the fracture of glass under quasi-static and dynamic loadings Journal of non-crystalline solids 316:42-53 doi:10.1016/S0022-3093(02)01936-1

Bramson MA (1968) Infrared radiation. A handbook for applications Optical Physics and Engineering, New York: Plenum Press, 19681

Brara A, Camborde F, Klepaczko J, Mariotti C (2001) Experimental and numerical study of concrete at high strain rates in tension Mechanics of materials 33:33-45 doi:10.1016/S0167-6636(00)00035-1

Brara A, Klepaczko JR (2006) Experimental characterization of concrete in dynamic tension Mechanics of Materials 38:253-267 doi:DOI: 10.1016/j.mechmat.2005.06.004

Braslau D (1970) Partitioning of energy in hypervelocity impact against loose sand targets Journal of Geophysical Research 75:3987-3999 doi:10.1029/JB075i020p03987

Brewster D (1816) On the communication of the structure of doubly refracting crystals to glass, muriate of soda, fluor spar, and other substances, by mechanical compression and dilatation Philosophical Transactions of the Royal Society of London 106:156-178

Cai M, Kaiser P, Suorineni F, Su K (2007) A study on the dynamic behavior of the Meuse/Haute-Marne argillite Physics and Chemistry of the Earth, Parts A/B/C 32:907-916

Caverzan A, Peroni M, Solomos G (2016) Compressive behaviour of dam concrete at higher strain rates The European Physical Journal Special Topics:1-11 doi:10.1140/epjst/e2016-02628-5

Chen J, Guo B, Liu H, Liu H, Chen P (2014a) Dynamic Brazilian Test of Brittle Materials Using the Split Hopkinson Pressure Bar and Digital Image Correlation Strain 50:563-570 doi:10.1111/str.12118

Chen R, Xia K, Dai F, Lu F, Luo S (2009) Determination of dynamic fracture parameters using a semi-circular bend technique in split Hopkinson pressure bar testing Engineering Fracture Mechanics 76:1268-1276 doi:10.1016/j.engfracmech.2009.02.001

Chen Z, Omidvar M, Iskander M, Bless S (2014b) Modelling of projectile penetration using transparent soils International Journal of Physical Modelling in Geotechnics 14:68-79

Chia Y, Tong J, Tou C (1984) A study of dynamic holographic photoelasticity using ruby laser Canadian Society for Mechanical Engineering, Transactions 8:117-120

Cho SH, Ogata Y, Kaneko K (2003) Strain-rate dependency of the dynamic tensile strength of rock International Journal of Rock Mechanics and Mining Sciences 40:763-777

Chu T, Ranson W, Sutton M (1985) Applications of digital-image-correlation techniques to experimental mechanics Experimental mechanics 25:232-244 doi:10.1007/BF02325092

Cintala MJ, Berthoud L, Hörz F (1999) Ejection - velocity distributions from impacts into coarse - grained sand Meteoritics \& Planetary Science 34:605-623 doi:10.1111/j.1945-5100.1999.tb01367.x

Cole RP (2010) Ballistic penetration of a sandbagged redoubt using silica sand and pulverized rubber of various grain sizes. University of South Florida

Coleman KR The photography of high temperature events. In: Proc. 4th Int. Kongress Kurzzeitphotographie, 1959. pp 32-39

Collins A, Addiss J, Walley S, Promratana K, Bobaru F, Proud W, Williamson D (2011) The effect of rod nose shape on the internal flow fields during the ballistic penetration of sand International Journal of Impact Engineering 38:951-963

Company C (2012a) high speed rotating mirror ccd camera Model 560. http://www.cordin.com/pdfs/Cordin560.pdf.

Company C (2012b) High speed rotating mirror ccd camera Model 580. http://www.cordin.com/pdfs/Cordin580.pdf.

Company S Shimadzu ultra-high speed camera HPV-2. http://www.ssi.shimadzu.com/products/product.cfm?product=hpv2-3.

Costin L, Crisman E, Hawley R, Duffy J On the localisation of plastic flow in mild steel tubes under dynamic torsional loading. In: Proc. 2 nd Conf. Mechanical Properties of Materials at High Rates of Strain, Oxford, England, Mar. 1979, 1980. pp 90-100

Courtney-Pratt J (1957) A review of the methods of high-speed photography Reports on progress in physics 20:379 
Courtney-Pratt J (1973) Advances in High-Speed Photography 1957-1972. In, vol 82. vol 108. Springer Netherlands, pp 595-607. doi:10.1007/978-94-017-0445-8 21

Courtney-Pratt J (1986) Advances in High-Speed Photography: 1972-1982. In: Fast Electrical and Optical Measurements. Springer, pp 595607. doi:10.1007/978-94-017-0445-8 21

Courtney-Pratt JS (1949) Photography of Fast Transients. Interferometric Study of Surfaces. University of Cambridge

Cranz C, Schardin H (1929) Kinematographie auf ruhendem Film und mit extrem hoher Bildfrequenz Zeitschrift für Physik 56:147-183 doi:10.1007/BF01342777

Crooks J, Marsh B, Turchetta R, Taylor K, Chan W, Lahav A, Fenigstein A Ultra-high speed imaging at megaframes per second with a megapixel CMOS image sensor. In: Proc. International Image Sensor Workshop, 2013. pp 369-372

Crump D, Dulieu-Barton J, Fruehmann R (2011) Challenges in synchronising high speed full-field temperature and strain measurement. In: Thermomechanics and Infra-Red Imaging, Volume 7. Springer, pp 1-7. doi:10.1007/978-1-4614-0207-7 1

Culp FL, Hooper HL (1961) Study of Impact Cratering in Sand Journal of Applied Physics 32:2480-2484 doi:10.1063/1.1777095

Daehnke A Stress wave and fracture propagation in rock. In: 9th ISRM Congress, 1999. International Society for Rock Mechanics,

Dai F, Chen R, Xia K (2010) A semi-circular bend technique for determining dynamic fracture toughness Experimental Mechanics 50:783791 doi:10.1007/s11340-009-9273-2

Daniel I, Rowlands RE (1975) On wave and fracture propagation in rock media Experimental Mechanics 15:449-457 doi:10.1007/BF02318359

De Ploey J, Savat J (1968) Contribution a l'étude de l'érosion par le splash Zeitschrift für Geomorphologie 12:174-193

Dear J, Field J (1988) High - speed photography of surface geometry effects in liquid/solid impact Journal of Applied Physics 63:1015-1021 doi:10.1063/1.340000

Denoual C, Cottenot CE (1998) Visualization of the damage evolution in impacted silicon carbide ceramics International journal of impact engineering 21:225-235 doi:10.1016/S0734-743X(97)00018-3

Descoeudres A, Hollenstein C, Wälder G, Perez R (2005) Time-resolved imaging and spatially-resolved spectroscopy of electrical discharge machining plasma Journal of Physics D: Applied Physics 38:4066 doi:10.1088/0022-3727

Draxler VC (2005) High-Speed Diagnostics for Ballistics and Explosive Studies. In: High-Pressure Shock Compression of Solids VIII. Springer, pp 227-249. doi:10.1007/3-540-27168-6_6

Eastman G (1888) Camera, Patent US 388850 A. American Patent,

Edgerton HE, Killian JR (1954) Flash!: Seeing the unseen by ultra high-speed photography. CT Branford Co., Massachusetts

Einstein HH, Meyer T Müller lecture: puzzles in rock. In: 9th ISRM Congress, 1999. International Society for Rock Mechanics,

Ellison W (1944) Studies of raindrop erosion Agricultural Engineering 25:131-136

Epstein J, Dadkhah M (1993) Moire interferometry in fracture research Experimental Techniques in Fracture:427-508

Etoh T (1992) High-speed video camera of 4,500 pps Japan Television Association 46:543-545

Etoh TG, Mutoh H An image sensor of 1 Mfps with photon counting sensitivity. In: 26th International Congress on High-Speed Photography and Photonics, 2005. International Society for Optics and Photonics, pp 301-307. doi:10.1117/12.566170

Etoh TG et al. (2003) An image sensor which captures 100 consecutive frames at 1000000 frames/s Electron Devices, IEEE Transactions on 50:144-151 doi:10.1109/TED.2002.806474

Etoh TG et al. (2007) Evolution of ultra-high-speed CCD imagers Plasma and Fusion Research 2:S1021-S1021 doi:10.1585/pfr.2.S1021

Fercher AF, Drexler W, Hitzenberger CK, Lasser T (2003) Optical coherence tomography-principles and applications Reports on progress in physics 66:239 doi:10.1088/0034-4885/66/2/204

Field J (1983) High-speed photography Contemporary Physics 24:439-459 doi:10.1080/00107518308210696

Field J, Proud W, Walley S (2009) Review of optical and X-ray techniques used at the Cavendish Laboratory The Imaging Science Journal $57: 317-325$

Field J, Walley S, Proud W, Goldrein H, Siviour C (2004) Review of experimental techniques for high rate deformation and shock studies International Journal of Impact Engineering 30:725-775

Fookes P (1991) Geomaterials Quarterly Journal of Engineering Geology and Hydrogeology 24:3-15

Forquin P (2017) Brittle materials at high-loading rates: an open area of research Philosophical Transactions of the Royal Society A: Mathematical, Physical and Engineering Sciences 375 doi:10.1098/rsta.2016.0436

Forsberg F, Mooser R, Arnold M, Hack E, Wyss P (2008) 3D micro-scale deformations of wood in bending: synchrotron radiation $\mu$ CT data analyzed with digital volume correlation Journal of structural biology 164:255-262 doi:10.1016/j.jsb.2008.08.004

Foster M, Love B, Kaste R, Moy P (2015) The rate dependent tensile response of polycarbonate and poly-methylmethacrylate Journal of Dynamic Behavior of Materials 1:162-175 doi:10.1007/s40870-015-0020-8

Fourmeau M, Gomon D, Vacher R, Hokka M, Kane A, Kuokkala V-T (2014) Application of DIC technique for studies of Kuru Granite rock under static and dynamic loading Procedia Materials Science 3:691-697 doi:10.1016/j.mspro.2014.06.114

Fourney W, Dally J, Holloway D (1976) Attenuation of strain waves in core samples of three types of rock Experimental Mechanics 16:121126

Fourney W, Holloway D, Dally J (1975) Fracture initiation and propagation from a center of dilatation International Journal of Fracture 11:1011-1029 doi:10.1007/BF00033847

Fowler A, Scheu B, Lee W, McGuinness M A theoretical model of the explosive fragmentation of vesicular magma. In: Proceedings of the Royal Society of London A: Mathematical, Physical and Engineering Sciences, 2009. The Royal Society, p rspa20090382

Fruehmann R, Crump D, Dulieu-Barton J (2011) The use of infrared thermography at high frame rates. In: Thermomechanics and Infra-Red Imaging, Volume 7. Springer, pp 9-15. doi:10.1007/978-1-4614-0207-7_2 
Fruehmann R, Crump D, Dulieu-Barton J (2013) Characterization of an infrared detector for high frame rate thermography Measurement Science and Technology 24:105403

Fuller PW (2005) Some highlights in the history of high-speed photography and photonics as applied to ballistics. In: High-Pressure Shock Compression of Solids VIII. Springer, pp 251-298. doi:10.1007/3-540-27168-6 7

Fuller PWW (1994) Aspects of high speed photography The Journal of Photographic Science 42:42-43

Fuller PWW (2009) An introduction to high speed photography and photonics The Imaging Science Journal 57:293-302 doi:10.1179/136821909x12490326247524

Furbish DJ, Hamner KK, Schmeeckle M, Borosund MN, Mudd SM (2007) Rain splash of dry sand revealed by high - speed imaging and sticky paper splash targets Journal of Geophysical Research: Earth Surface 112 doi:10.1029/2006JF000498

Gao G, Huang S, Xia K, Li Z (2015) Application of digital image correlation (DIC) in dynamic notched semi-circular bend (NSCB) tests Experimental Mechanics 55:95-104 doi:10.1007/s11340-014-9863-5

Garbowski T, Gajewski T, Lodygowski T (2012) Identification of rate dependent material model parameters based on Split Hopkinson Pressure Bar test and high speed camera with Digital Image Correlation. Paper presented at the European Congress on Computational Methods in Applied Science and Engineering Vienna, Austria,

Gault DE, Moore HJ, Shoemaker EM (1963) Spray ejected from the lunar surface by meteoroid impact. National aeronautics and space administration,

Giachetti A (2000) Matching techniques to compute image motion Image and Vision Computing 18:247-260 doi:10.1016/S0262$8856(99) 00018-9$

Gilat A, Schmidt T, Walker A (2009) Full field strain measurement in compression and tensile split Hopkinson bar experiments Experimental Mechanics 49:291-302 doi:10.1007/s11340-008-9157-x

Glenn L, Jaun H (1978) Crack propagation in rock plates loaded by projectile impact Experimental Mechanics 18:35-40 doi:10.1007/BF02326555

Gong M, Jia J-p, Wang D-s (2005) A Review of Studies on the Blasting Model by Dynamic Photomechanics [J] Blasting 22:7-12

Grady D, Benson D (1983) Fragmentation of metal rings by electromagnetic loading Experimental Mechanics 23:393-400

Grady D, Kipp M The micromechanics of impact fracture of rock. In: International Journal of Rock Mechanics and Mining Sciences \& Geomechanics Abstracts, 1979. vol 5. Elsevier, pp 293-302. doi:10.1016/0148-9062(79)90240-7

Grange S, Forquin P, Mencacci S, Hild F (2008) On the dynamic fragmentation of two limestones using edge-on impact tests International Journal of Impact Engineering 35:977-991 doi:10.1016/j.ijimpeng.2007.07.006

Grattan KT, Meggitt B (1995) Optical fiber sensor technology vol 1. vol 3. Springer, London. doi:10.1007/978-1-4757-6077-4

Greated C, Skyner D, Bruce T Particle image velocimetry (PIV) in the coastal engineering laboratory. In: Coastal Engneering Conference, 1992. ASCE pp 212-212. doi:10.1061/9780872629332.016

Grogan J, Tekalur SA, Shukla A, Bogdanovich A, Coffelt RA (2007) Ballistic resistance of 2D and 3D woven sandwich composites vol 9. Springer Netherlands. doi:10.1007/1-4020-3848-8_63

Guduru P, Rosakis A, Ravichandran G (2001) Dynamic shear bands: an investigation using high speed optical and infrared diagnostics Mechanics of Materials 33:371-402 doi:10.1016/S0167-6636(01)00051-5

Guzman IL, Iskander M, Bless S (2015) Observations of projectile penetration into a transparent soil Mechanics Research Communications 70:4-11 doi:10.1016/j.mechrescom.2015.08.008

Hall J, Barigou M, Simmons M, Stitt E (2005) A PIV study of hydrodynamics in gas-liquid high throughput experimentation (HTE) reactors with eccentric impeller configurations Chemical engineering science 60:6403-6413 doi:10.1016/j.ces.2005.03.044

Hariharan P, Oreb BF (1986) Stroboscopic holographic interferometry: application of digital techniques Optics Communications 59:83-86

Hartley K, Duffy J, Hawley R (1987) Measurement of the temperature profile during shear band formation in steels deforming at high strain rates Journal of the Mechanics and Physics of Solids 35:283-301 doi:10.1016/0022-5096(87)90009-3

Haug T, Kääb A, Skvarca P (2010) Monitoring ice shelf velocities from repeat MODIS and Landsat data-a method study on the Larsen C ice shelf, Antarctic Peninsula, and 10 other ice shelves around Antarctica The Cryosphere 4:161-178 doi:10.5194/tc-4-161-2010

Held M Streak technique in detonics. In: 17th Int'l Conference on High Speed Photography and Photonics, 1987. International Society for Optics and Photonics, pp 421-443. doi:10.1117/12.975571

Hertegård S, Larsson H, Wittenberg T (2003) High-speed imaging: applications and development Logopedics Phoniatrics Vocology 28:133139 doi:10.1080/14015430310015246

Hild F, Roux S (2006) Digital image correlation: from displacement measurement to identification of elastic properties-a review Strain 42:6980 doi:10.1111/j.1475-1305.2006.00258.x

Hino K (1956) Velocity of rock fragments and shape of shock wave Journal of the industrial explosives society, Japan 17:2-36

Hogan J, Spray J, Rogers R, Vincent G, Schneider M (2014) Impact Failure of Planetary Materials Experimental Mechanics 54:665-675

Hogan JD, Spray JG, Rogers RJ, Vincent G, Schneider M (2013a) Dynamic fragmentation of natural ceramic tiles: ejecta measurements and kinetic consequences International Journal of Impact Engineering 58:1-16 doi:10.1016/j.ijimpeng.2013.02.007

Hogan JD, Spray JG, Rogers RJ, Vincent G, Schneider M (2013b) Dynamic fragmentation of planetary materials: Ejecta length quantification and semi-analytical modelling International Journal of Impact Engineering 62:219-228

Holloway D, Patacca A, Fourney W Application of holographic interferometry to a study of wave propagation in rock: Exp mech, V17, N8, Aug 1977, P314-384. In: International Journal of Rock Mechanics and Mining Sciences \& Geomechanics Abstracts, 1978. vol 2. Pergamon, p A28. doi:10.1016/0148-9062(78)91719-9

Honour J (2009) A brief history of principles used in high speed cameras The Imaging Science Journal 57:303-316 doi:10.1179/136821909x12490307953035 
Hornemann U, Rothenhausler H, Senf H, Kalthoff J, Winkler S Experimental investigation of wave and fracture propagation in glass slabs loaded by steel cylinders at high-impact velocities. In: Institute of Physics Conference Series, 1984. vol 70. PLENUM PUBL CORP 233 SPRING ST, NEW YORK, NY 10013, pp 291-298

Hu G, Ramesh K, Cao B, McCauley J (2011) The compressive failure of aluminum nitride considered as a model advanced ceramic Journal of the Mechanics and Physics of Solids 59:1076-1093 doi:10.1016/j.jmps.2011.02.003

Huang $\mathrm{J}$ et al. (2016) Heterogeneity in deformation of granular ceramics under dynamic loading Scripta Materialia 111:114-118 doi:10.1016/j.scriptamat.2015.08.028

Huang S, Luo S, Xia K Dynamic fracture initiation toughness and propagation toughness of PMMA. In: Proceedings of the SEM annual conference, Albuquerque, 2009. pp 1-4

Huntley J, Field J (1989) High resolution moiré photography: application to dynamic stress analysis Optical Engineering 28:288926-288926doi: $10.1117 / 12.7977058$

Huston A (1978) High-speed photography and photonic recording Journal of Physics E: Scientific Instruments 11:601 doi:10.1088/00223735

Ifju PG, Masters JE, Jackson WC (1995) The use of moiré interferometry as an aid to standard test-method development for textile composite materials Composites science and technology 53:155-163 doi:10.1016/0266-3538(95)00014-3

Ilstad T, Elverhøi A, Issler D, Marr JG (2004a) Subaqueous debris flow behaviour and its dependence on the sand/clay ratio: a laboratory study using particle tracking Marine Geology 213:415-438

Ilstad T, Marr JG, Elverhøi A, Harbitz CB (2004b) Laboratory studies of subaqueous debris flows by measurements of pore-fluid pressure and total stress Marine Geology 213:403-414 doi:10.1016/j.margeo.2004.10.016

Islam MT, Bindiganavile V (2012) Stress rate sensitivity of Paskapoo sandstone under flexure Canadian Journal of Civil Engineering 39:1184-1192 doi:10.1139/12012-101

ISRM (1978) Suggested methods for determining tensile strength of rock materials International Journal of Rock Mechanics and Mining Sciences 15:99-103 doi:10.1016/0148-9062(78)90003-7

Jacquot P (2008) Speckle interferometry: a review of the principal methods in use for experimental mechanics applications Strain 44:57-69 doi:10.1111/j.1475-1305.2008.00372.x

Jiang C, Dong Z, Zhang Z (2015) Measurement of the movement parameters of saltating sand over a flat sand bed using a high-speed digital camera Environmental Earth Sciences 74:4865-4874 doi:10.1007/s12665-015-4490-8

Jiang C, Zhao G-F, Zhu J, Zhao Y-X, Shen L (2016) Investigation of Dynamic Crack Coalescence Using a Gypsum-Like 3D Printing Material Rock Mechanics and Rock Engineering 49:3983-3998 doi:10.1007/s00603-016-0967-3

Ju Y, Xie H, Zheng Z, Lu J, Mao L, Gao F, Peng R (2014) Visualization of the complex structure and stress field inside rock by means of 3D printing technology Chinese Science Bulletin 59:5354-5365 doi:10.1007/s11434-014-0579-9

Jung W, Utagawa M, Ogata Y, Seto M, Katsuyama K, Miyake A, Ogawa T (2001) Effects of rock pressure on crack generation during tunnel blasting Kayaku Gakkaishi/Journal of the Japan Explosives Society 62:138-146

Kekić G, Dojčinović IP (2003) Application of the digital imaging technique using IMACON 790 camera for compression plasma flows investigation Scientific Technical Review 53:3-9

Kimberley J, Ramesh K (2011) The dynamic strength of an ordinary chondrite Meteoritics \& Planetary Science 46:1653-1669 doi:10.1111/j.1945-5100.2011.01254.x

Kirk S (2014) Shock compression and dynamic fragmentation of geological materials. University of Cambridge

Kirugulige M, Tippur H (2009) Measurement of Fracture Parameters for a Mixed - Mode Crack Driven by Stress Waves using Image Correlation Technique and High - Speed Digital Photography Strain 45:108-122 doi:10.1111/j.1475-1305.2008.00449.x

Kiser T, Eigensatz M, Nguyen MM, Bompas P, Pauly M (2013) Architectural caustics-Controlling light with geometry. Springer, London. doi:10.1007/978-3-7091-1251-9_7

Klepaczko J, Brara A (2001) An experimental method for dynamic tensile testing of concrete by spalling International Journal of Impact Engineering 25:387-409

Knauss W, Babcock C, Chai H (1980) Visualization of Impact Damage of Composite Plates by Means of the Moire Technique. DTIC Document,

Koerber H, Xavier J, Camanho P, Essa Y, de la Escalera FM (2015) High strain rate behaviour of 5-harness-satin weave fabric carbon-epoxy composite under compression and combined compression-shear loading International Journal of Solids and Structures 54:172-182 doi:10.1016/j.ijsolstr.2014.10.018

Kondo Y et al. (2012) Development of "HyperVision HPV-X" high-speed video camera Shimadzu Review 69:285-291

Koschatzky V, Moore P, Westerweel J, Scarano F, Boersma B (2011) High speed PIV applied to aerodynamic noise investigation Experiments in fluids 50:863-876 doi:10.1007/s00348-010-0935-8

Kubota S, Ogata Y, Wada Y, Simangunsong G, Shimada H, Matsui K (2008) Estimation of dynamic tensile strength of sandstone International Journal of Rock Mechanics and Mining Sciences 45:397-406 doi:10.1016/j.ijrmms.2007.07.003

Kutter H, Fairhurst C On the fracture process in blasting. In: International Journal of Rock Mechanics and Mining Sciences \& Geomechanics Abstracts, 1971. vol 3. Elsevier, pp 181-202

Lagarde A (2014) Static and dynamic photoelasticity and caustics: recent developments vol 290. Springer, London. doi:10.1007/978-3-7091$2630-1$

Lauterborn W, Hentschel W (1985) Cavitation bubble dynamics studied by high speed photography and holography: part one Ultrasonics 23:260-268 doi:10.1016/0041-624X(85)90048-4

Lazovsky L, Cismas D, Allan G, Given D CCD sensor and camera for $100 \mathrm{Mfps}$ burst frame rate image capture. In: Defense and Security, 2005. International Society for Optics and Photonics, pp 184-190. doi:10.1117/12.604523 
Leith EN, Upatnieks J (1963) Wavefront Reconstruction with Continuous-Tone Objects* JOSA 53:1377-1381

Lenoir N, Bornert M, Desrues J, Bésuelle P, Viggiani G (2007) Volumetric digital image correlation applied to X - ray microtomography images from triaxial compression tests on argillaceous rock Strain 43:193-205 doi:10.1111/j.1475-1305.2007.00348.x

Levy S, Molinari J-F (2010) Dynamic fragmentation of ceramics, signature of defects and scaling of fragment sizes Journal of the Mechanics and Physics of Solids 58:12-26 doi:10.1016/j.jmps.2009.09.002

Li D, Wong LNY (2013) The Brazilian disc test for rock mechanics applications: review and new insights Rock Mechanics and Rock Engineering 46:269-287

Li q, Yang R, Li J, Qiao C, Zhao Y, Ma Y (2005) Experimental study on propagation of dynamic cracks under blasting loading Chinese Journal of Rock Mechanics and Engineering 16:019

Li X, Xie H, Kang Y, Wu X (2010) A brief review and prospect of experimental solid mechanics in China Acta Mechanica Solida Sinica 23:498-548 doi:10.1016/S0894-9166(11)60003-7

Li Y, Yang Y, Yang R (1999) Study on effect of blasting in rock by laser holography Journal of China University of Mining and Technology 28:322-325

Li Z, Jia X-z (2005) Research on X-ray sensitive ICCD image sensor [J] Optics and Precision Engineering 6:021

Lima R et al. (2008) In vitro blood flow in a rectangular PDMS microchannel: experimental observations using a confocal micro-PIV system Biomedical microdevices 10:153-167

Lindholm U (1964) Some experiments with the split hopkinson pressure bar Journal of the Mechanics and Physics of Solids 12:317-335 doi:10.1016/0022-5096(64)90028-6

Litwiller D (2001) CMOS vs. CCD: Facts and fiction,".

Locat J, Lee HJ (2005) Subaqueous debris flows. In: Debris-flow Hazards and Related Phenomena. Springer, pp 203-245

Lohse D et al. (2004) Impact on soft sand: void collapse and jet formation Physical Review Letters 93:198003

Lu H, Cary P (2000) Deformation measurements by digital image correlation: implementation of a second-order displacement gradient Experimental mechanics 40:393-400 doi:10.1007/BF02326485

Luo H, Du Y, Hu Z, Lu H (2015) High-strain rate compressive behavior of dry mason sand under confinement. In: Dynamic Behavior of Materials, Volume 1. Springer, pp 325-333

Luo P, Chao Y, Sutton M, Peters Iii W (1993) Accurate measurement of three-dimensional deformations in deformable and rigid bodies using computer vision Experimental Mechanics 33:123-132 doi:10.1007/BF02322488

Maas H, Gruen A, Papantoniou D (1993) Particle tracking velocimetry in three-dimensional flows Experiments in Fluids 15:133-146 doi:10.1007/BF00190953

Manogg P (1964) Anwendungen der schattenoptik zur Untersuchung des zerreissvorgangs von platten. Ernst-Mach-Inst,

Marchand A, Duffy J (1988) An experimental study of the formation process of adiabatic shear bands in a structural steel Journal of the Mechanics and Physics of Solids 36:251-283 doi:10.1016/0022-5096(88)90012-9

Mardoukhi A, Saksala T, Hokka M, Kuokkala V-T (2015) An experimental and numerical study of the dynamic Brazilian disc test on Kuru granite

Marquez AM, Braithwaite CH, Weihs TP, Krywopusk NM, Gibbins DJ, Vecchio KS, Meyers MA (2016) Fragmentation and constitutive response of tailored mesostructured aluminum compacts Journal of Applied Physics 119:145903

Mayne PW, Coop MR, Springman SM, Huang A-B, Zornberg JG Geomaterial behavior and testing. In: Proc. 17th Int. Conf. on Soil Mechanics and Geotechnical Engineering, 2009. IOS, pp 2777-2872

McCormick N, Lord J (2010) Digital image correlation Materials today 13:52-54 doi:10.1016/S1369-7021(10)70235-2

Meinhart C, Wereley S, Gray M (2000) Volume illumination for two-dimensional particle image velocimetry Measurement Science and Technology 11:809 doi:10.1088/0957-0233

Meng X (1994) Application of dynamic reflection moire method in studying rock blasting mechanism Explosion and Shock Waves:193-198

Meola C, Carlomagno GM (2004) Recent advances in the use of infrared thermography Measurement science and technology 15:R27

Meyers MA (1994) Dynamic behavior of materials. John wiley \& sons, USA. doi:10.1002/9780470172278

Miguel A A-I, Bettina S, Donald B D (2011) Influence of the fragmentation process on the dynamics of Vulcanian eruptions: An experimental approach Earth and Planetary Science Letters 302:51-59 doi:10.1016/j.eps1.2010.11.045

Miller C (1949) Half-million stationary images per second with refocused revolving beams Journal of the Society of Motion Picture Engineers 53:479-488 doi: $10.5594 / \mathrm{J} 11690$

Min Y, Hong M, Xi Z, Jian L (2006) Determination of residual stress by use of phase shifting moiré interferometry and hole-drilling method Optics and Lasers in Engineering 44:68-79 doi:10.1016/j.optlaseng.2005.02.006

Mindess S, Bentur A (1985) A preliminary study of the fracture of concrete beams under impact loading, using high speed photography Cement and Concrete Research 15:474-484 doi:10.1016/0008-8846(85)90121-8

Moeyersons J, De Ploey J (1976) Quantitative data on splash erosion, simulated on unvegetated slopes Zeitschrift für Geomorphologie Suppl 25:120-131

Mollenhauer D, Iarve EV, Kim R, Langley B (2006) Examination of ply cracking in composite laminates with open holes: a moiré interferometric and numerical study Composites Part A: Applied Science and Manufacturing 37:282-294 doi:10.1016/j.compositesa.2005.06.004

Moss GL, Pond RB (1975) Inhomogeneous thermal changes in copper during plastic elongation Metallurgical Transactions A 6:1223-1235 doi:10.1007/BF02658532

Moulart R, Pierron F, Hallett SR, Wisnom MR (2011) Full-field strain measurement and identification of composites moduli at high strain rate with the virtual fields method Experimental mechanics 51:509-536 doi:10.1007/s11340-010-9433-4 
Muybridge E (1878) The horse in motion. Library of Congress Prints and Photographs Division http://hdllocgov/locpnp/cph3a45870, [online accessed 08 August 2014]

Nagao M, Terada T, Somekawa H, Singh A, Mukai T (2014) Deformation Behavior of Binary Mg-Y Alloy Under Dynamic Compression Loading JOM 66:305-311 doi:10.1007/s11837-013-0854-2

Nguyen TL, Hall SA, Vacher P, Viggiani G (2011) Fracture mechanisms in soft rock: identification and quantification of evolving displacement discontinuities by extended digital image correlation Tectonophysics 503:117-128 doi:10.1016/j.tecto.2010.09.024

Nicoletto G (1991) Moiré interferometry determination of residual stresses in the presence of gradients Experimental Mechanics 31:252-256

Nicoletto G, Post D, Smith C Moire interferometry for high sensitivity measurements in fracture mechanics. In: SESA/JSME Jt Conf Exp Mech, Oahu-Maui, HI, 1982.

Freeze Frame Eadweard Muybridge's Photography of Motion: National Museum of American History (NMAH) (2001).

Ohtani K, Numata D, Kikuchi T, Sun M, Takayama K, Togami K (2006) A study of hypervelocity impact on cryogenic materials International journal of impact engineering 33:555-565 doi:10.1016/j.ijimpeng.2006.09.025

Oxfordlasers Lasers for High Speed Imaging. http://www.oxfordlasers.com/imaging/high-speed-imaging/.

Pan B (2011) Recent progress in digital image correlation Experimental Mechanics 51:1223-1235 doi:10.1007/s11340-010-9418-3

Pan B, Qian K, Xie H, Asundi A (2009) Two-dimensional digital image correlation for in-plane displacement and strain measurement: a review Measurement science and technology 20:062001 doi:10.1088/0957-0233

Pan B, Xie H, Wang Z (2010) Equivalence of digital image correlation criteria for pattern matching Applied optics 49:5501-5509 doi:10.1364/AO.49.005501

Parab ND et al. (2014) Experimental assessment of fracture of individual sand particles at different loading rates International Journal of Impact Engineering 68:8-14 doi:10.1016/j.ijimpeng.2014.01.003

Parab ND et al. (2017) In situ observation of fracture processes in high-strength concretes and limestone using high-speed X-ray phasecontrast imaging Philosophical Transactions of the Royal Society A: Mathematical, Physical and Engineering Sciences 375 doi:10.1098/rsta.2016.0178

Parker R, Jones D (1988) The use of holographic interferometry for turbomachinery fan evaluation during rotating tests Journal of turbomachinery 110:393-400 doi:10.1115/1.3262209

Patorski K (1993) Handbook of the moiré fringe technique. Elsevier Science, Amsterdam

Pedrini G, Osten W, Gusev ME (2006) High-speed digital holographic interferometry for vibration measurement Applied Optics 45:34563462 doi:10.1364/AO.45.003456

Peres MR (2013) The Focal Encyclopedia of Photography. Taylor \& Francis,

Perkins R, Green S (1968) High speed photography in dynamic materials testing Review of Scientific Instruments 39:1209-1210 doi:10.1063/1.1683621

Persson P-A, Holmberg R, Lee J (1993) Rock blasting and explosives engineering. CRC press,

Peters W, Ranson W (1982) Digital imaging techniques in experimental stress analysis Optical engineering 21:213427 doi:10.1117/12.7972925

Pierron F, Cheriguene R, Forquin P, Moulart R, Rossi M, Sutton M Performances and limitations of three ultra high-speed imaging cameras for full-field deformation measurements. In: Applied Mechanics and Materials, 2011a. Trans Tech Publ, pp 81-86. doi:10.4028/www.scientific.net/AMM.70.81

Pierron F, Forquin P (2012) Ultra - High - Speed Full - Field Deformation Measurements on Concrete Spalling Specimens and Stiffness Identification with the Virtual Fields Method Strain 48:388-405 doi:10.1111/j.1475-1305.2012.00835.x

Pierron F, Grédiac M (2012) The virtual fields method: extracting constitutive mechanical parameters from full-field deformation measurements. Springer Science \& Business Media, London. doi:10.1007/978-1-4614-1824-5

Pierron F, Sutton M, Tiwari V (2011b) Ultra high speed DIC and virtual fields method analysis of a three point bending impact test on an aluminium bar Experimental Mechanics 51:537-563 doi:10.1007/s11340-010-9402-y

Post D, Han B, Ifju P (2012) High sensitivity moiré: experimental analysis for mechanics and materials. Springer Science \& Business Media, London. doi:10.1007/978-1-4612-4334-2

Post D, Han B, Ifju PG (2000) Moiré methods for engineering and science-Moiré interferometry and shadow moiré. In: Photomechanics. Springer, pp 151-196. doi:10.1007/3-540-48800-6 5

Prasad AK (2000) Particle image velocimetry CURRENT SCIENCE-BANGALORE- 79:51-60

Qin YW (1981) Application of Faraday's effect in static and dynamic holographic photoelasticity Experimental Mechanics 21:389-393 doi:10.1007/BF02324801

Raffel M, Willert CE, Kompenhans J (2013) Particle image velocimetry: a practical guide. Springer, London. doi:10.1007/978-3-540-723080

Ramesh K, Hogan JD, Kimberley J, Stickle A (2015) A review of mechanisms and models for dynamic failure, strength, and fragmentation Planetary and Space Science 107:10-23 doi:10.1016/j.pss.2014.11.010

Rastogi P (2015) Digital Optical Measurement Techniques and Applications. Artech House,

Rastogi PK (2000) Principles of holographic interferometry and speckle metrology. In: Photomechanics. Springer, pp 103-151

Rastogi PK, Hack E (2012) Optical methods for solid mechanics: a full-field approach. John Wiley \& Sons, Germany

Ravi-Chandar K (2004) Dynamic fracture. Elsevier, UK

Ray SF (2006) High Speed Photography and Photonics vol PM120. SPIE Press, United States

Rayleigh L (1874) XII. On the manufacture and theory of diffraction-gratings The London, Edinburgh, and Dublin Philosophical Magazine and Journal of Science 47:81-93 doi:10.1080/14786447408640996

Reu PL High/Ultra-high speed imaging as a diagnostic tool. In: Applied Mechanics and Materials, 2011. Trans Tech Publ, pp 69-74 
Reu PL, Miller TJ (2008) The application of high-speed digital image correlation The Journal of Strain Analysis for Engineering Design 43:673-688 doi:10.1243/03093247JSA414

Righi A (1887) Sui fenomeni che si producono colla sovrapposizione di due peticoli e sopra alcune loro applicazioni Il Nuovo Cimento (1877-1894) 21:203-228

Riley W, Dally J (1969) Recording dynamic fringe patterns with a Cranz-Schardin camera Experimental Mechanics 9:27N-33N doi:10.1007/BF02327718

Rossmanith H, Fourney W (1982) Fracture initiation and stress wave diffraction at cracked interfaces in layered media I. brittle/brittle transition Rock Mechanics 14:209-233

Rossmanith H, Knasmillner R, Daehnke A, Mishnaevsky Jr L (1996) Wave propagation, damage evolution, and dynamic fracture extension. Part II. Blasting Materials Science 32:403-410 doi:10.1007/BF02538964

Sanborn B, Gunnarsson C, Foster M, Weerasooriya T (2014) Quantitative Visualization of Human Cortical Bone Mechanical Response: Studies on the Anisotropic Compressive Response and Fracture Behavior as a Function of Loading Rate Experimental Mechanics:1-15 doi:10.1007/s11340-015-0060-y

Sarva SS, Deschanel S, Boyce MC, Chen W (2007) Stress-strain behavior of a polyurea and a polyurethane from low to high strain rates Polymer 48:2208-2213 doi:10.1016/j.polymer.2007.02.058

Schuler H, Mayrhofer C, Thoma K (2006) Spall experiments for the measurement of the tensile strength and fracture energy of concrete at high strain rates International Journal of Impact Engineering 32:1635-1650 doi:10.1016/j.ijimpeng.2005.01.010

Schultz PH, Heineck JT, Anderson JLB (2000) Using 3-D PIV in laboratory impact experiments. Paper presented at the Lunar Planetary Science Conference XXXI, Houston, TX, USA, Mar 01

Seah CC, Børvik T, Remseth S, Pan T-C (2011) Penetration and perforation of rock targets by hard projectiles Advances in Rock Dynamics and Applications: 143

Settles G (2006) High-speed Imaging of Shock Waves, Explosions and Gunshots New digital video technology, combined with some classic imaging techniques, reveals shock waves as never before American Scientist 94:22-31 doi:10.1511/2006.1.22

Sharma A, Shukla A, Prosser R (2002) Mechanical characterization of soft materials using high speed photography and split Hopkinson pressure bar technique Journal of Materials Science 37:1005-1017 doi:10.1023/A:1014308216966

Sharma SP, Ruffin SM, Meyer SA, Gillespie WD, Yates LA (1993) Density measurements in an expanding flow using holographic interferometry Journal of thermophysics and heat transfer 7:261-268 doi:10.2514/3.415

Sharpe WN (2008) Springer handbook of experimental solid mechanics. Springer Science \& Business Media, USA. doi:10.1007/978-0-387$30877-73$

Shi W, Wu Y, Wu L (2007) Quantitative analysis of the projectile impact on rock using infrared thermography International Journal of Impact Engineering 34:990-1002

Shockey DA, Curran DR, Seaman L, Rosenberg JT, Petersen CF Fragmentation of rock under dynamic loads. In: International Journal of Rock Mechanics and Mining Sciences \& Geomechanics Abstracts, 1974. vol 8. Elsevier, pp 303-317. doi:10.1016/0148-9062(74)91760-

Shukla A (1991) Dynamic photoelastic studies of wave propagation in granular media Optics and Lasers in Engineering 14:165-184 doi:10.1016/0143-8166(91)90047-W

Shukla A, Damania C (1987) Experimental investigation of wave velocity and dynamic contact stresses in an assembly of disks Experimental mechanics 27:268-281 doi:10.1007/BF02318093

Siebert T, Crompton MJ (2013) Application of high speed digital image correlation for vibration mode shape analysis. In: Application of Imaging Techniques to Mechanics of Materials and Structures, Volume 4. Springer, pp 291-298. doi:10.1007/978-1-4419-9796-8 37

Sollier A, Bouyer V, Terzulli L, Doucet M, Decaris L, Hébert P Expansion of the Detonation Products of a TATB Based High Explosive: Experimental Characterization by Photon Doppler Velocimetry and High-Speed Digital Shadowgraphy. In: 28th International Symposium on Shock Waves, 2012. Springer, pp 251-257. doi:10.1007/978-3-642-25688-2_38

Song Y, Li M, Wang X, Li X, Fu X (2015) Experimental test on marble containing two pre-existing cracks under loading and unloading conditions based on high-speed photography Journal of Rock Mechanics and Engineering 43:773-781 doi:10.13722/j.cnki.jrme.2013.1718

Song Y, Li M, Wang X, LIu X, Fu X (2014) Experimental test on marble containing single pre-existing cracks under loading and unloading conditions based on high-speed photography Journal of China University of Mining \& Technology

Starikovskaia S, Kukaev E, Kuksin AY, Nudnova M, Starikovskii AY (2004) Analysis of the spatial uniformity of the combustion of a gaseous mixture initiated by a nanosecond discharge Combustion and flame 139:177-187 doi:10.1016/j.combustflame.2004.07.005

Stetson KA, Powell RL (1965) Interferometric hologram evaluation and real-time vibration analysis of diffuse objects JOSA 55:1694-1695 doi:10.1364/JOSA.55.001694

Strassburger E, Senf H, Rothenhäusler H (1994) Fracture propagation during impact in three types of ceramics Le Journal de Physique IV 4:C8-653-C658-658 doi:10.1051/jp4:1994899

Sultanoff M (1950) A 100,000,000-Frame-per-Second Camera Review of Scientific Instruments 21:653-656 doi:10.1063/1.1745678

Surrel Y (2003) Optique C1-18851 Images optiques; mesures 2D et 3D Polycopié de cours vol 8. Conservatoire National des Arts et Métiers.

Sutton M, Mingqi C, Peters W, Chao Y, McNeill S (1986) Application of an optimized digital correlation method to planar deformation analysis Image and Vision Computing 4:143-150 doi:10.1016/0262-8856(86)90057-0

Sutton M, Yan J, Tiwari V, Schreier H, Orteu J (2008) The effect of out-of-plane motion on 2D and 3D digital image correlation measurements Optics and Lasers in Engineering 46:746-757 doi:10.1016/j.optlaseng.2008.05.005

Sutton MA, Orteu JJ, Schreier H (2009) Image correlation for shape, motion and deformation measurements: basic concepts, theory and applications. Springer Science \& Business Media, 
Theocaris PS, Gdoutos E (1972) An optical method for determining opening-mode and edge sliding-mode stress-intensity factors Journal of Applied Mechanics 39:91-97 doi:10.1115/1.3422676

Thomson KC, Ahrens TJ, Toksöz MN (1969) Dynamic photoelastic studies of $\mathrm{p}$ and s wave propagation in prestressed media Geophysics 34:696-712 doi:10.1190/1.1440041

Thoroddsen ST, Etoh TG, Takehara K (2008) High-Speed Imaging of Drops and Bubbles Annual Review of Fluid Mechanics 40:257-285 doi:10.1146/annurev.fluid.40.111406.102215

Tieng SM, Lai WZ (1992) Temperature measurements of reacting flowfield by phase-shifting holographic interferometry Journal of thermophysics and heat transfer 6:445-451 doi:10.2514/3.381

Tiwari V, Sutton M, McNeill KO, Fourney W, Bretall D On studying improvised explosive devices (IEDs) using digital image correlations. . In: Proc. 2007 SEM Annu. Conf. Exposition Exp. Appl. Mech, MA, USA, January 2007. Springfield,

Tiwari V, Sutton M, McNeill S (2007) Assessment of high speed imaging systems for 2D and 3D deformation measurements: methodology development and validation Experimental mechanics 47:561-579

Tochigi Y et al. (2013) A global-shutter CMOS image sensor with readout speed of 1-Tpixel/s burst and 780-Mpixel/s continuous IEEE Journal of Solid-State Circuits 48:329-338 doi:10.1109/JSSC.2012.2219685

Tong W (2005) An evaluation of digital image correlation criteria for strain mapping applications Strain 41:167-175 doi:10.1111/j.14751305.2005.00227.x

Trojanowski A, Macdougall D, Harding J (1998) An improved technique for the experimental measurement of specimen surface temperature during Hopkinson-bar tests Measurement Science and Technology 9:12

Trolinger J, Hsu J Flowfield Diagnostics by Holographic Interferometry and Tomography. In: Fringe, 1993. pp 423-439

True DG (1975) Penetration of projectiles into seafloor soils. DTIC Document,

Turchi P et al. (1991) Generation of high - energy x - radiation using a plasma flow switch Journal of applied physics 69:1999-2007 doi: $10.1063 / 1.348773$

Tuzi Z (1928) Photographic and Kinematographic Study of Photo-Elasticity Scientif ic Papers of the Institute of Physical and Chemical Research 8:247-267

Van Dijk A, Meesters A, Bruijnzeel L (2002) Exponential distribution theory and the interpretation of splash detachment and transport experiments Soil Science Society of America Journal 66:1466-1474 doi:10.2136/sssaj2002.1466

Versluis M (2013) High-speed imaging in fluids Experiments in Fluids 54:1-35

Walley S (2014) An Introduction to the Properties of Silica Glass in Ballistic Applications Strain 50:470-500 doi:10.1111/str.12075

Wang D, Wang Y, Yang B, Zhang W, Lancaster N (2008) Statistical analysis of sand grain/bed collision process recorded by high - speed digital camera Sedimentology 55:461-470 doi:10.1111/j.1365-3091.2007.00909.x

Wang H, Liu Da, Gong W, Li L (2015) Dynamic analysis of granite rockburst based on the PIV technique International Journal of Mining Science and Technology 25:275-283 doi:10.1016/j.ijmst.2015.02.017

Wang Y, Wang D, Wang L, Zhang Y (2009) Measurement of sand creep on a flat sand bed using a high - speed digital camera Sedimentology 56:1705-1712 doi:10.1111/sed.12232

Weinstein LA (1969) Open resonators and open waveguides. The Golem Press, Boulder, Colorado, USA

White D, Take W, Bolton M (2003) Soil deformation measurement using particle image velocimetry (PIV) and photogrammetry Geotechnique 53:619-632 doi:10.1680/geot.2003.53.7.619

Whittles D, Kingman S, Lowndes I, Jackson K (2006) Laboratory and numerical investigation into the characteristics of rock fragmentation Minerals engineering 19:1418-1429 doi:10.1016/j.mineng.2006.02.004

Willert C, Gharib M (1992) Three-dimensional particle imaging with a single camera Experiments in Fluids 12:353-358 doi:10.1007/BF00193880

Willmott G, Field J (2006) A high-speed photographic study of fast cracks in shocked diamond Philosophical Magazine 86:4305-4318

Wiza JL (1979) Microchannel plate detectors Nuclear Instruments and Methods 162:587-601

Wong L, Einstein H (2009a) Crack coalescence in molded gypsum and Carrara marble: part 1. Macroscopic observations and interpretation Rock Mechanics and Rock Engineering 42:475-511 doi:10.1007/s00603-008-0002-4

Wong L, Einstein H (2009b) Using high speed video imaging in the study of cracking processes in rock Geotechnical Testing Journal 32:1 doi:10.1520/GTJ101631

Wong LN, Einstein H Fracturing behavior of prismatic specimens containing single flaws. In: Golden Rocks 2006, The 41st US Symposium on Rock Mechanics (USRMS), Colorado, 21 June 2006. American Rock Mechanics Association,

Wong LNY, Zou C, Cheng Y (2014) Fracturing and failure behavior of Carrara marble in quasistatic and dynamic Brazilian disc tests Rock mechanics and rock engineering 47:1117-1133 doi:10.1007/s00603-013-0465-9

Wu S, Chau K, Yu T (2004) Crushing and fragmentation of brittle spheres under double impact test Powder technology 143:41-55 doi:10.1016/j.powtec.2004.04.028

Wu Z, Lu J, Han B (1998) Study of residual stress distribution by a combined method of Moire interferometry and incremental hole drilling, part II: implementation Journal of applied mechanics 65:844-850

Wyant JC, Koliopoulos CL, Bhushan B, George OE (1984) An optical profilometer for surface characterization of magnetic media ASLE transactions 27:101-113 doi:10.1080/05698198408981550

Xiang G, Zhang Q, Liu H, Wu X, Ju X (2007) Time-resolved deformation measurements of the Portevin-Le Chatelier bands Scripta Materialia 56:721-724

Xu LR, Huang YY, Rosakis AJ (2003) Dynamic crack deflection and penetration at interfaces in homogeneous materials: experimental studies and model predictions Journal of the Mechanics and Physics of Solids 51:461-486 doi:10.1016/S0022-5096(02)00080-7 
Xu S, Huang J, Wang P, Zhang C, Zhou L, Hu S (2015) Investigation of rock material under combined compression and shear dynamic loading: An experimental technique International Journal of Impact Engineering 86:206-222 doi:10.1016/j.ijimpeng.2015.07.014

$\mathrm{Xu}$ W, Yao X, Yeh H, Jin G (2005) Fracture investigation of PMMA specimen using coherent gradient sensing (CGS) technology Polymer testing 24:900-908 doi:10.1016/j.polymertesting.2005.06.005

Yang B, Wang Y, Zhang Y (2009a) The 3-D spread of saltation sand over a flat bed surface in aeolian sand transport Advanced Powder Technology 20:303-309 doi:10.1016/j.apt.2008.11.002

Yang L, Xu P, Gao X, Sun J (2014) Digital Laser High-speed Photography System and Its Application in Photomechanical Tests with Blast Loading Science \& Technology Review 32:013 doi:10.3981/j.issn.1000-7857.2014.32.002

Yang R, Wang Y, Ding C (2016a) Laboratory study of wave propagation due to explosion in a jointed medium International Journal of Rock Mechanics and Mining Sciences 81:70-78

Yang R, Xu P, Yue Z, Chen C (2016b) Dynamic fracture analysis of crack-defect interaction for mode I running crack using digital dynamic caustics method Engineering Fracture Mechanics 161:63-75 doi:10.1016/j.engfracmech.2016.04.042

Yang R, Yang L, Yue Z, Xiao T, Dong J, Niu X (2009b) Dynamic caustics experiment of crack propagation in material containing flaws under blasting load Journal of China Coal Society 34

Yang R, Yue Z, Dong J, Gui L, Xiao T (2008a) Dynamic Caustics Experiment of Blasting Crack Propagation in Discontinuous Jointed Material [J] Journal of China University of Mining \& Technology 4:006

Yang R, Yue Z, Sun Z, Xiao T, Guo D (2009c) Dynamic fracture behavior of rock under impact load using the caustics method Mining Science and Technology (China) 19:79-83 doi:10.1016/S1674-5264(09)60015-6

Yang R, Yue Z, Xiao T, Dong J, Yang L (2008b) Dynamic caustics experiment on crack propagation of jointed medium fracture with controlled blasting Chinese Journal of Rock Mechanics and Engineering 2:005

Yao X, Xu W (2011) Recent application of caustics on experimental dynamic fracture studies Fatigue \& Fracture of Engineering Materials \& Structures 34:448-459

Yao X, Xu W, Arakawa K, Takahashi K, Mada T (2005) Dynamic optical visualization on the interaction between propagating crack and stationary crack Optics and lasers in engineering 43:195-207 doi:10.1016/j.optlaseng.2004.06.003

Yao X, Xu W, Xu M, Arakawa K, Mada T, Takahashi K (2003) Experimental study of dynamic fracture behavior of PMMA with overlapping offset-parallel cracks Polymer testing 22:663-670 doi:10.1016/S0142-9418(02)00173-3

Yao XF, Jin GC, Arakawa K, Takahashi K (2002) Experimental studies on dynamic fracture behavior of thin plates with parallel single edge cracks Polymer testing 21:933-940 doi:10.1016/S0142-9418(02)00037-5

Yao Y, Bonakdar A, Faber J, Gries T, Mobasher B (2014) Distributed cracking mechanisms in textile-reinforced concrete under high speed tensile tests Materials and Structures:1-18 doi:10.1617/s11527-015-0685-4

Yin Z, Ma H, Hu Z, Zou Y (2014a) Effect of Static-Dynamic Coupling Loading on Fracture Toughness and Failure Characteristics in Marble Journal of Engineering Science and Technology Review 7:169-174

Yin Z, Wang L, Ma H, Hu Z, Jin J (2014b) Application of Optical Measurement Method in Brazilian Disk Splitting Experiment Under Dynamic Loading Sensors \& Transducers 171:176-182

Younis N (2012) Experimental Strain Investigation of Bolt Torque Effect in Mechanically Fastened Joints Engineering 4:359-367 doi:10.4236/eng.2012.47047

Yu-wen Q (1979) Application of faraday's effect in the holographic photoelasticity Acta Mechanica Sinica 3:008

$\mathrm{Yu}$ L, Pan B (2015) The errors in digital image correlation due to overmatched shape functions Measurement Science and Technology 26:045202 doi:10.1088/0957-0233

Zauel R, Yeni Y, Bay B, Dong X, Fyhrie D (2006) Comparison of the linear finite element prediction of deformation and strain of human cancellous bone to 3D digital volume correlation measurements Journal of biomechanical engineering 128:1-6 doi:10.1115/1.2146001

Zehnder AT, Guduru PR, Rosakis AJ, Ravichandran G (2000) Million frames per second infrared imaging system Review of Scientific Instruments 71:3762-3768 doi:10.1063/1.1310350

Zehnder AT, Rosakis AJ (1990) Dynamic fracture initiation and propagation in 4340 steel under impact loading International Journal of Fracture 43:271-285 doi:10.1007/BF00035087

Zehnder AT, Rosakis AJ (1991) On the temperature distribution at the vicinity of dynamically propagating cracks in 4340 steel Journal of the Mechanics and Physics of Solids 39:385-415 doi:10.1016/0022-5096(91)90019-K

Zhang C (2014a) Application of digital image correlation in dynamic testing. Univeristy of Science and Technology of China

Zhang J, Tao B, Katz J (1997) Turbulent flow measurement in a square duct with hybrid holographic PIV Experiments in Fluids 23:373-381 doi: $10.1007 / \mathrm{s} 003480050124$

Zhang QB (2014b) Mechanical Behaviour of Rock Materials under Dynamic Loading. École Polytechnique Fédérale de Lausanne

Zhang QB, Braithwaite CH, Zhao J (2017) Hugoniot equation of state of rock materials under shock compression Philosophical Transactions of the Royal Society A: Mathematical, Physical and Engineering Sciences 375

Zhang QB, Zhao J (2013a) Determination of mechanical properties and full-field strain measurements of rock material under dynamic loads Int J Rock Mech Min 60:423-439 doi:10.1016/j.ijrmms.2013.01.005

Zhang QB, Zhao J (2013b) Effect of loading rate on fracture toughness and failure micromechanisms in marble Engineering Fracture Mechanics 102:288-309 doi:10.1016/j.engfracmech.2013.02.009

Zhang QB, Zhao J (2014a) Quasi-static and dynamic fracture behaviour of rock materials: phenomena and mechanisms International Journal of Fracture 189:1-32 doi:10.1007/s10704-014-9959-z

Zhang QB, Zhao J (2014b) A review of dynamic experimental techniques and mechanical behaviour of rock materials Rock Mechanics and Rock Engineering 47:1411-1478 doi:10.1007/s00603-013-0463-y 
Zhang R, Guo R, Wang S (2014a) Mixed mode fracture study of PMMA using digital gradient sensing method Engineering Fracture Mechanics 119:164-172 doi:10.1016/j.engfracmech.2014.02.020

Zhang W, Wang Y, Lee S-J (2007) Two-phase measurements of wind and saltating sand in an atmospheric boundary layer Geomorphology 88:109-119 doi:10.1016/j.geomorph.2006.10.017

Zhang X, Sun Z, Hu X (2014b) Low temperature fracture toughness of PMMA and crack-tip conditions under flat-tipped cylindrical indenter Polymer Testing 38:57-63 doi:10.1016/j.polymertesting.2014.06.009

Zhang Y, Wang Y, Jia P (2014c) Measuring the kinetic parameters of saltating sand grains using a high-speed digital camera Science China Physics, Mechanics \& Astronomy 57:1137-1143 doi:10.1007/s11433-013-5284-1

Zhang Z, Kou S, Jiang L, Lindqvist P-A (2000) Effects of loading rate on rock fracture: fracture characteristics and energy partitioning International Journal of Rock Mechanics and Mining Sciences 37:745-762 doi:10.1016/S1365-1609(00)00008-3

Zhou M, Rosakis A, Ravichandran G (1996) Dynamically propagating shear bands in impact-loaded prenotched plates-I. Experimental investigations of temperature signatures and propagation speed Journal of the Mechanics and Physics of Solids 44:981-1006 doi:10.1016/S1365-1609(00)00008-3

Zhou YX, Zhao J (eds) (2011) Advances in rock dynamics and applications. CRC Press,

Zhou Z, Li X, Zou Y, Jiang Y, Li G (2014) Dynamic Brazilian tests of granite under coupled static and dynamic loads Rock mechanics and rock engineering 47:495-505 doi:10.1007/s00603-013-0441-4

Zhu H (2015) A novel methodology for high strain rate testing using full-field measurements and the virtual fields methods. University of Technology of Troyes

Zou C, Wong LNY Study of Mechanical Properties and Fracturing Processes of Carrara Marble in Dynamic Brazilian Tests by Two Optical Observation Methods. In: Rock Mechanics and Its Applications in Civil, Mining, and Petroleum Engineering, 2014. ASCE, pp 20-29. doi:10.1061/9780784413395.004

Zou X-Y, Wang Z-L, Hao Q-Z, Zhang C-L, Liu Y-Z, Dong G-R (2001) The distribution of velocity and energy of saltating sand grains in a wind tunnel Geomorphology 36:155-165 


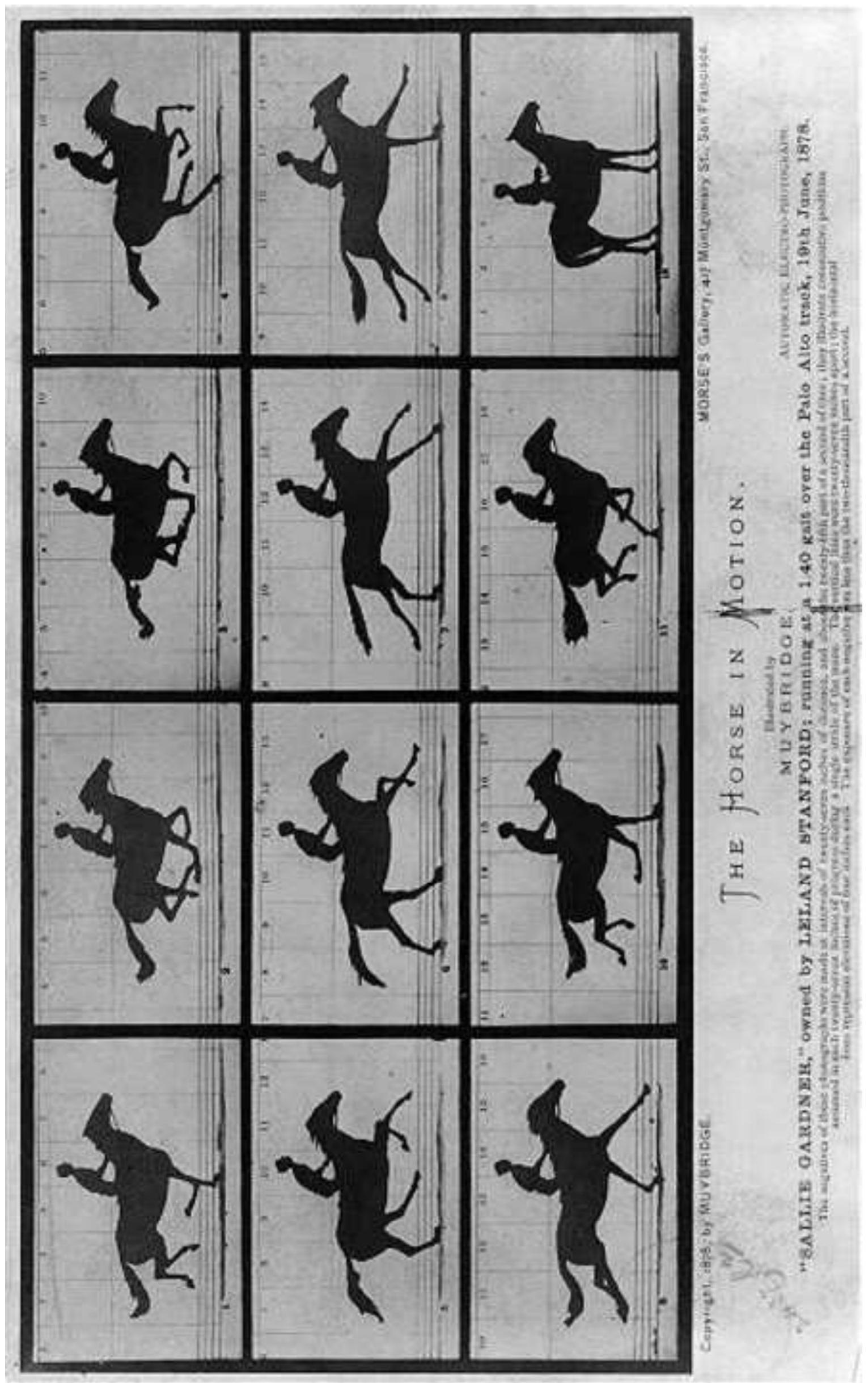




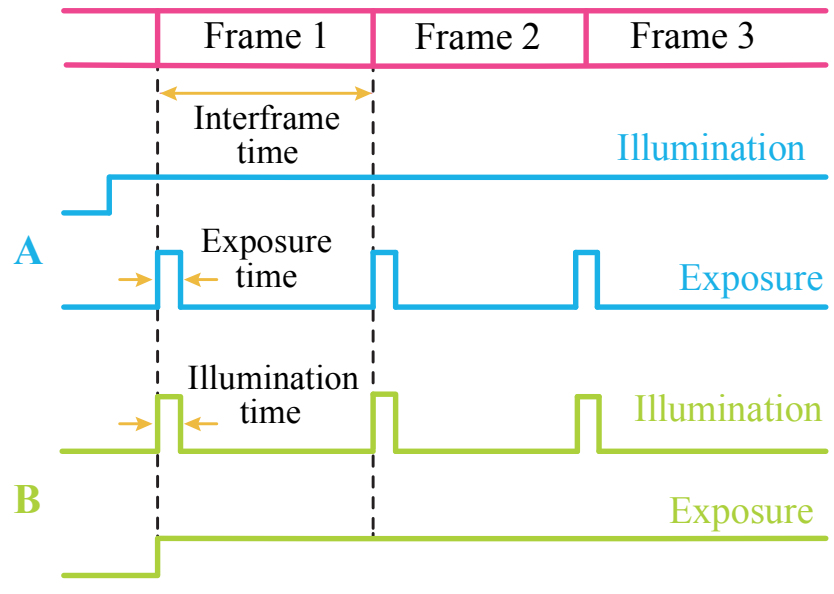



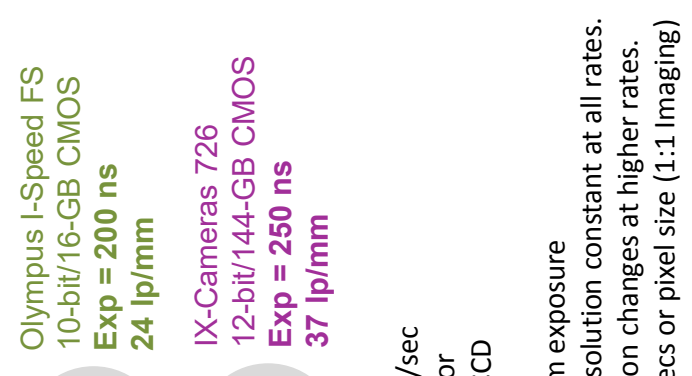

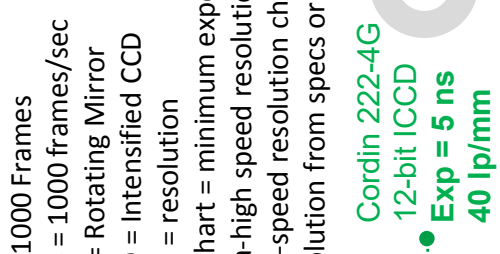

产

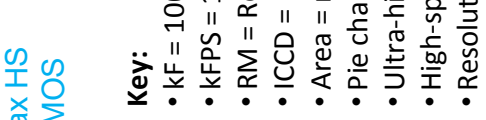

密界

证星

잉

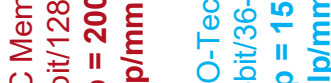

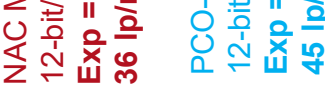
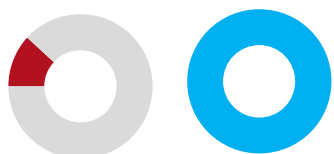

ปั
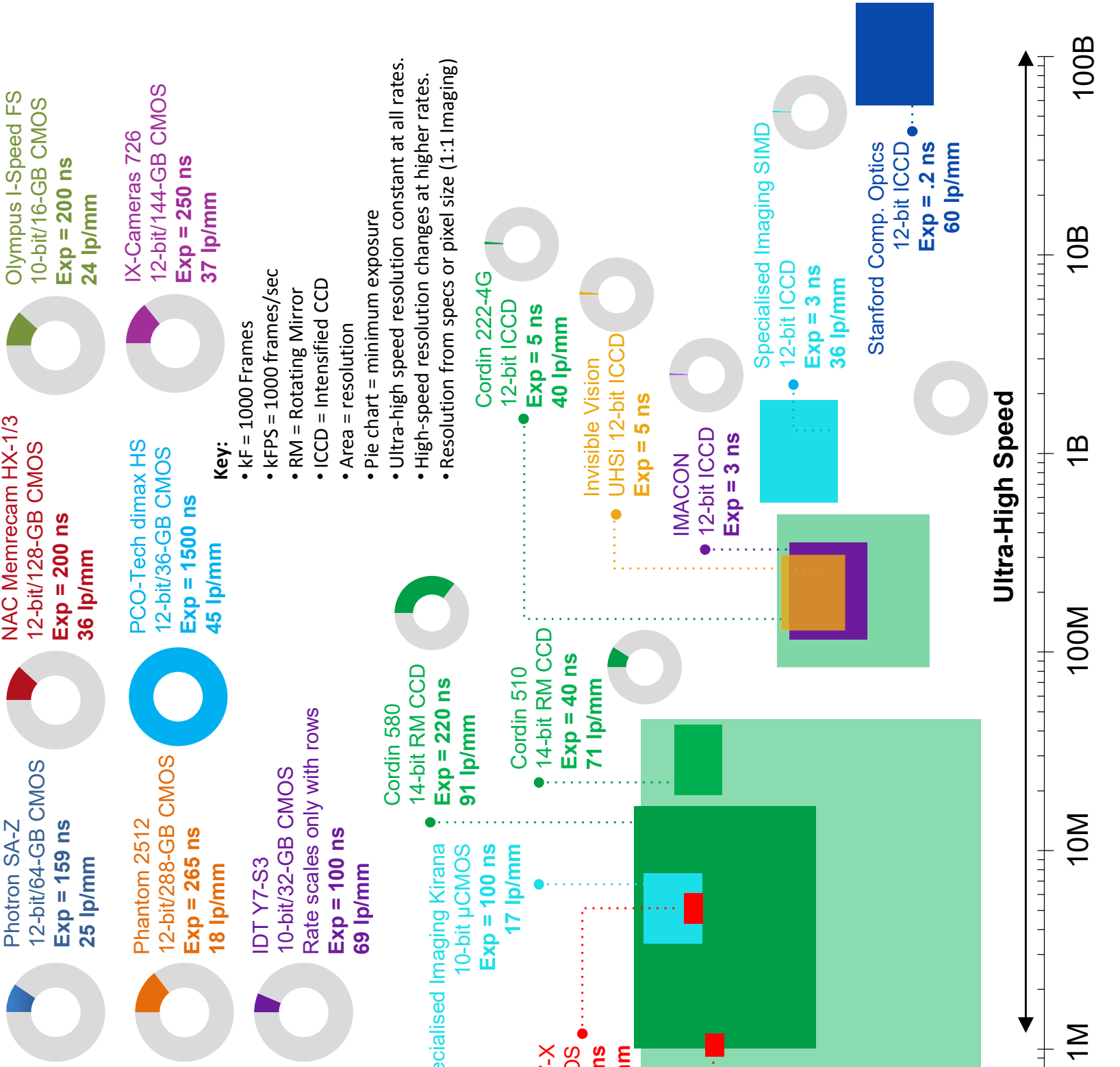



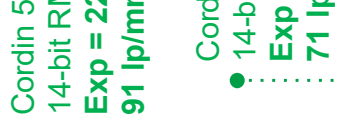



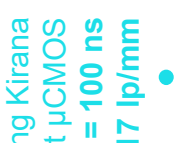

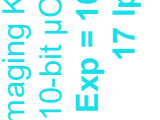

$\stackrel{m}{\stackrel{m}{ \pm}}$


늘

II 으

울

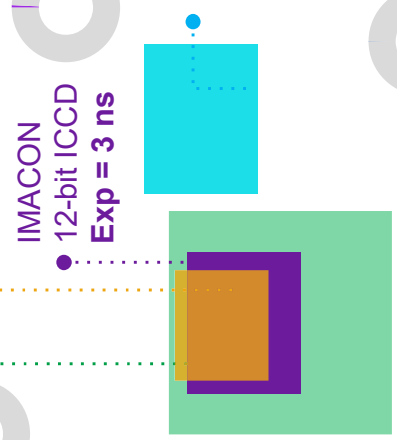

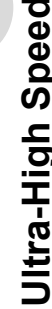

$\sum_{8}$

$=\stackrel{m}{-}$

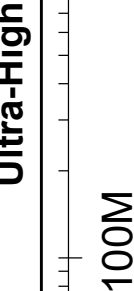




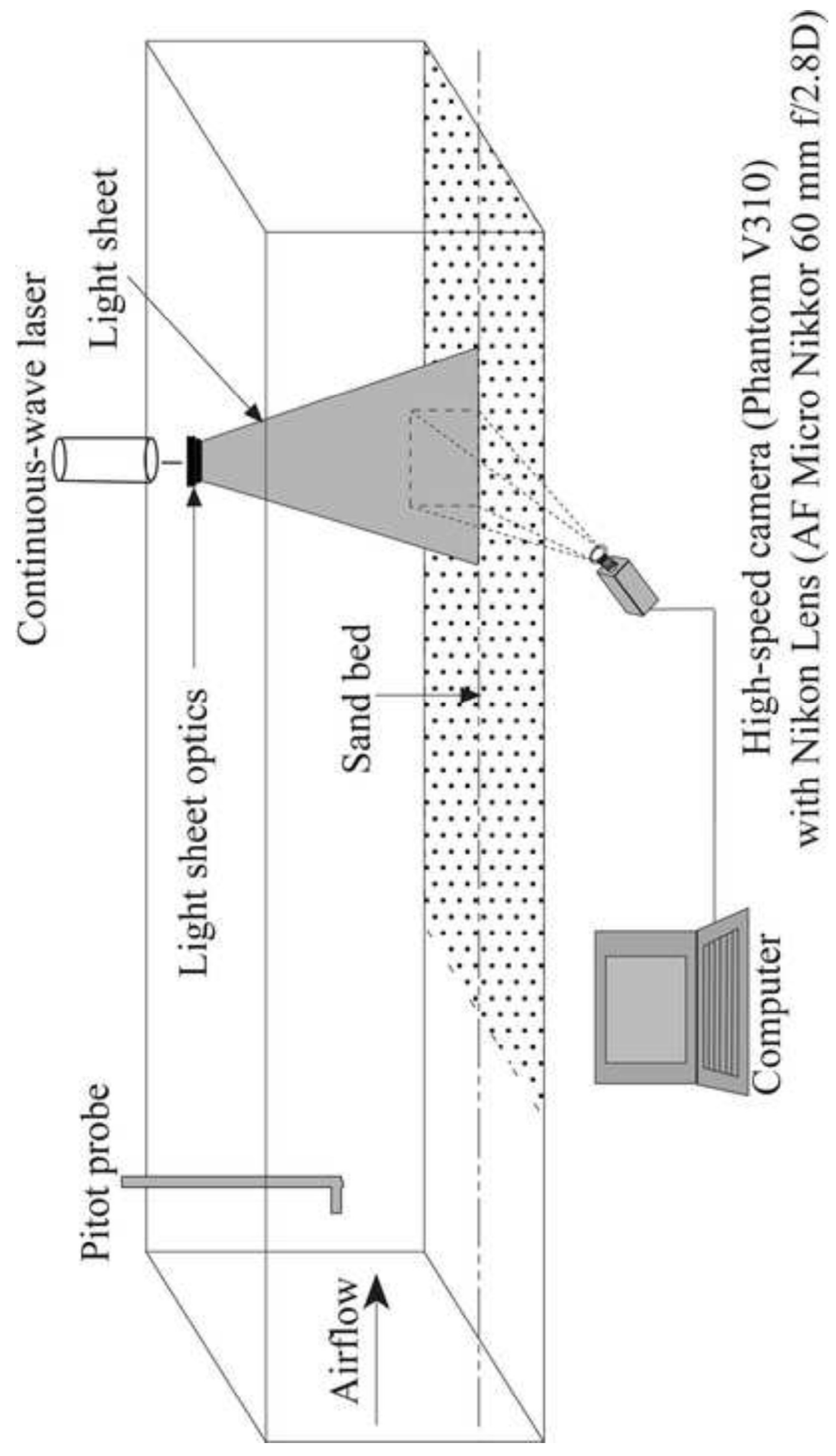






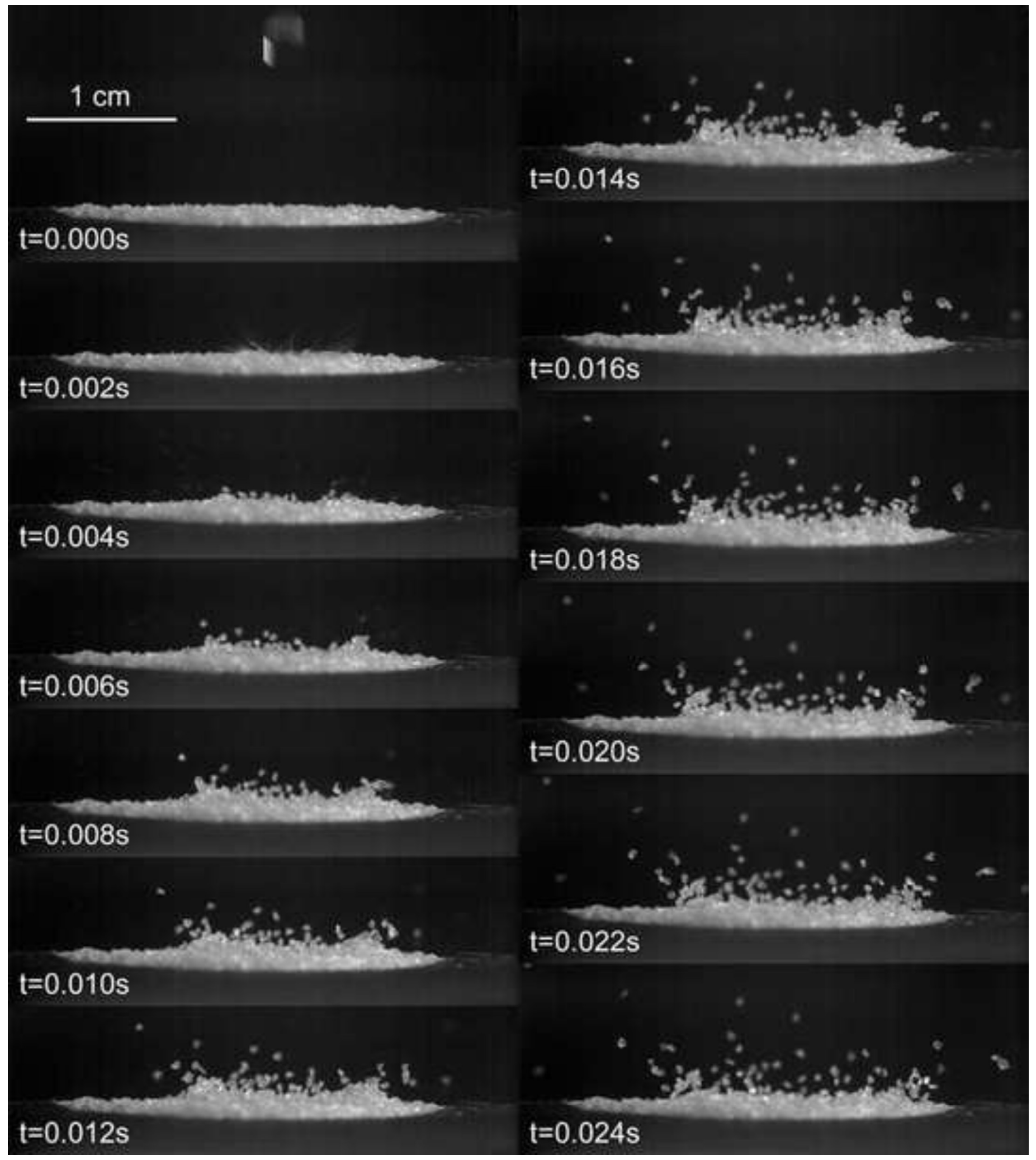




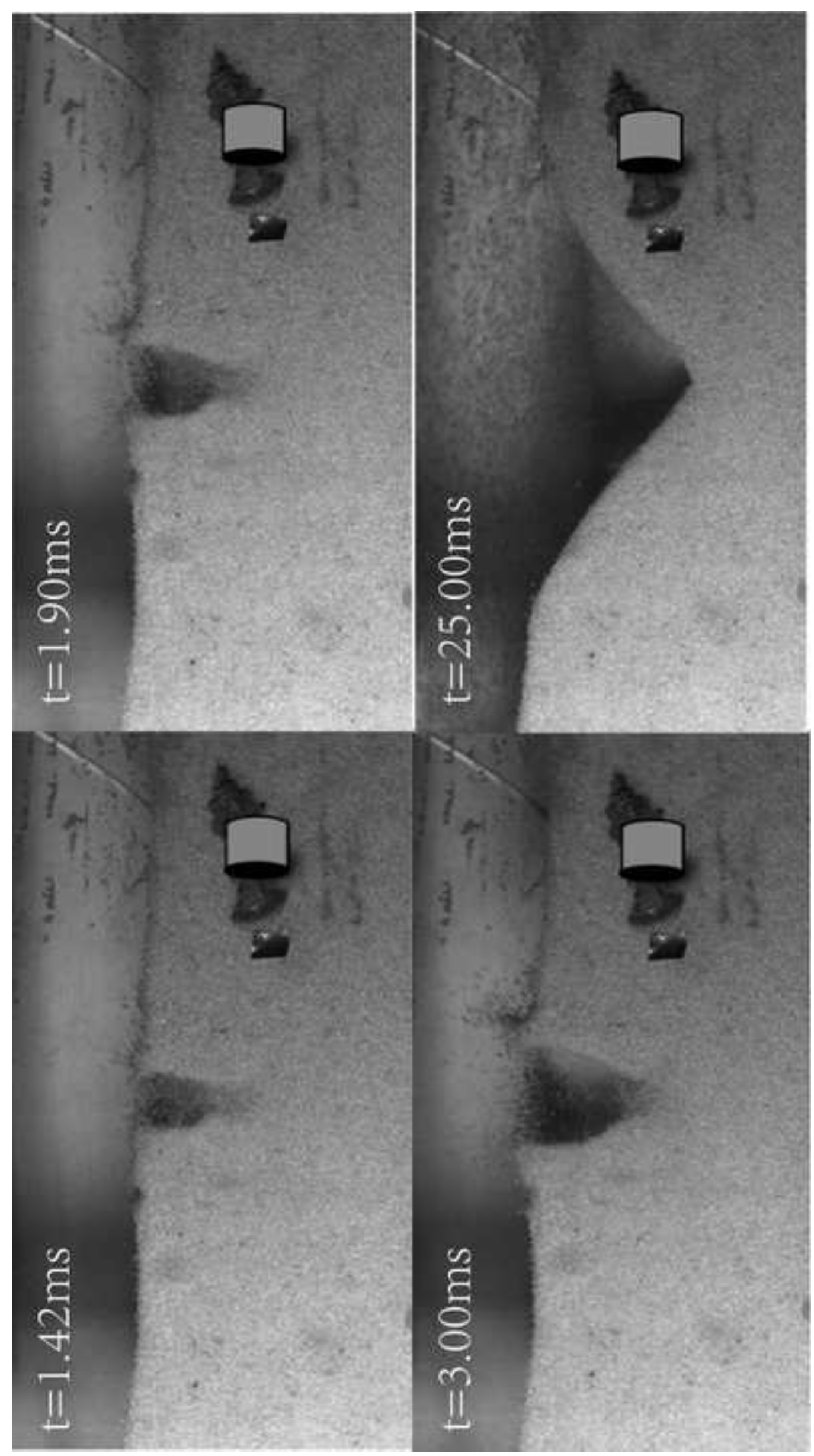



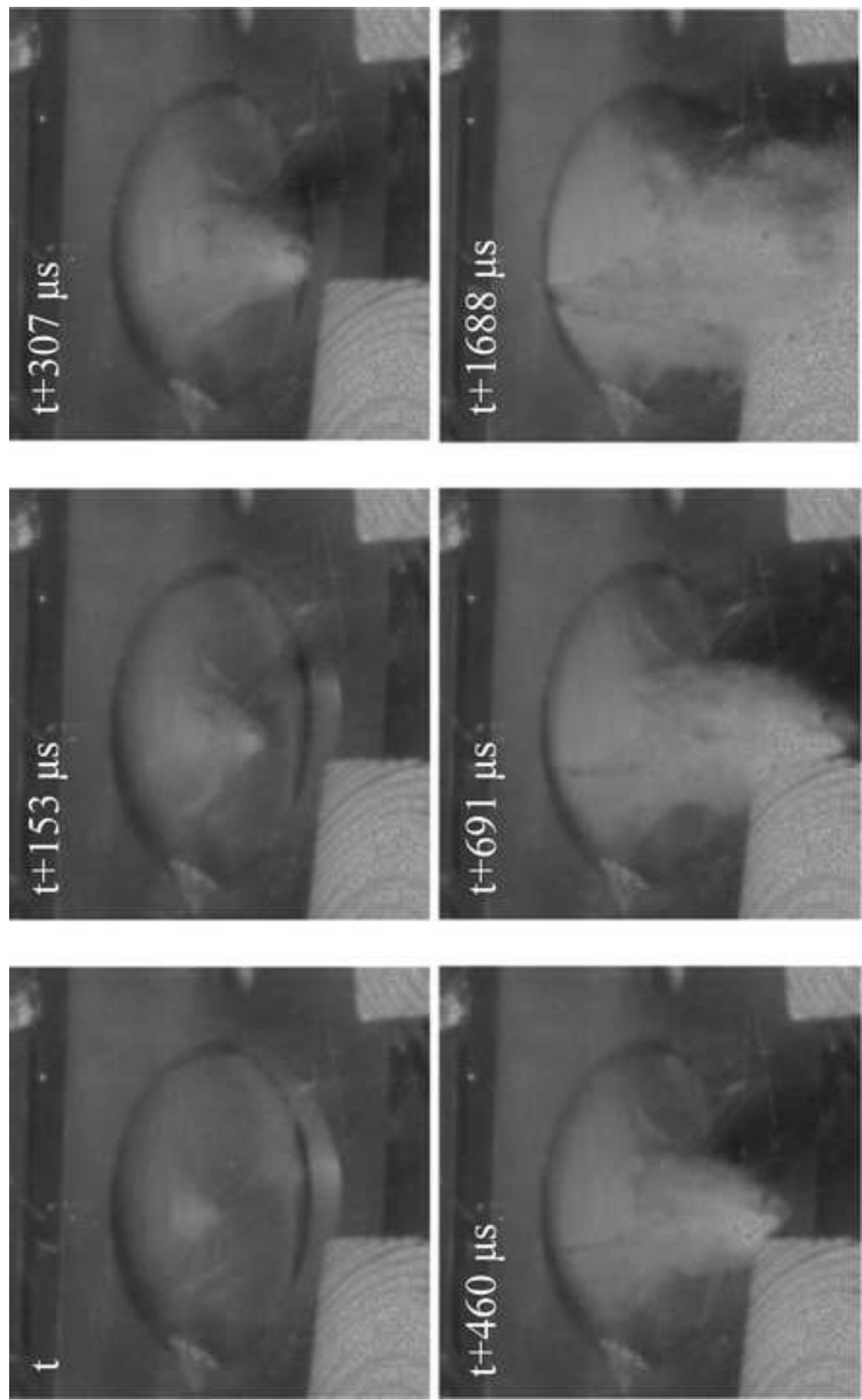

은 




\begin{tabular}{|l|c|c|c|}
\hline $\begin{array}{c}\text { Photograph during } \\
\text { penetration }\end{array}$ & $\begin{array}{c}\text { Photograph just as the } \\
\text { opaque area reaches its } \\
\text { maximum depth }\end{array}$ & $\begin{array}{c}\text { Photograph after the event } \\
\text { (residual opaque region) }\end{array}$ \\
\hline \multicolumn{3}{|c|}{ Sucrose Saturated $\mathrm{FQ}-60 \mathrm{~m} / \mathrm{s}(\mathrm{M}-1)$} \\
\hline
\end{tabular}



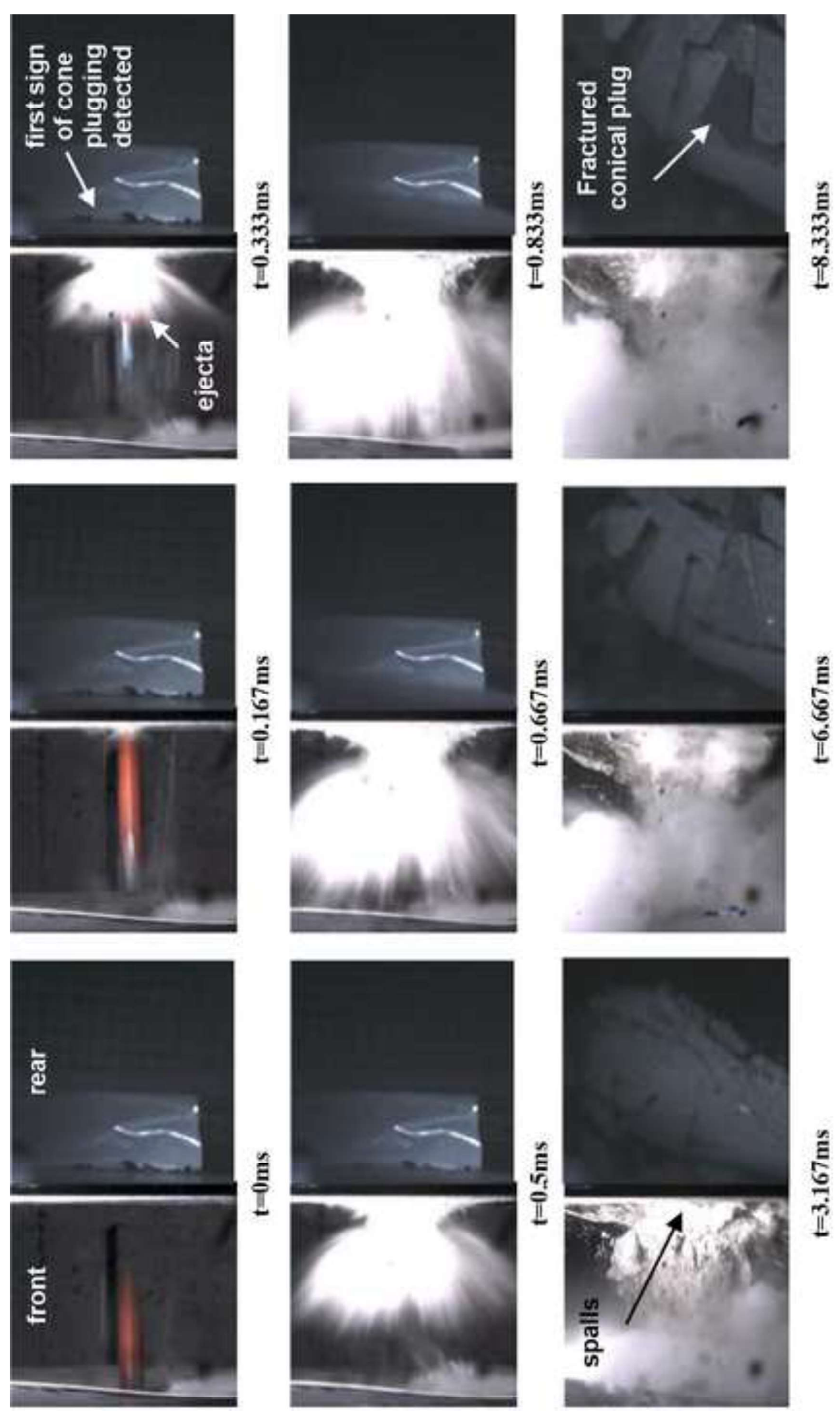

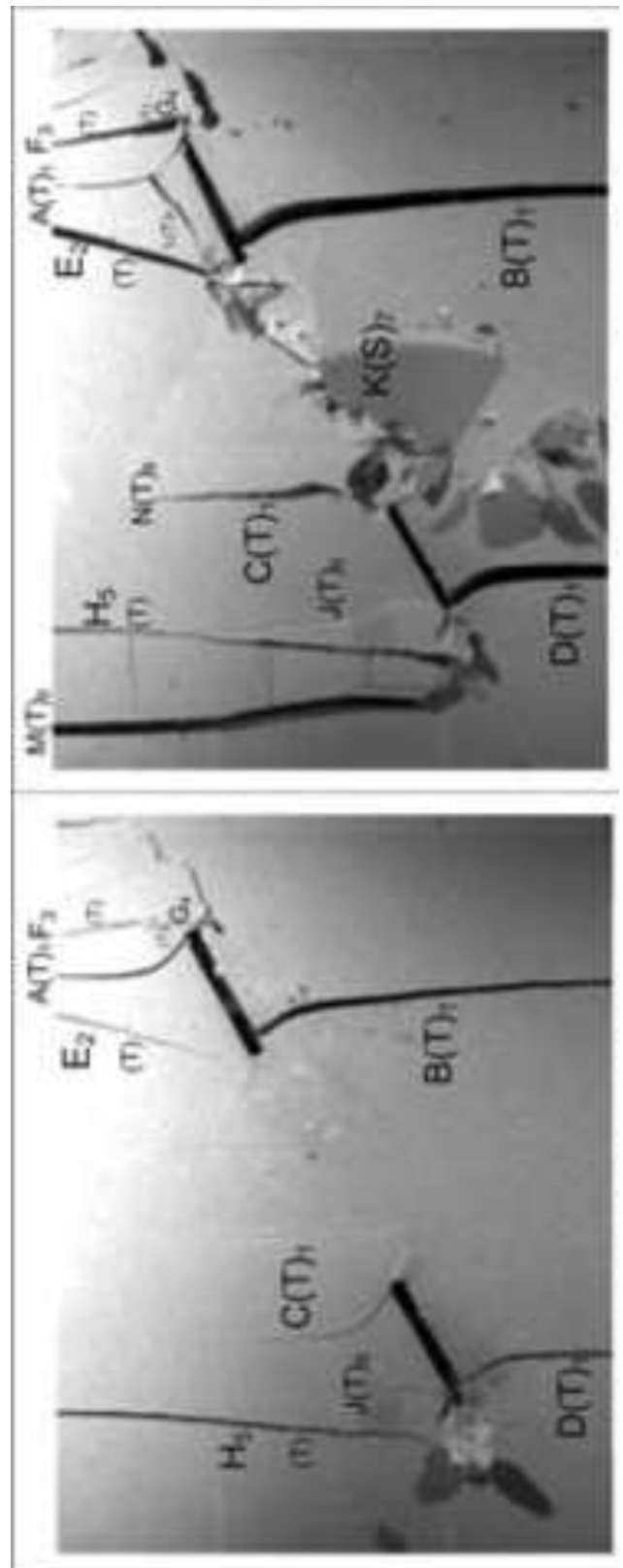

$\frac{E}{\&} \mid \frac{E}{\text { के }}$

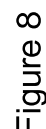



का

\section{E}








$\frac{\circ}{\stackrel{0}{\oplus}}$ 

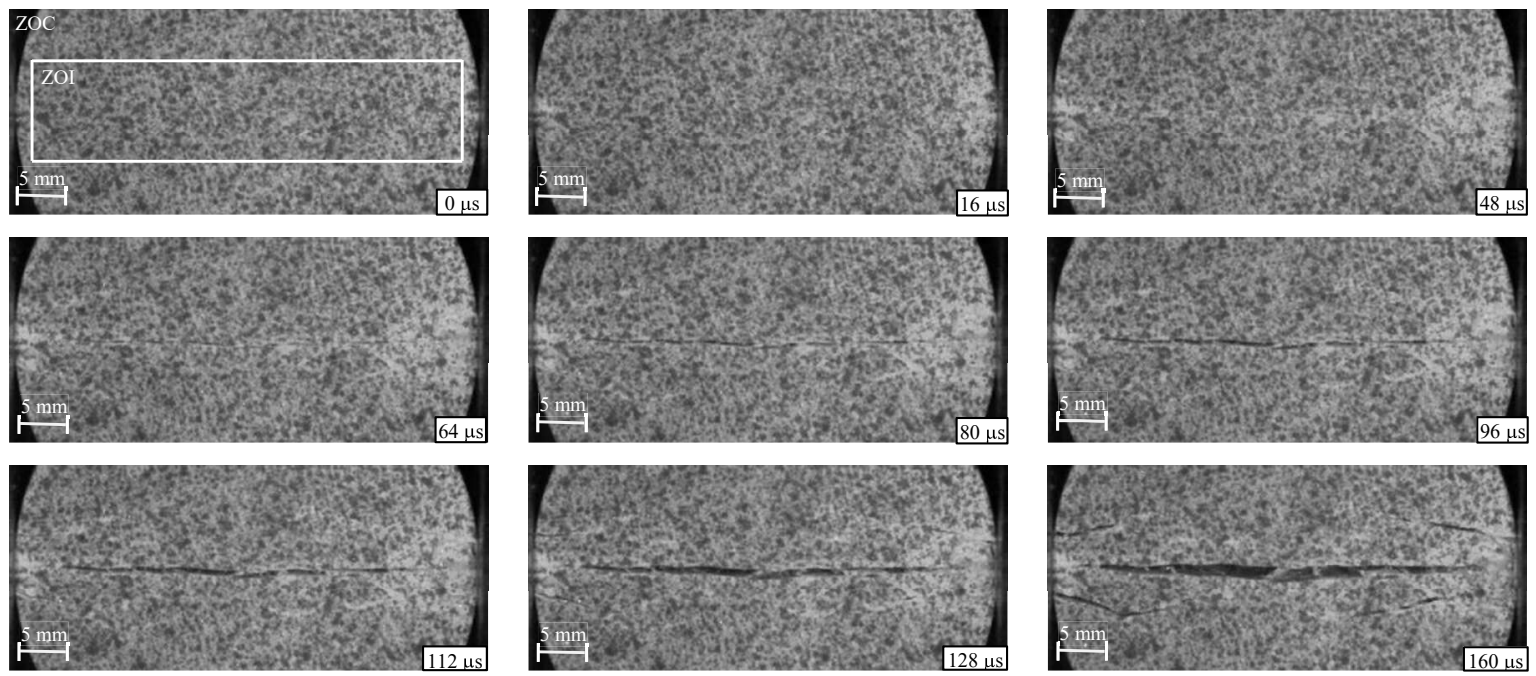






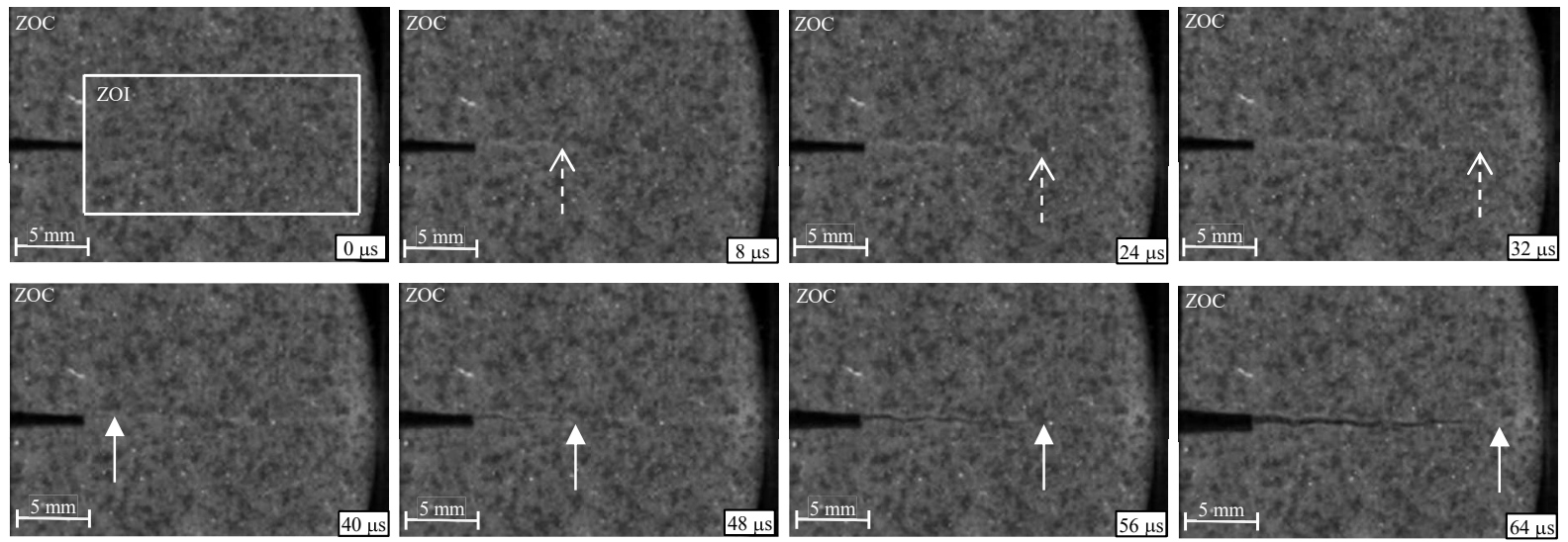

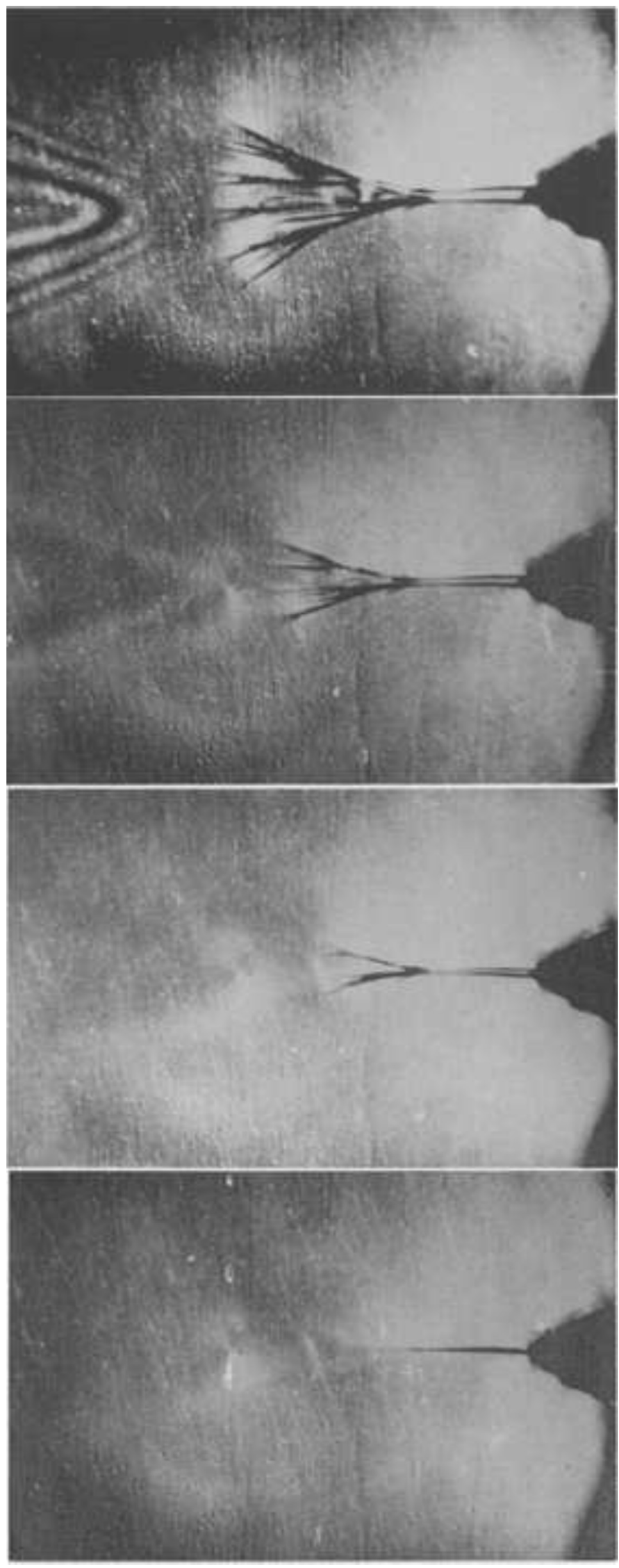



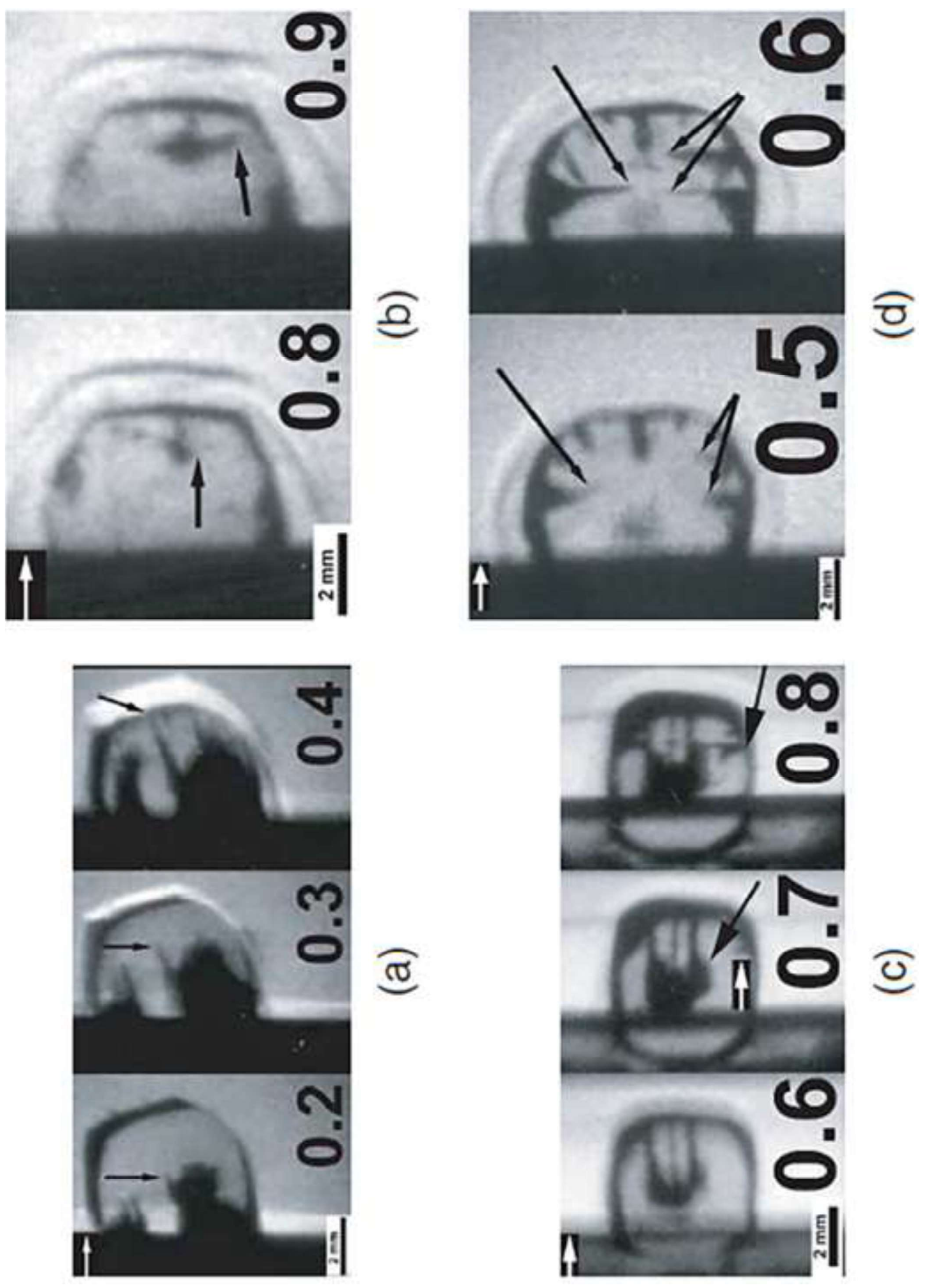

$\frac{1}{0}$
$\frac{0}{5}$
$\frac{0}{2}$
$i \frac{1}{1}$ 


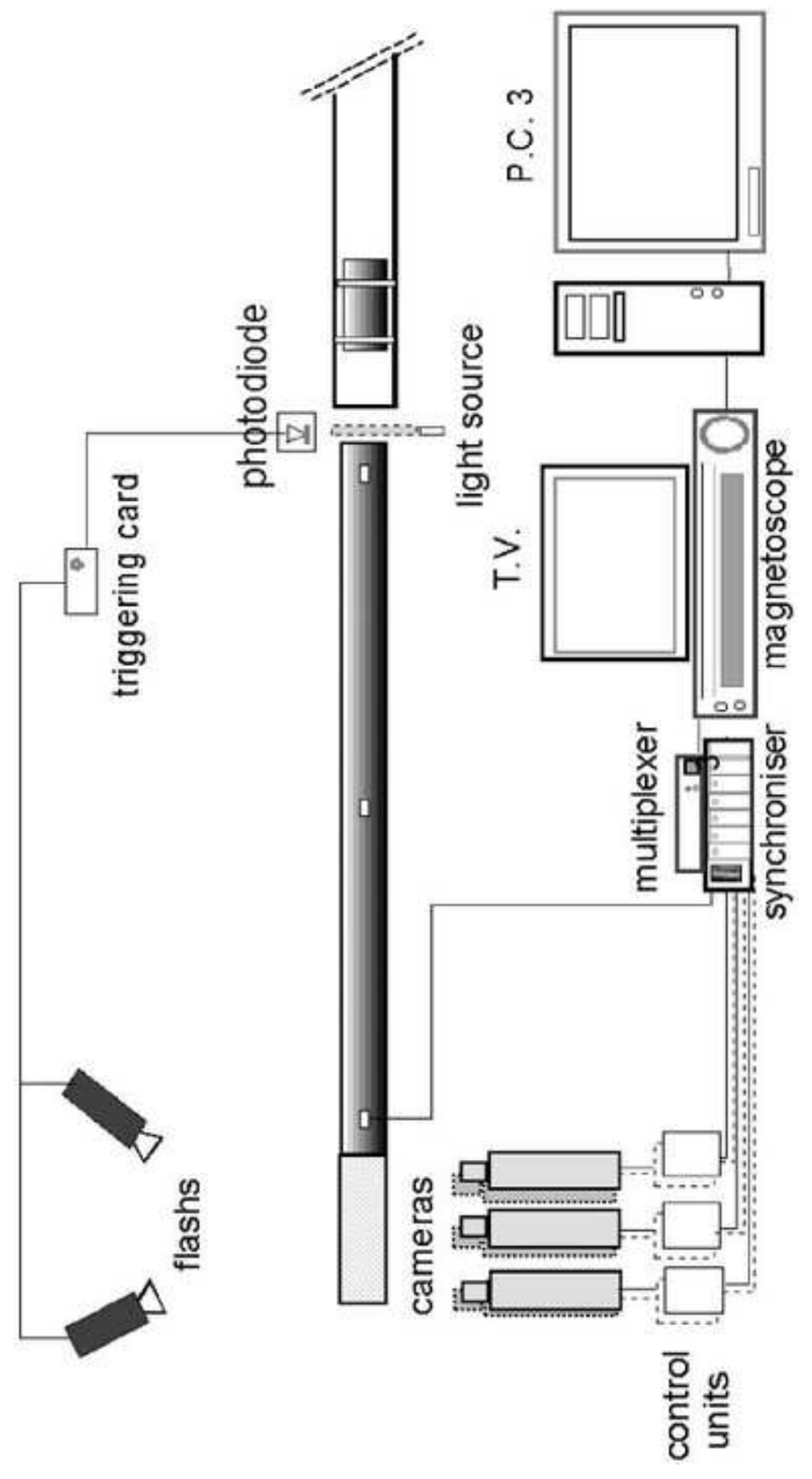



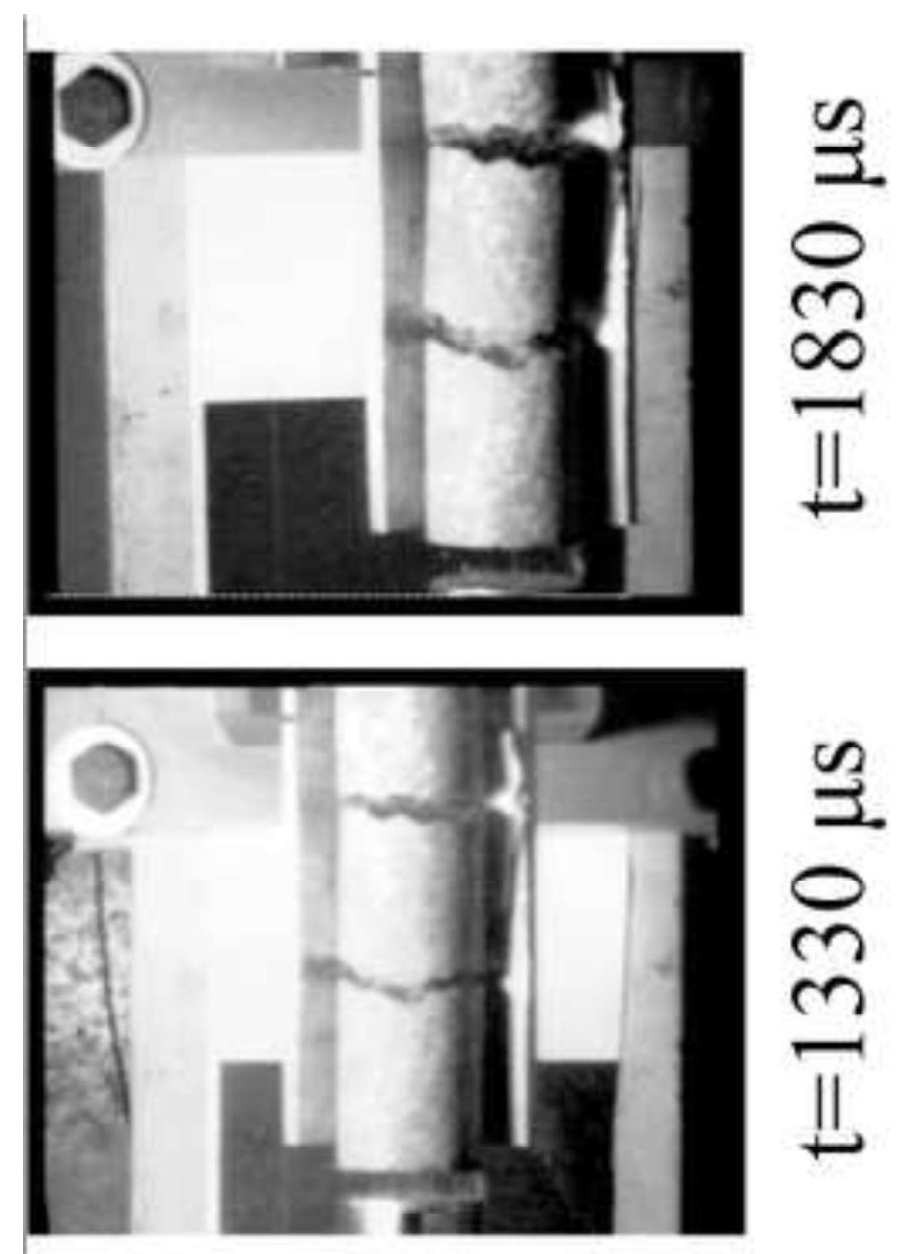

$\frac{n}{3}$

m

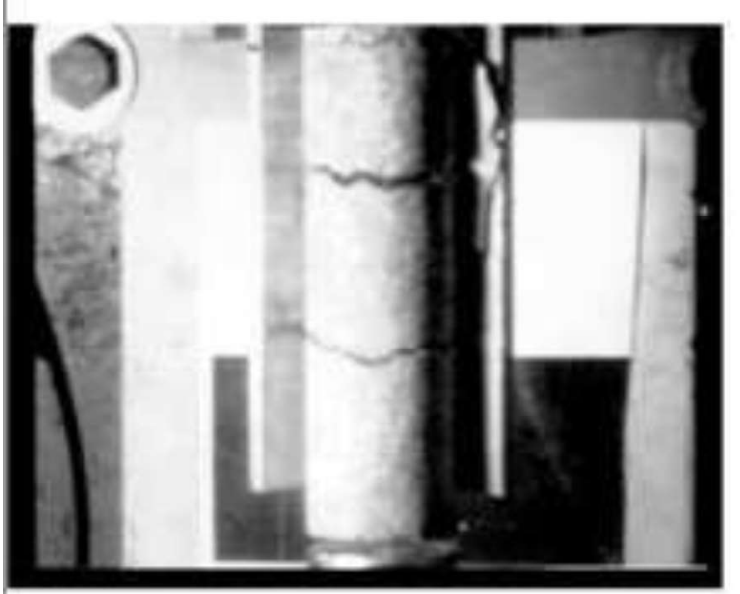

$\frac{n}{3}$

$\frac{0}{0}$
$\frac{0}{0}$
$\frac{0}{2}$

$\int_{1}^{\frac{n}{3}}$

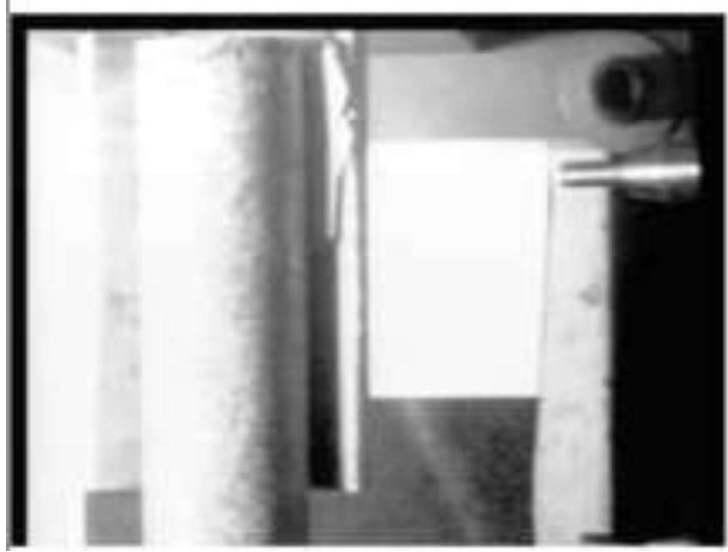



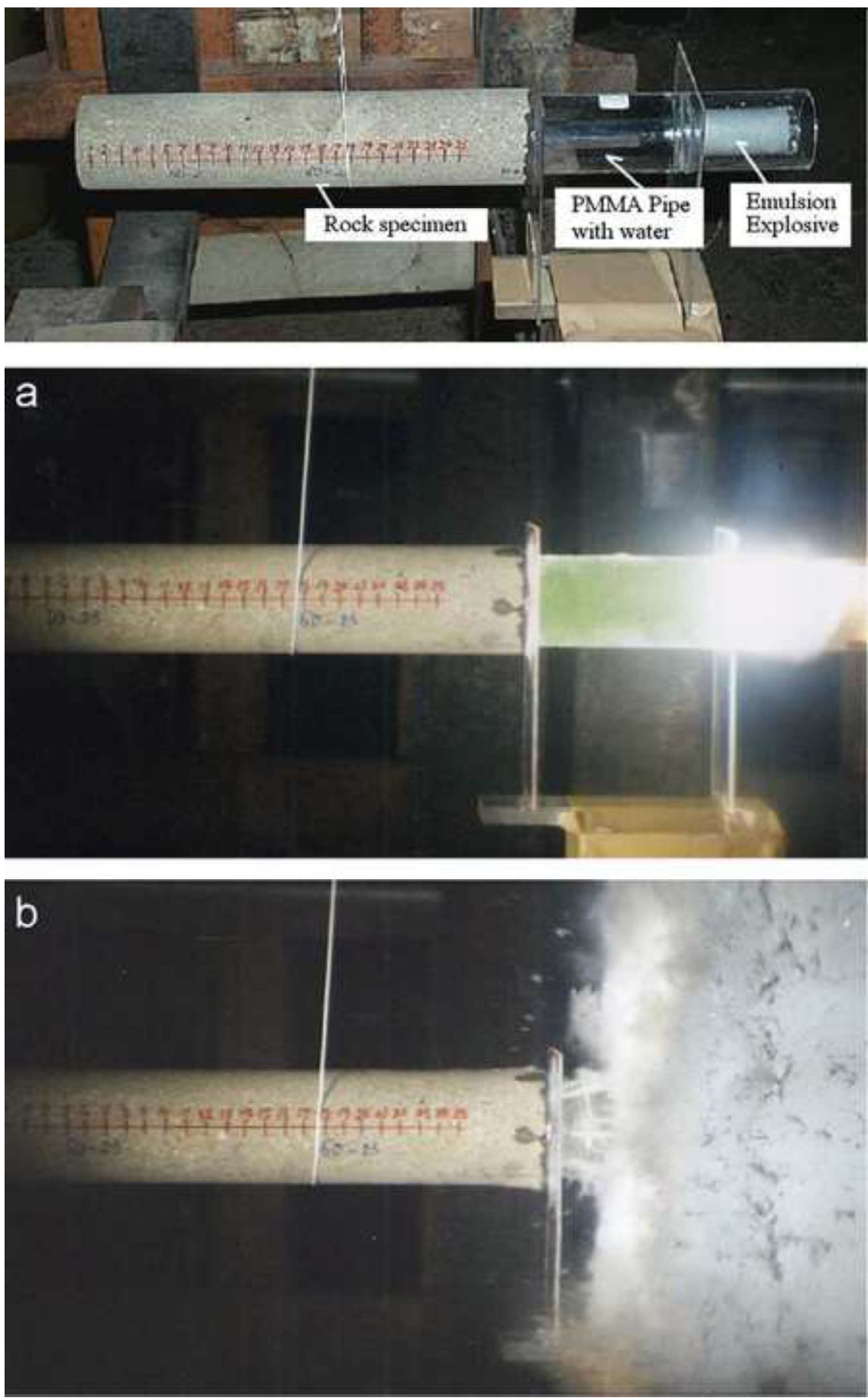

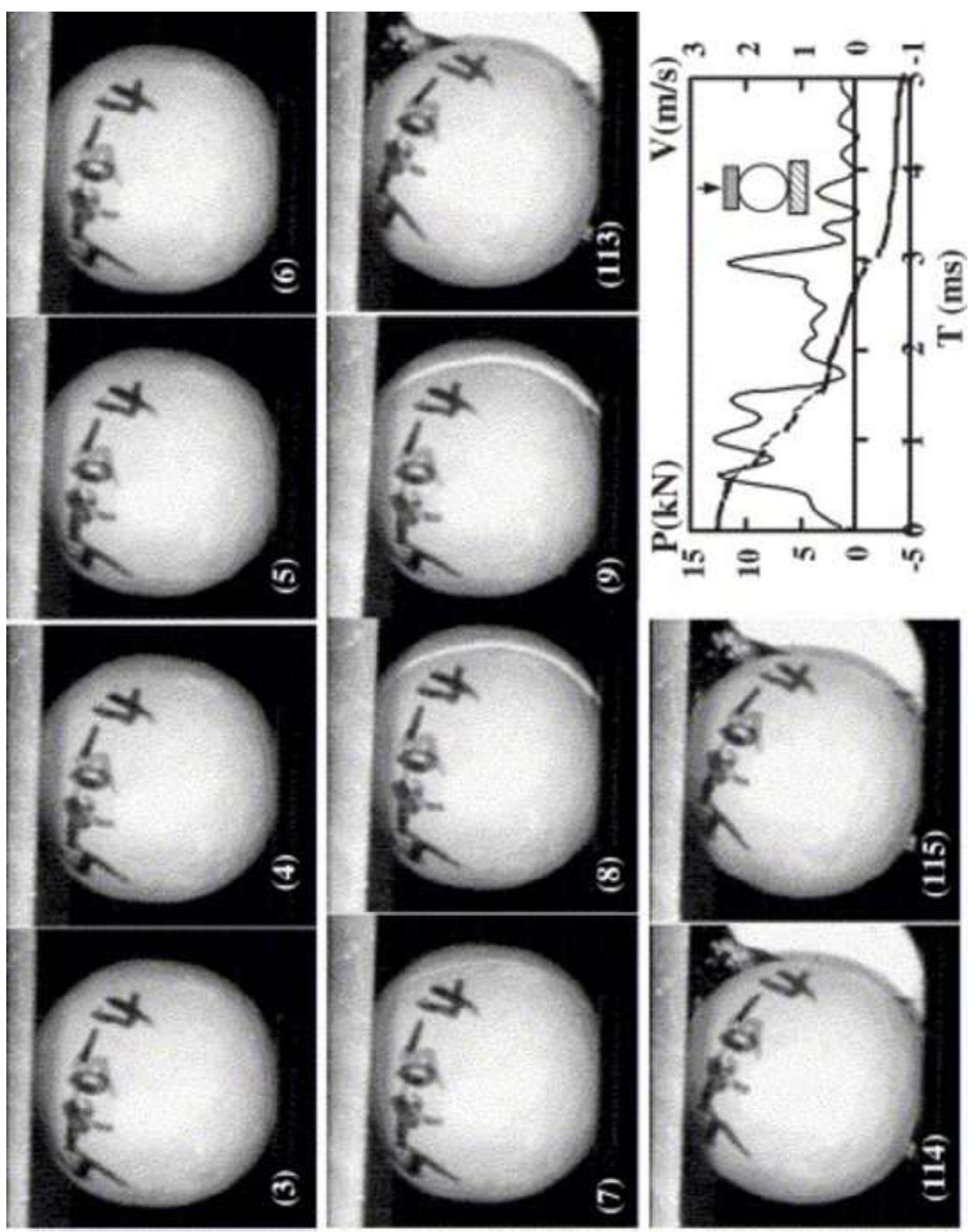


\section{$t=20 \mu s$}

\section{$20 \mathrm{~mm}$}

\section{$\mathrm{t}=30 \mu \mathrm{s}$}

\section{$\mathrm{t}=60 \mu \mathrm{s}$}

\section{$t=40 \mu s$}

\section{$t=50 \mu s$}




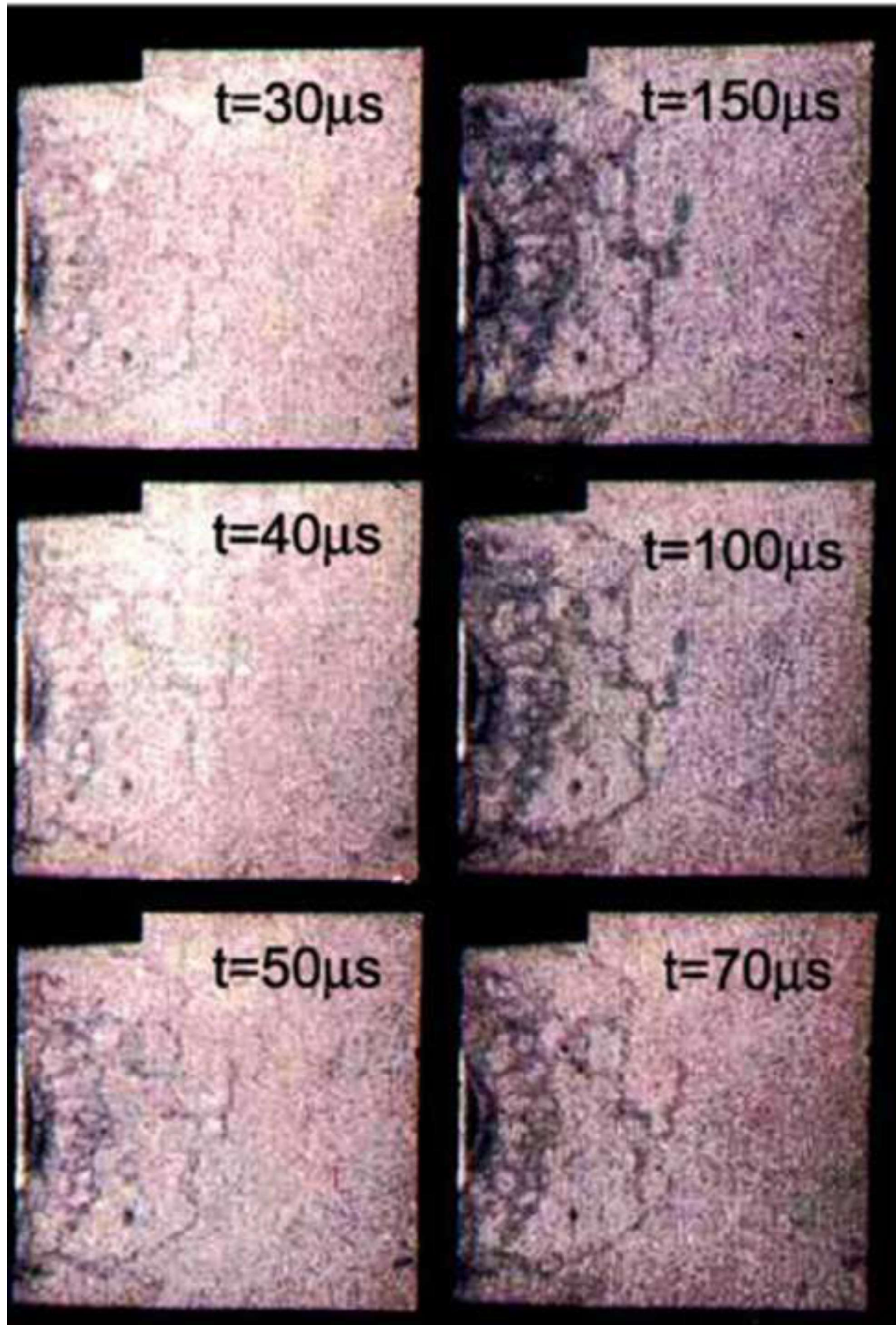



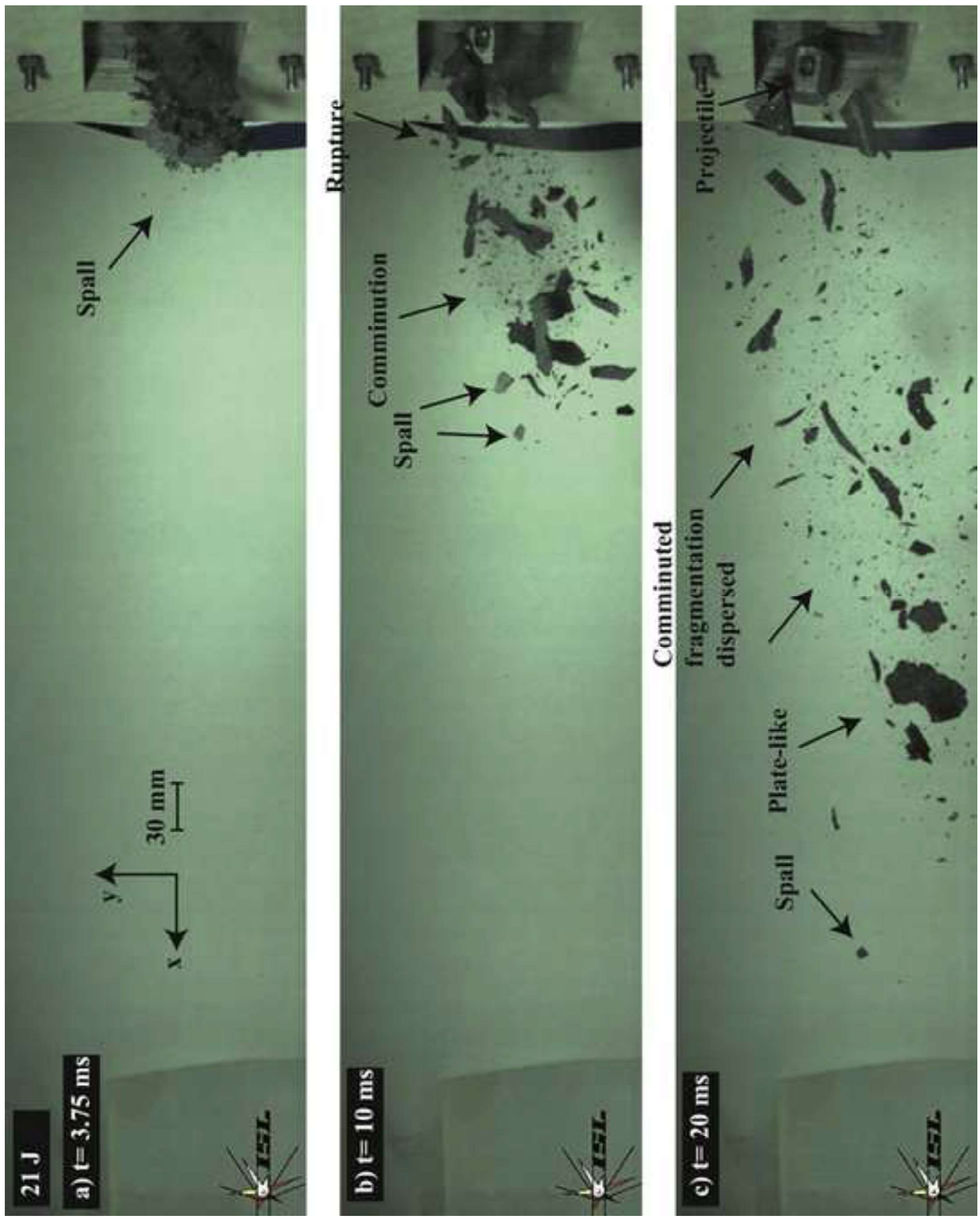

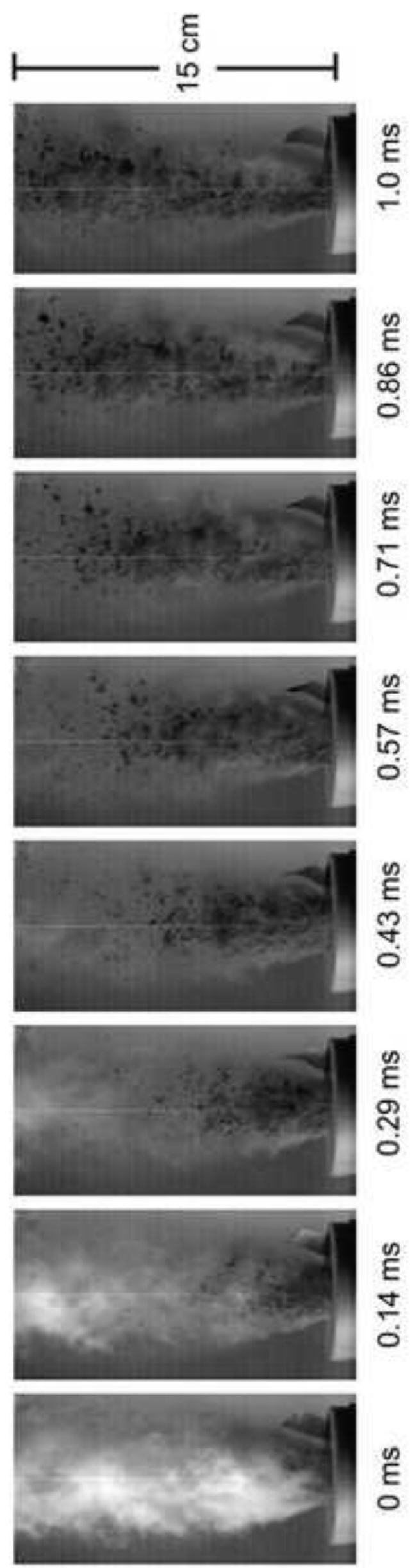

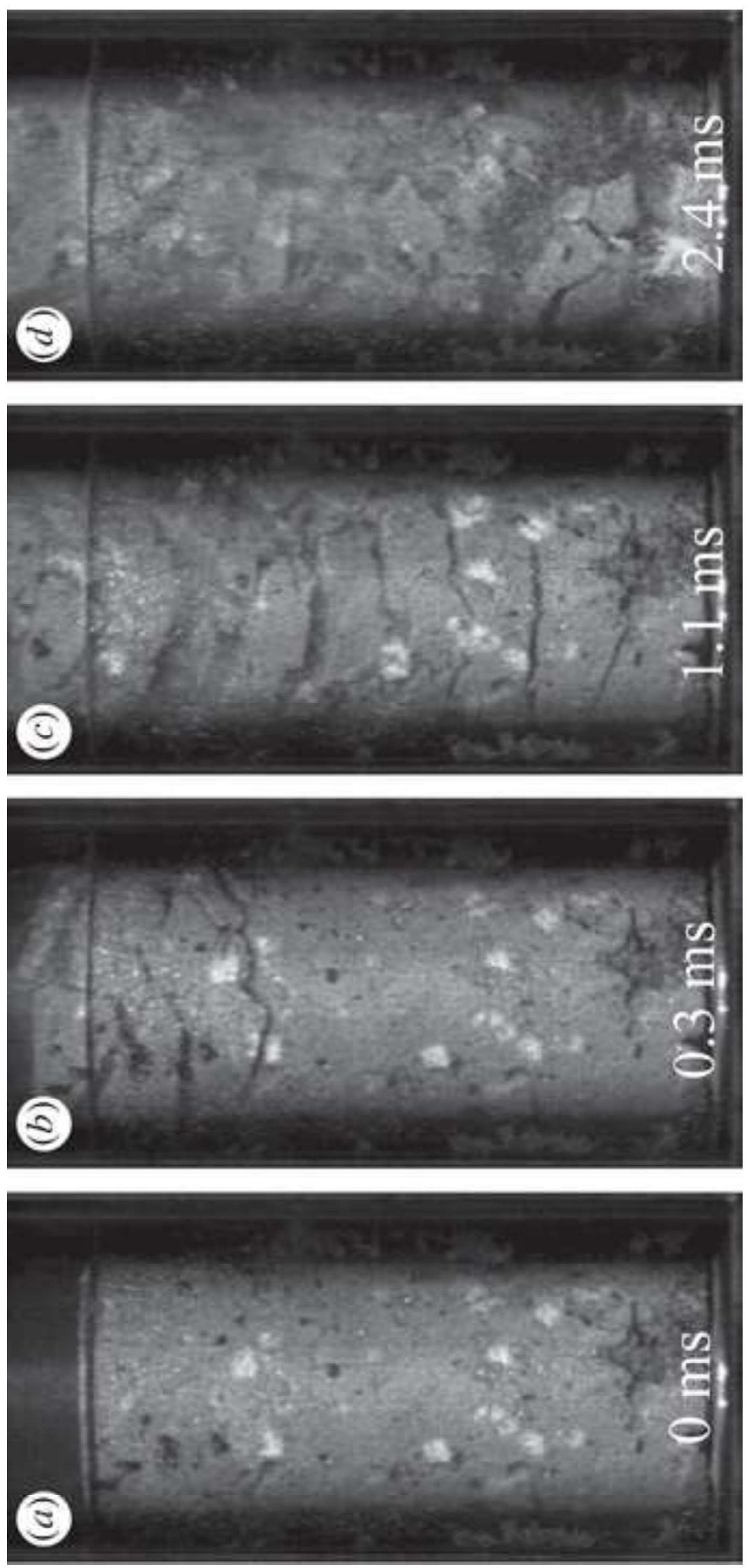

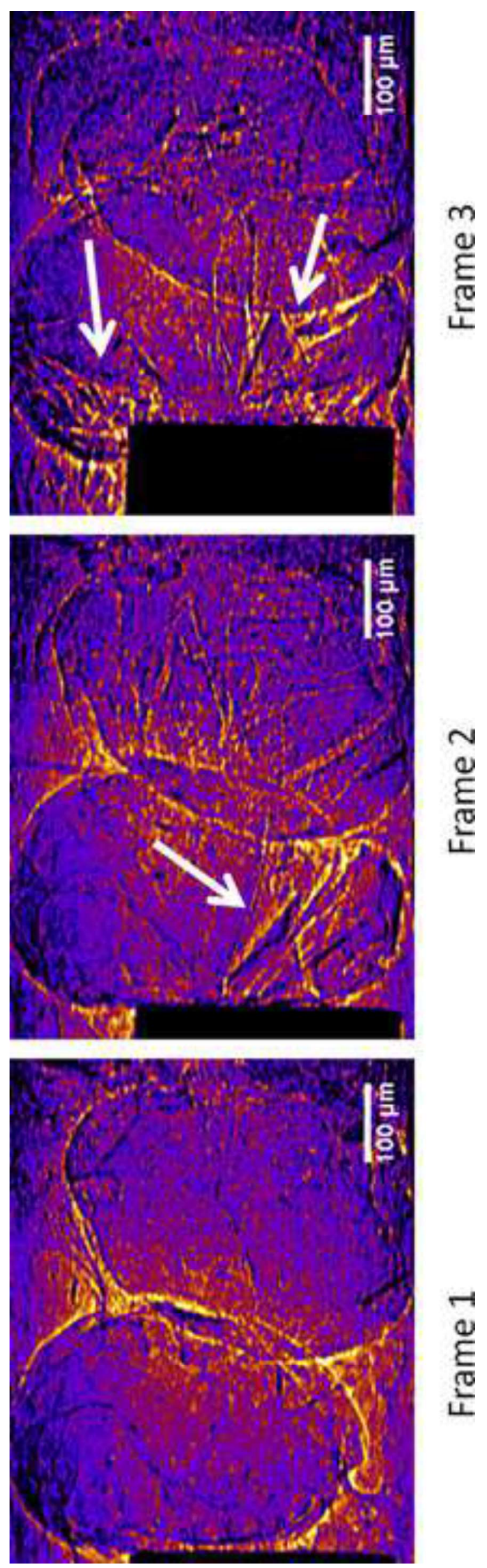

$\frac{N}{\frac{0}{2}}$

담 

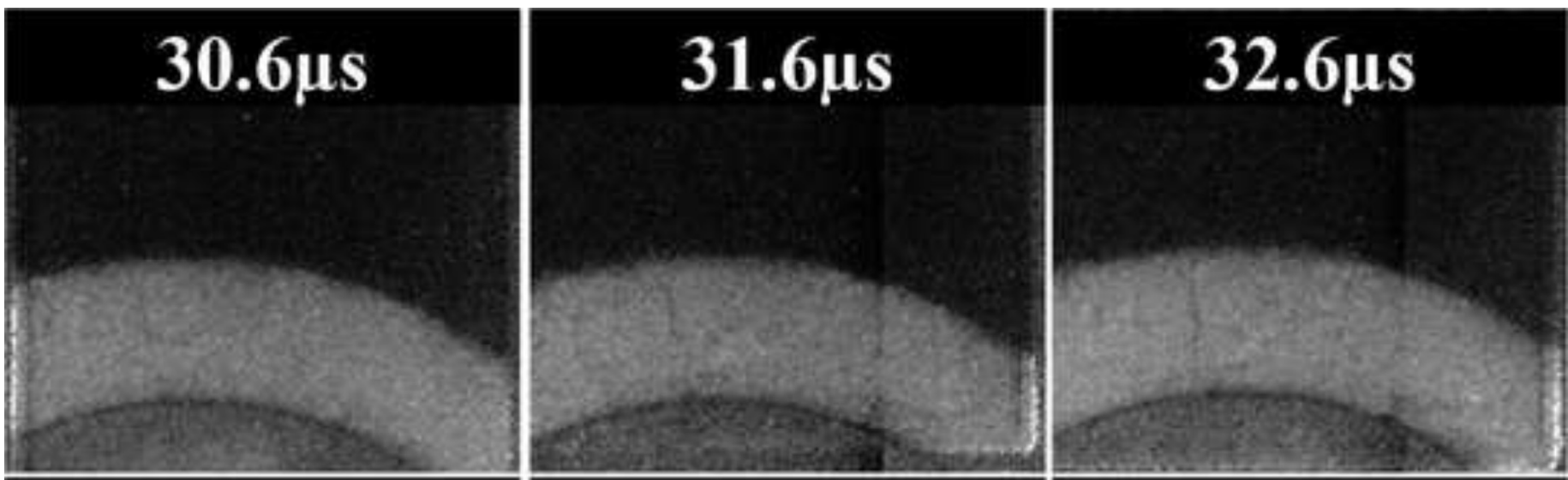

\section{$33.6 \mu \mathrm{s}$}

\section{$34.6 \mu \mathrm{s}$}

\section{$35.6 \mu \mathrm{s}$}

\section{$46.1 \mu \mathrm{s}$}

$$
47.1 \mu \mathrm{s}
$$

$48.1 \mu \mathrm{s}$

\section{$49.1 \mu \mathrm{s}$}
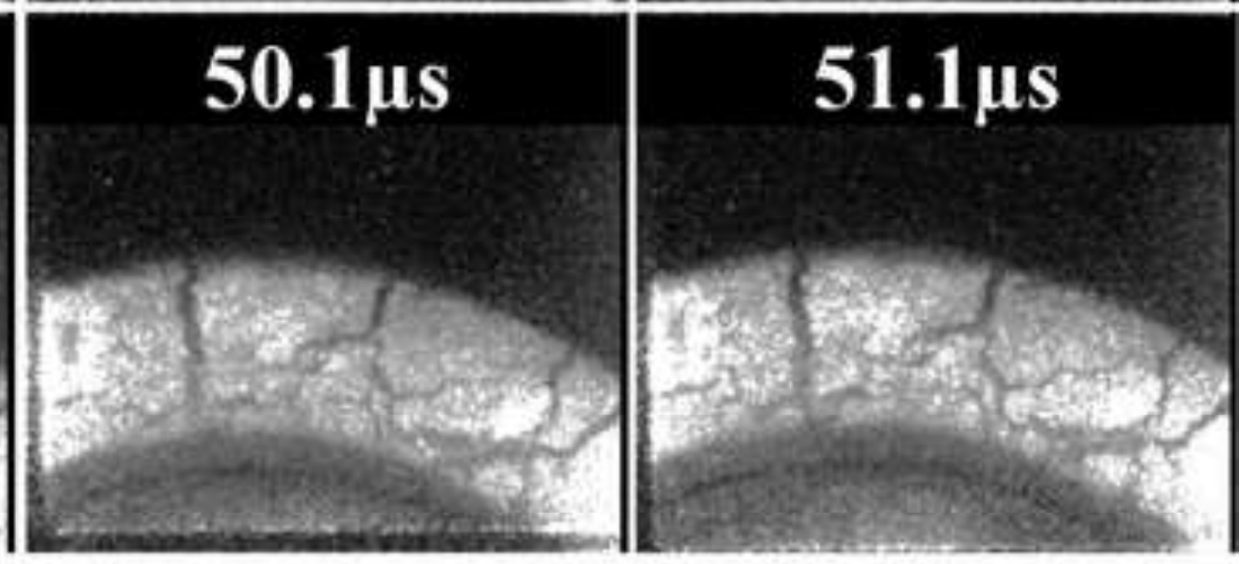

$10 \mathrm{~mm}$ 






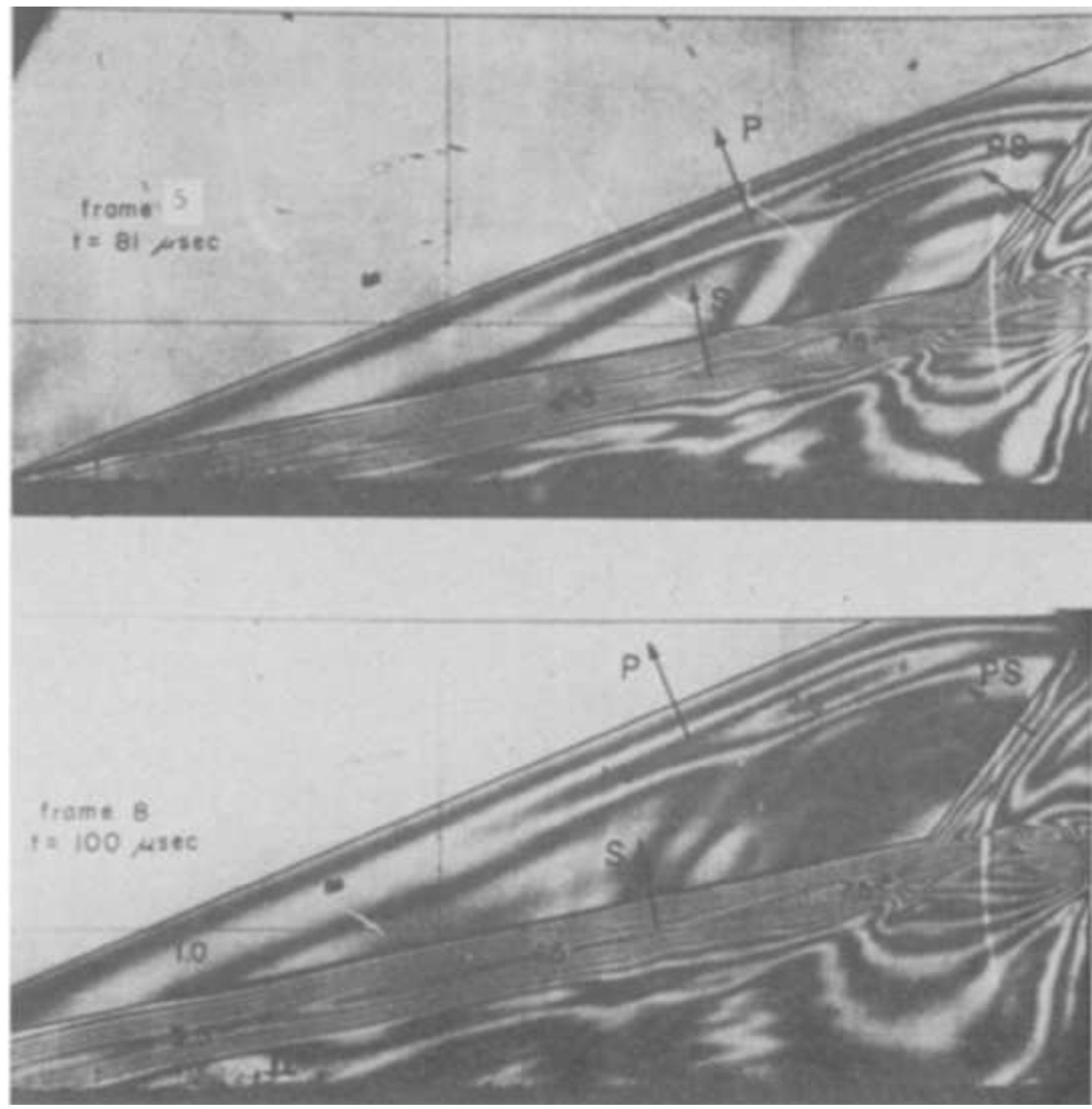
T旧





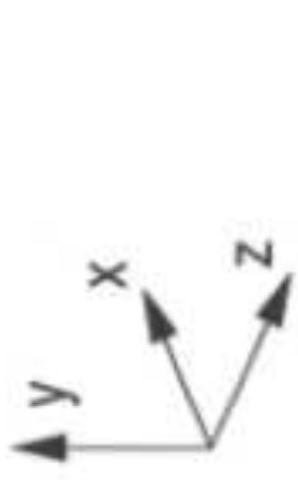

II

둥

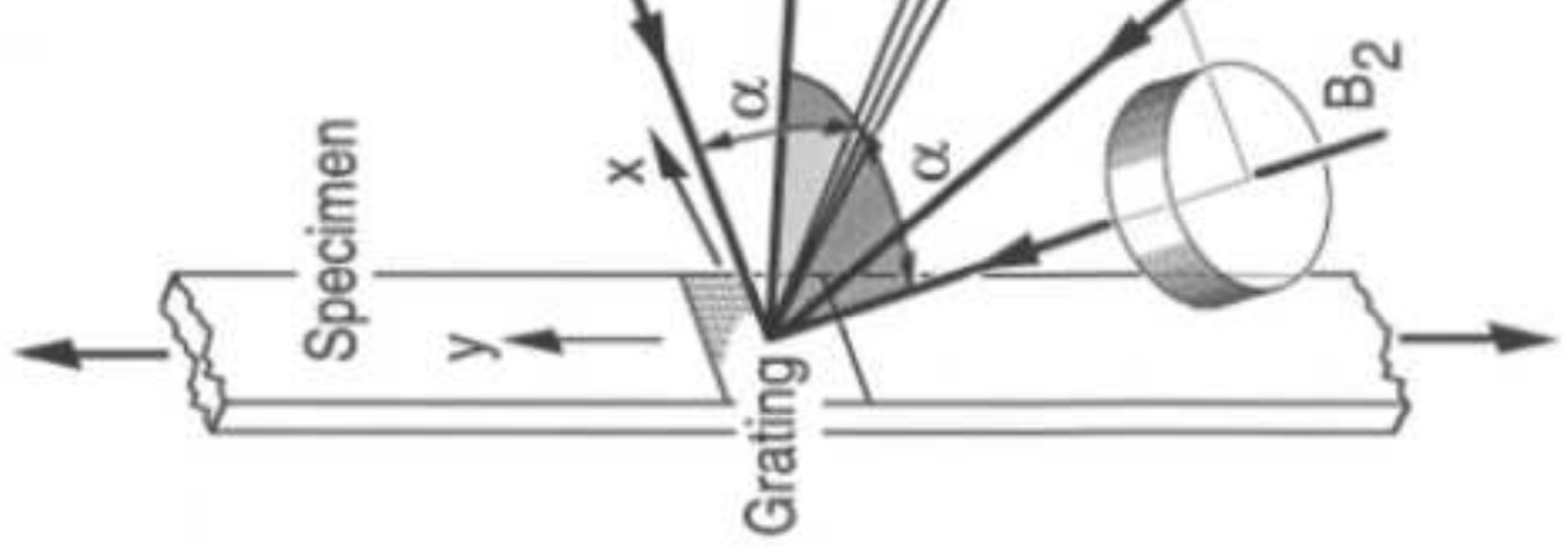




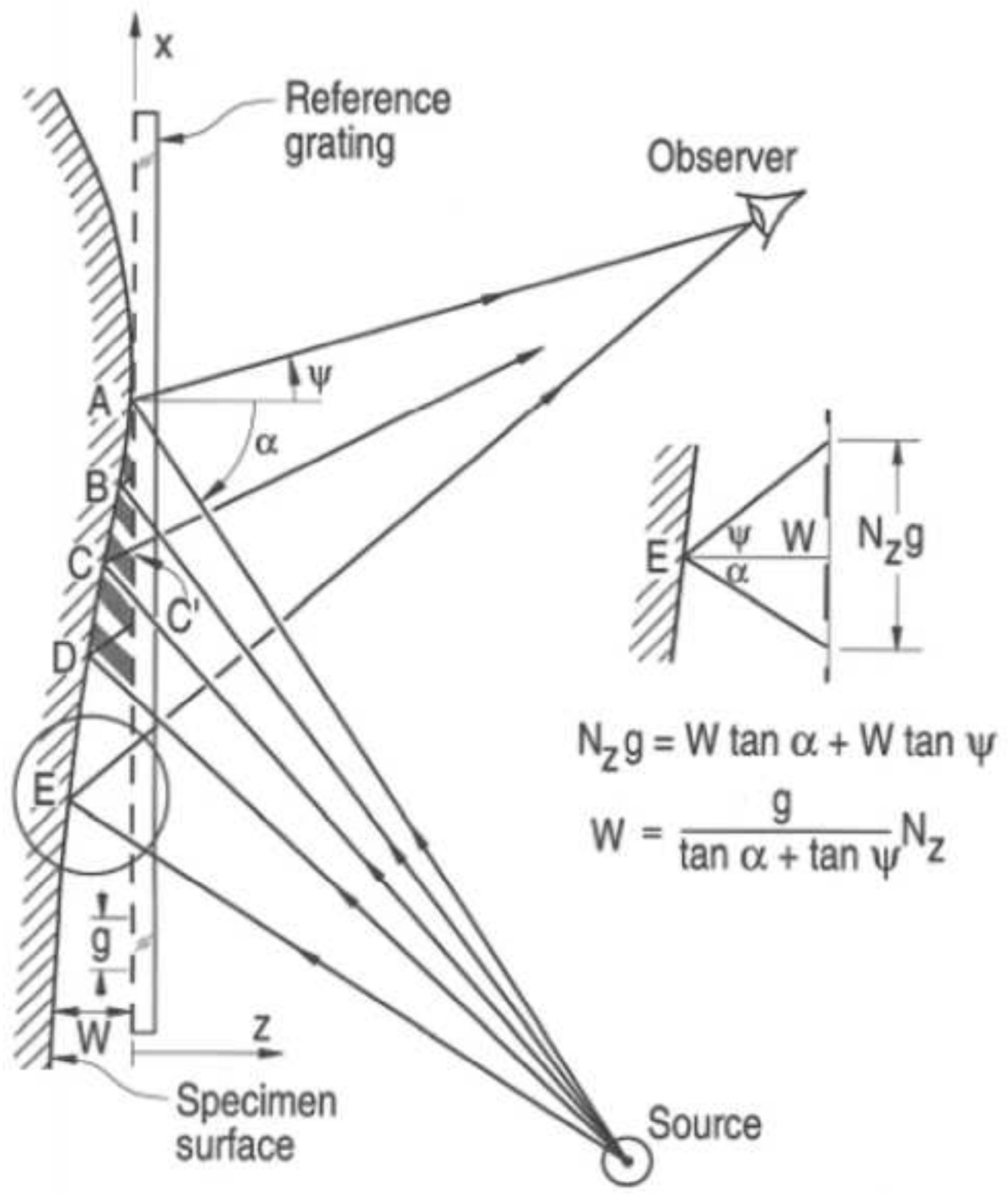



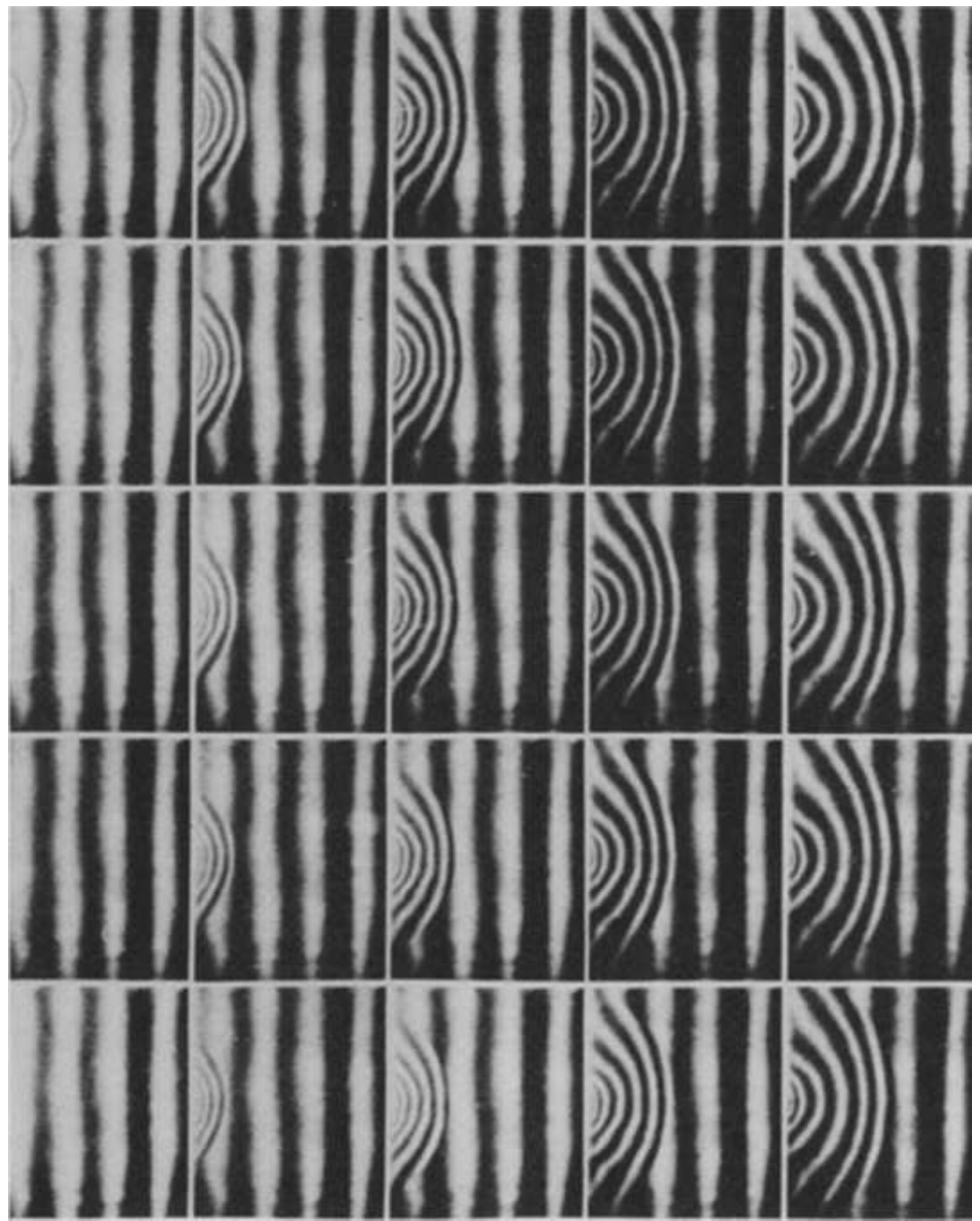


\section{Refractive Caustics}

\section{incoming light}

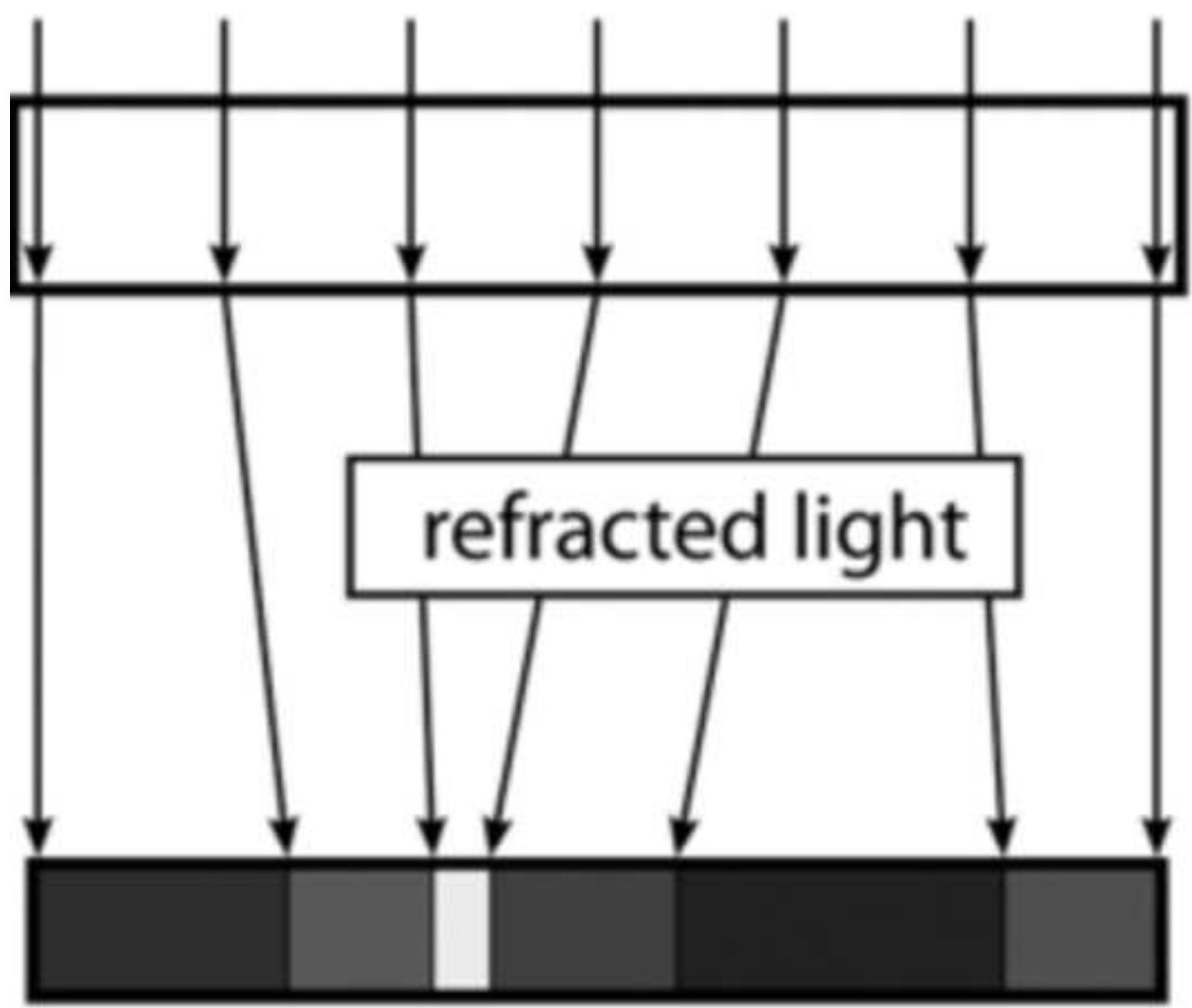




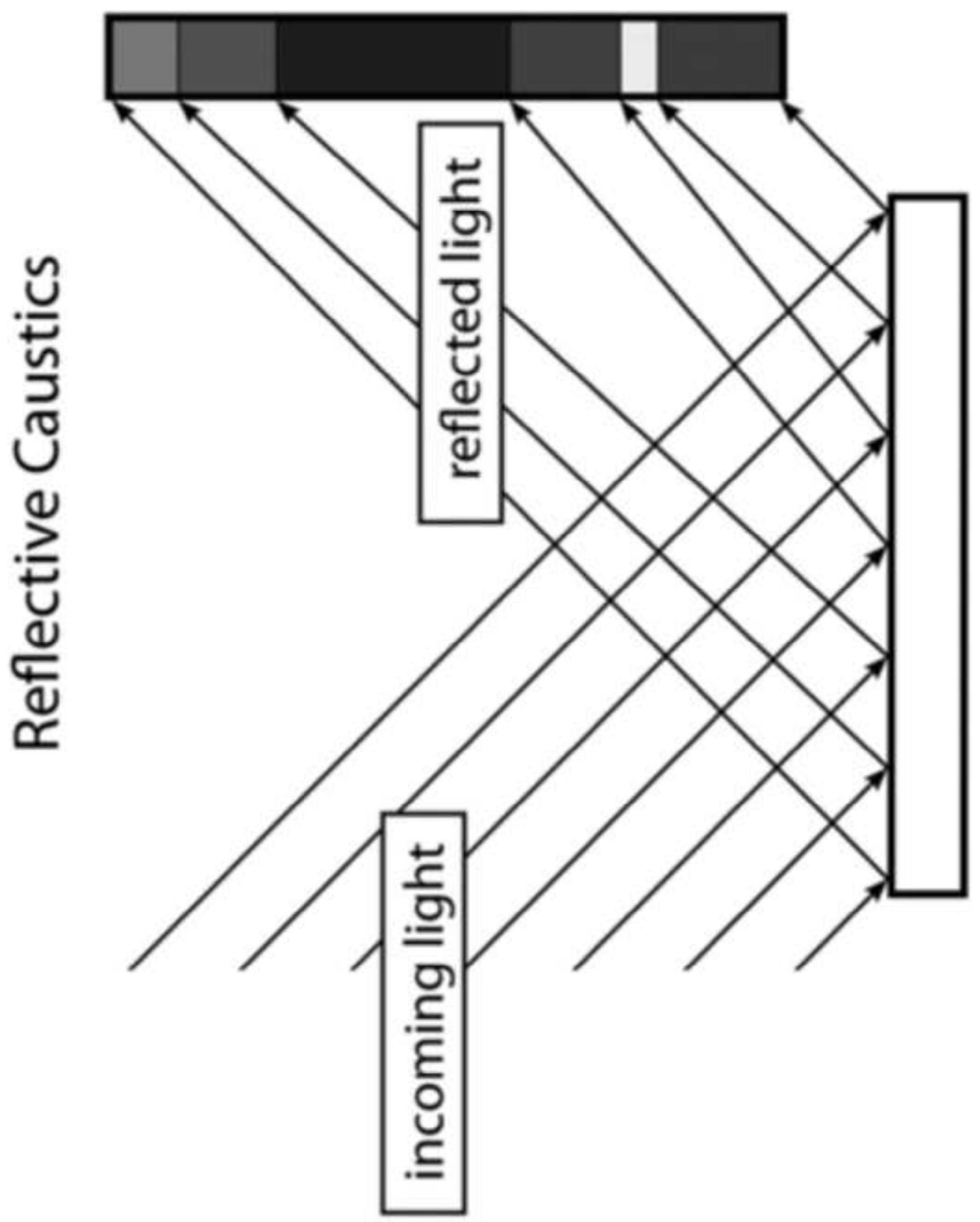

율
No
$\stackrel{0}{\bar{\nu}}$
흔 

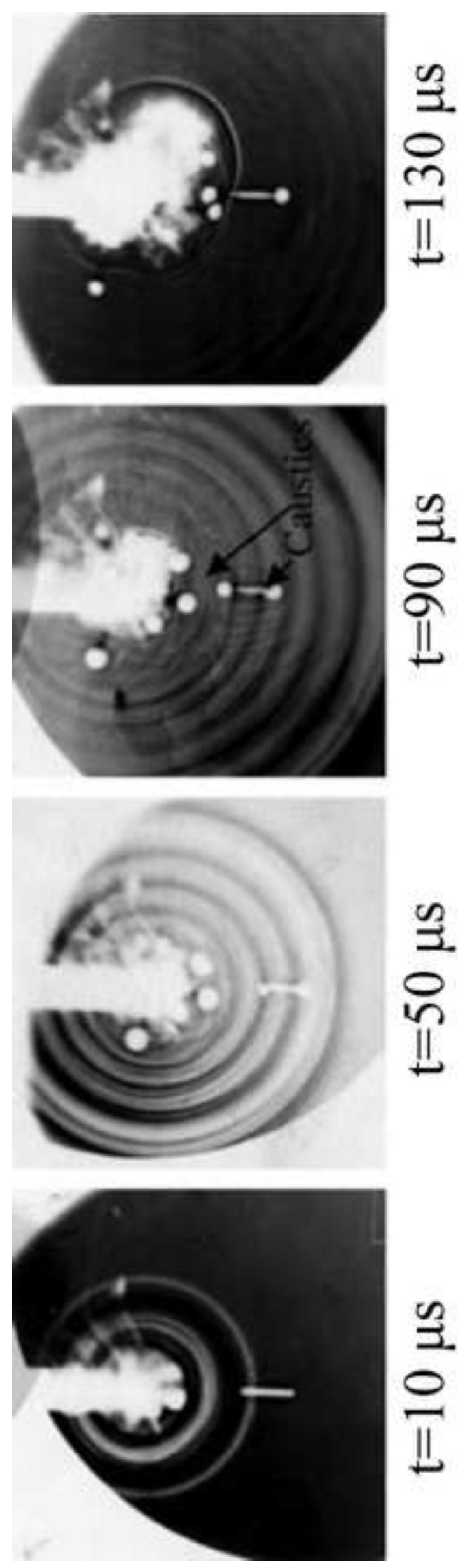

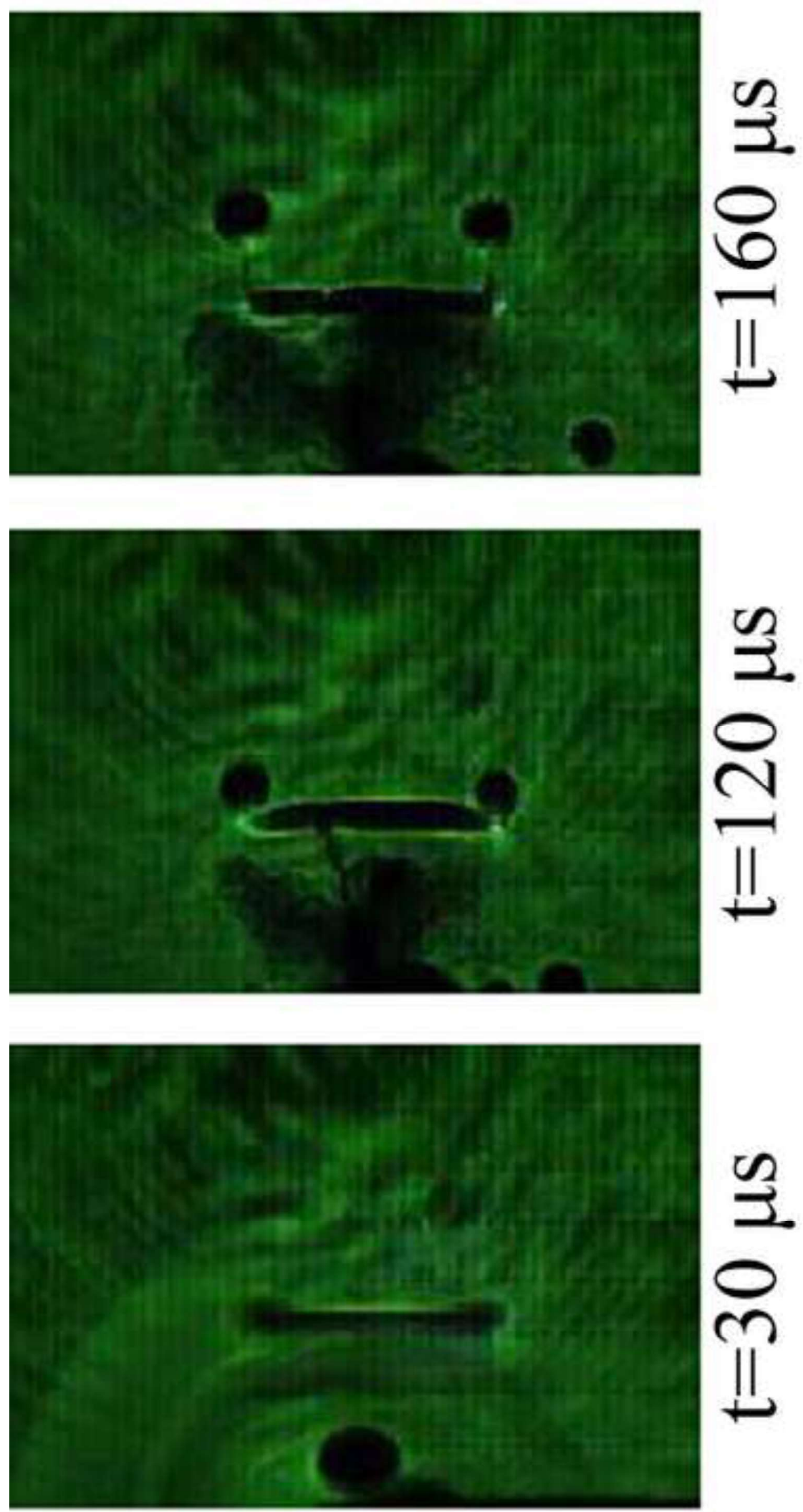

告

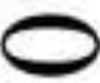

ก



(2) 



플

光 


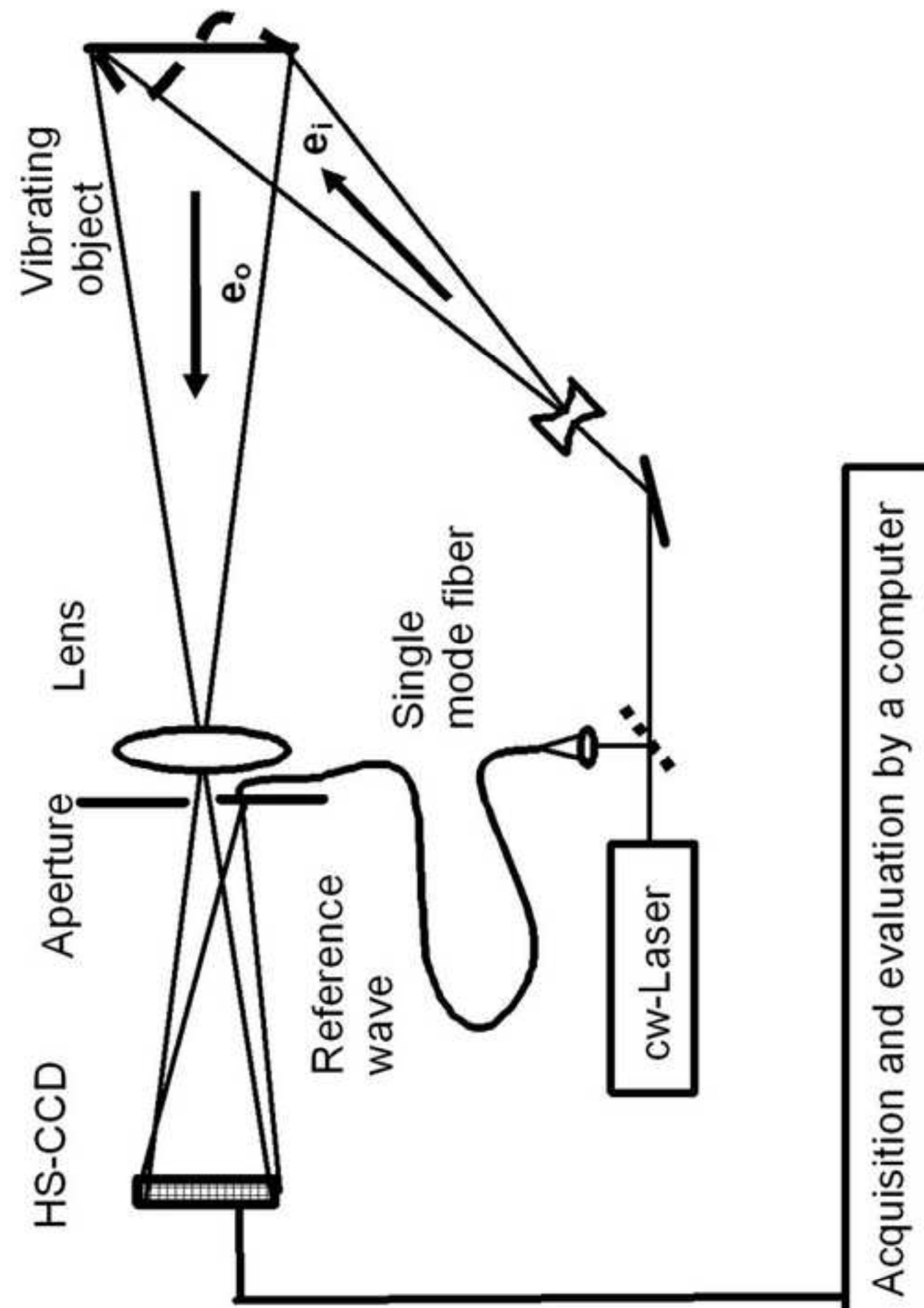

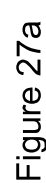




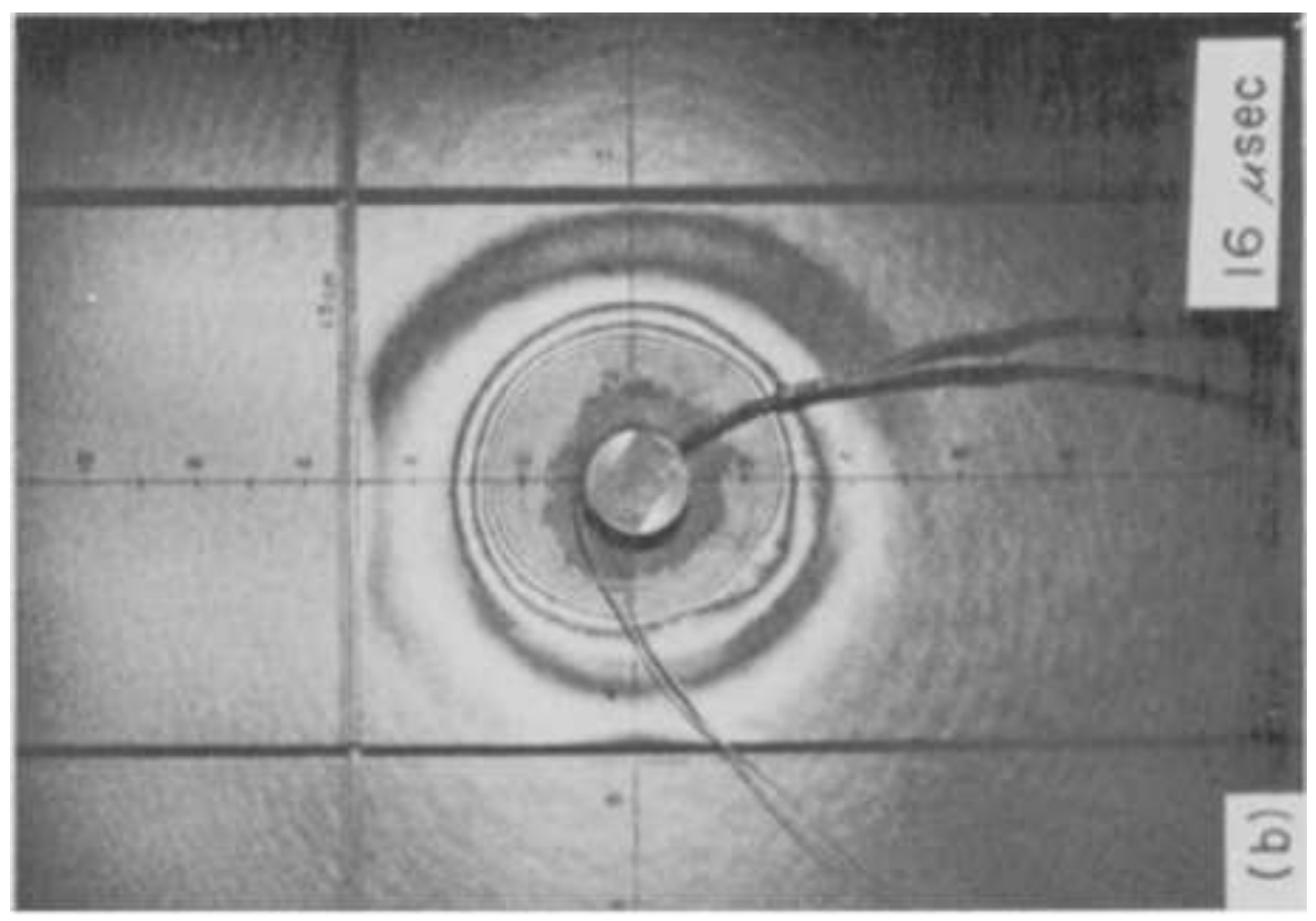




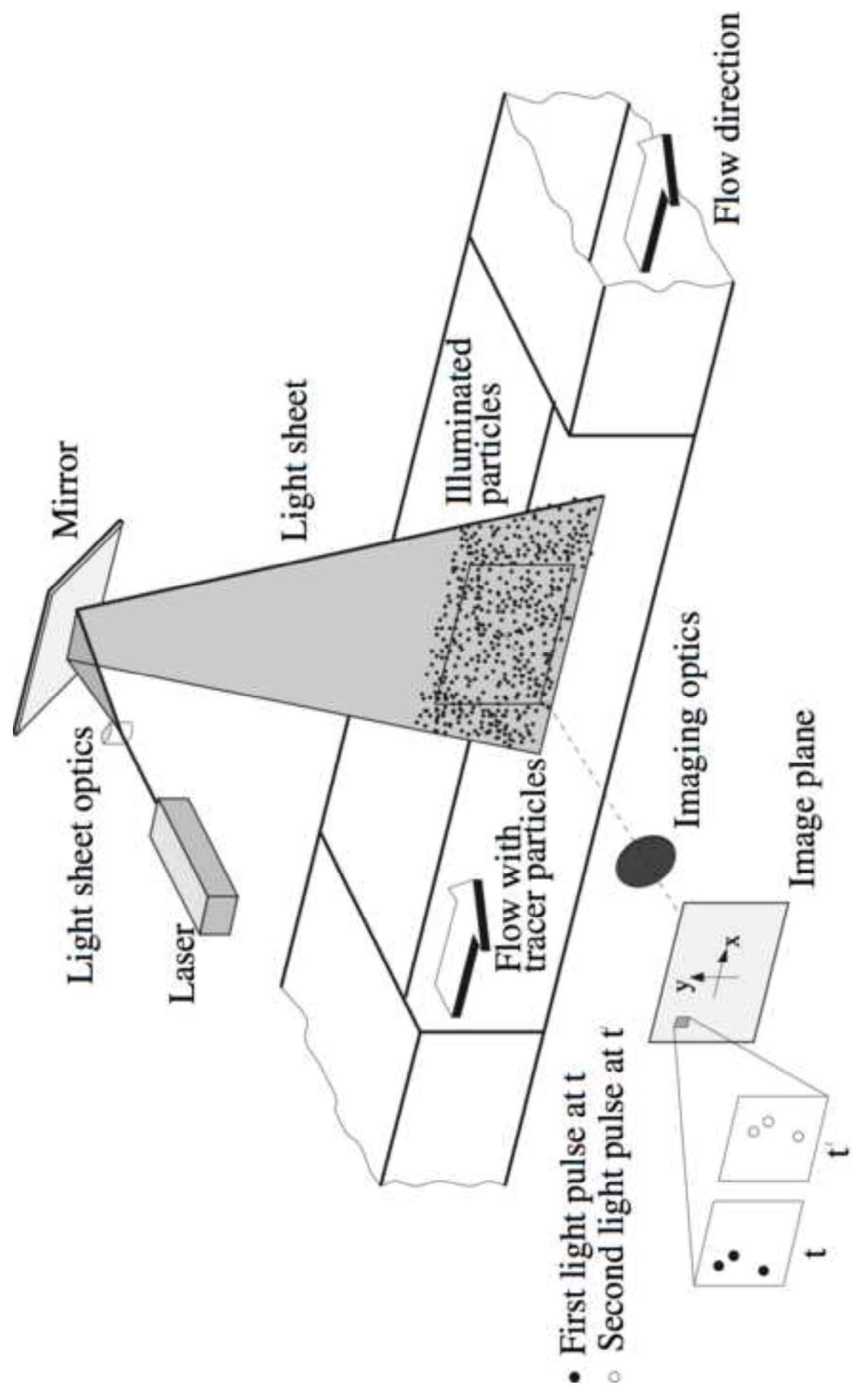

$\stackrel{\infty}{N}$
$\stackrel{\infty}{\nu}$
$\stackrel{0}{5}$
$i \frac{1}{4}$ 

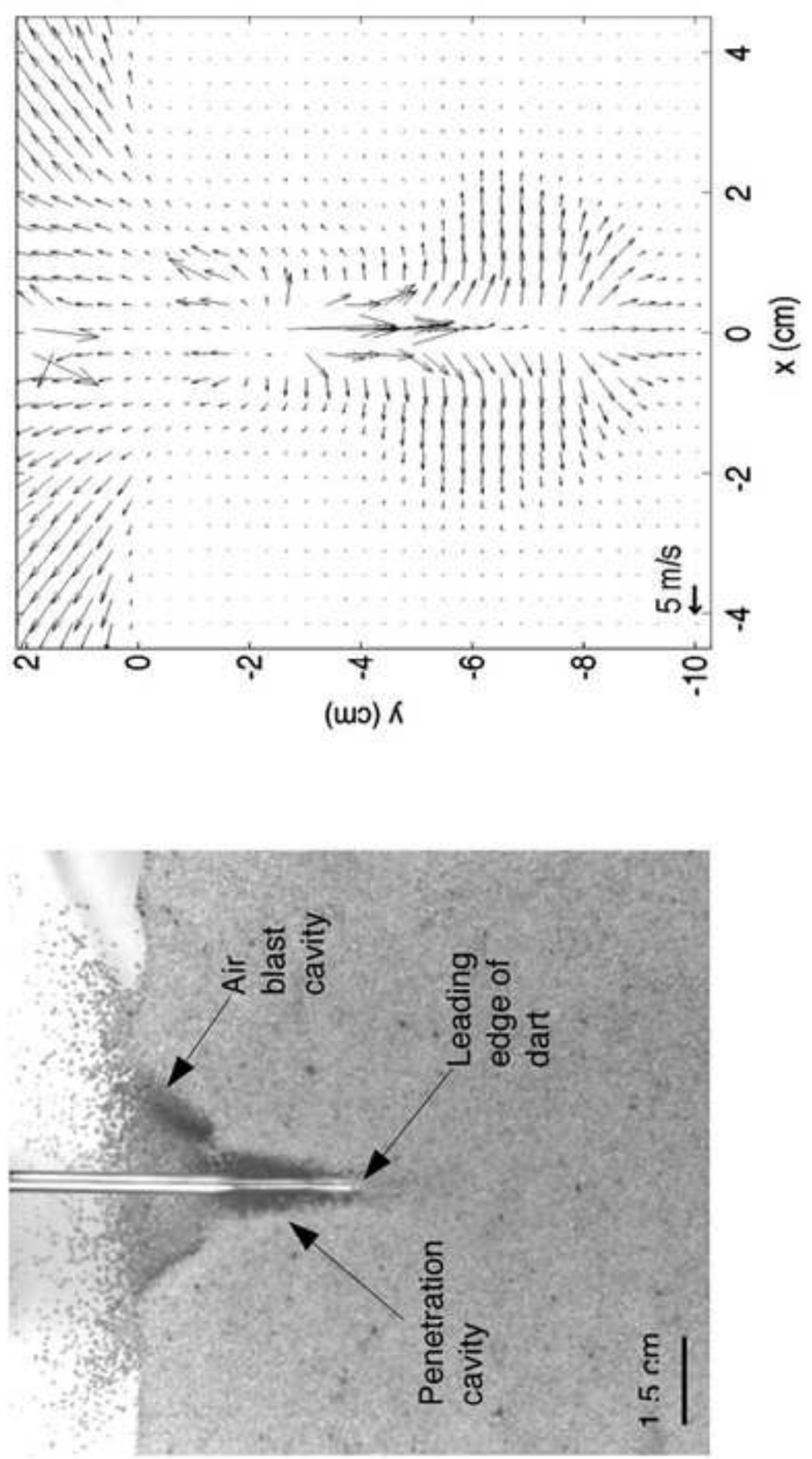









\section{F}
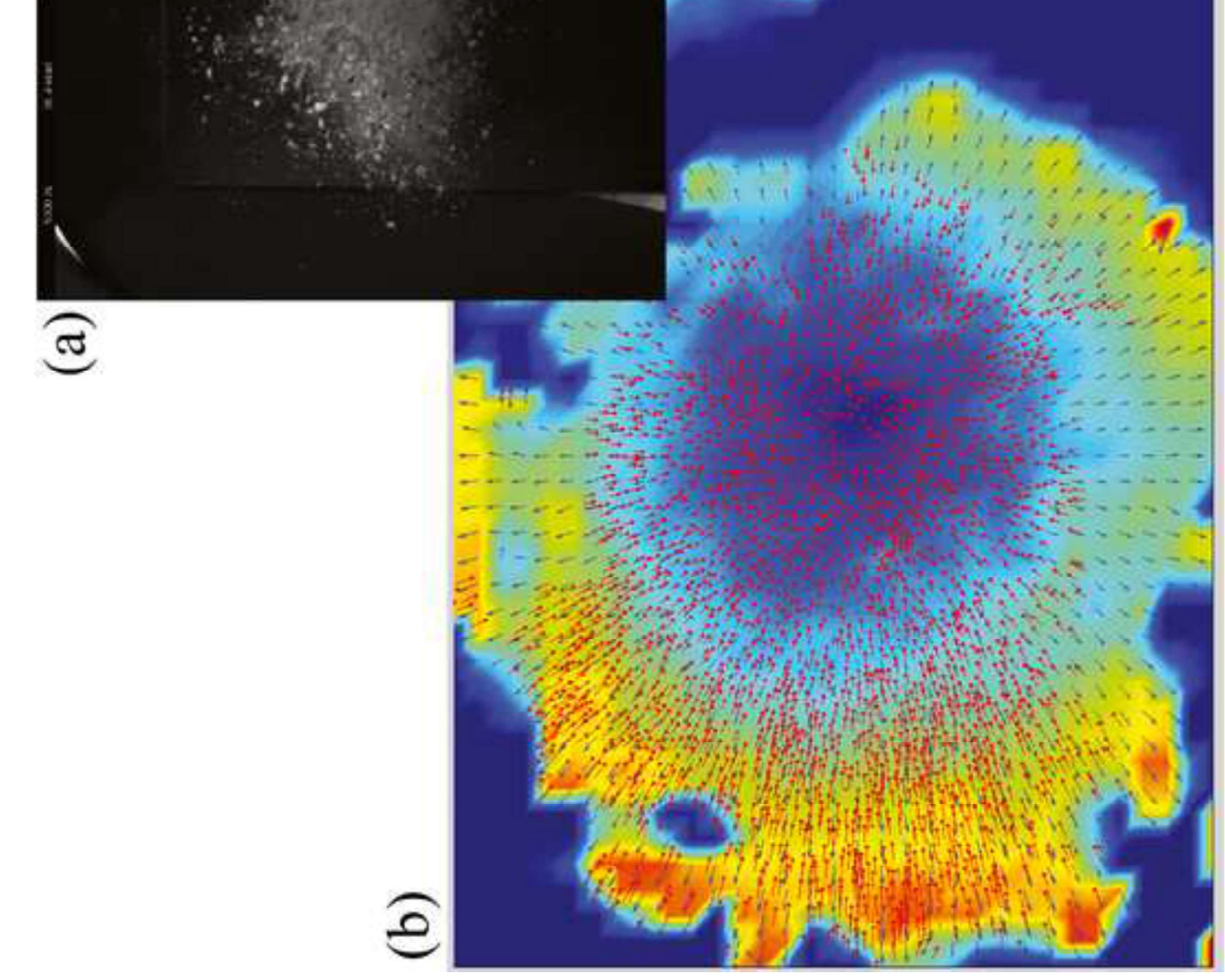


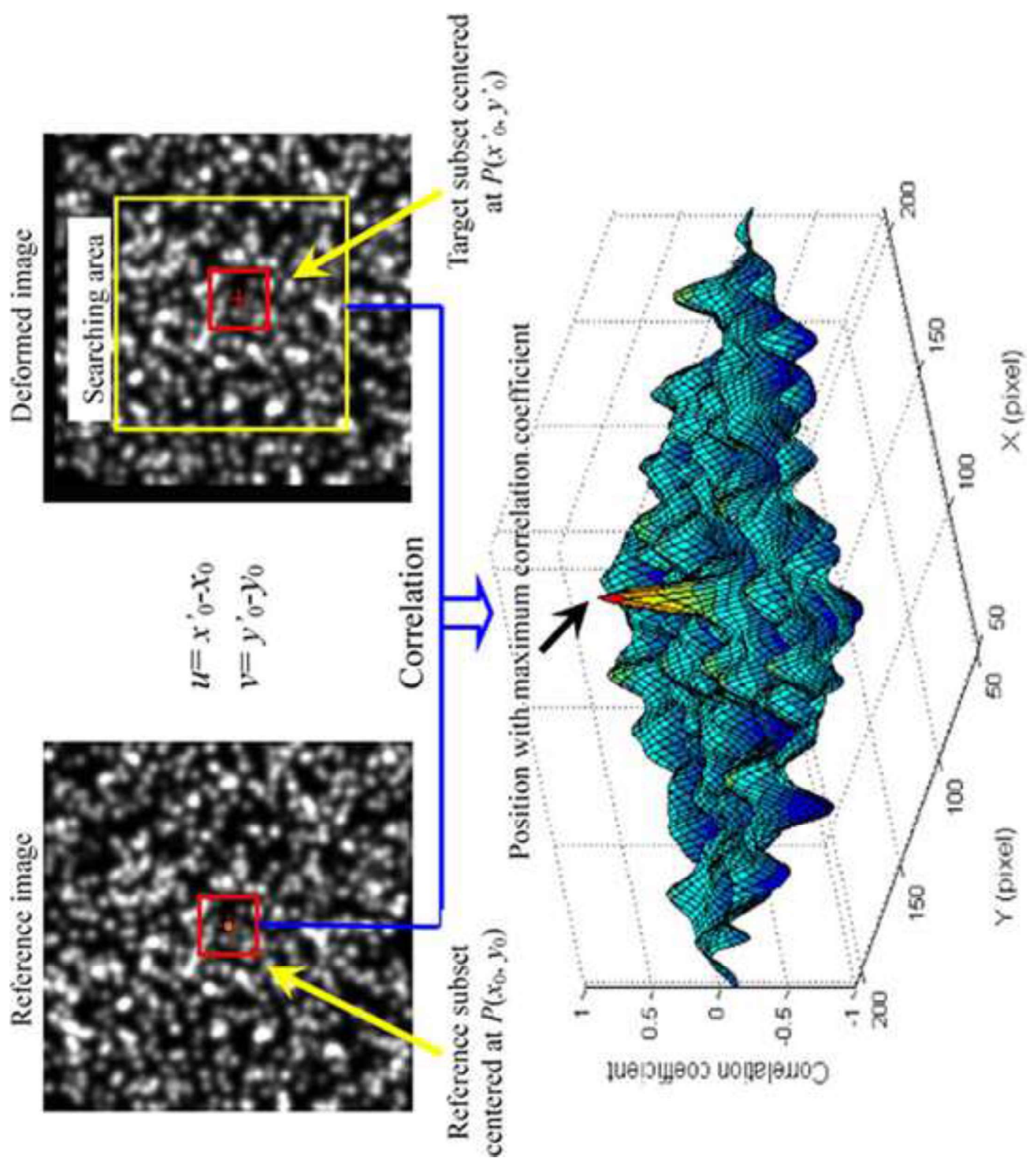



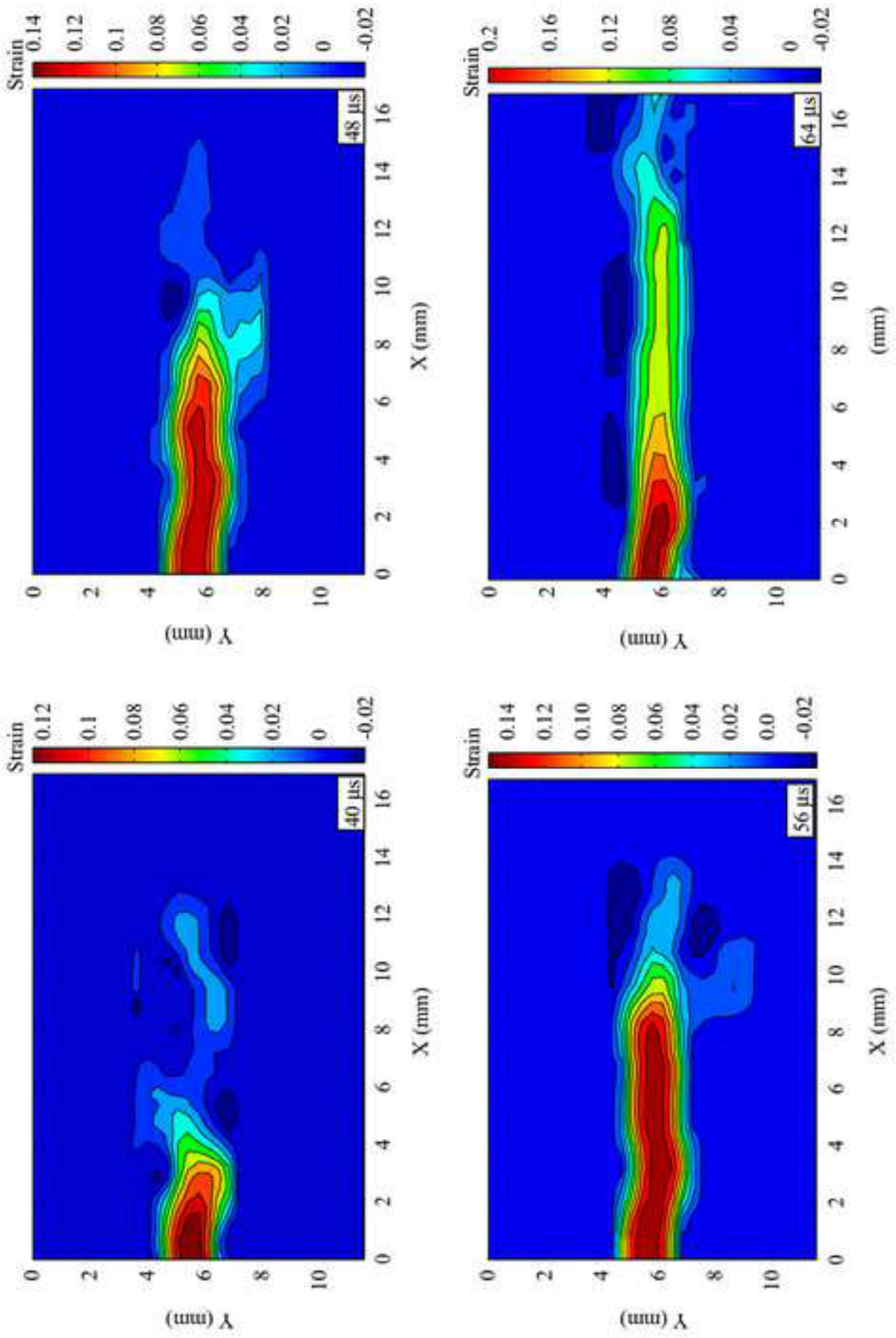

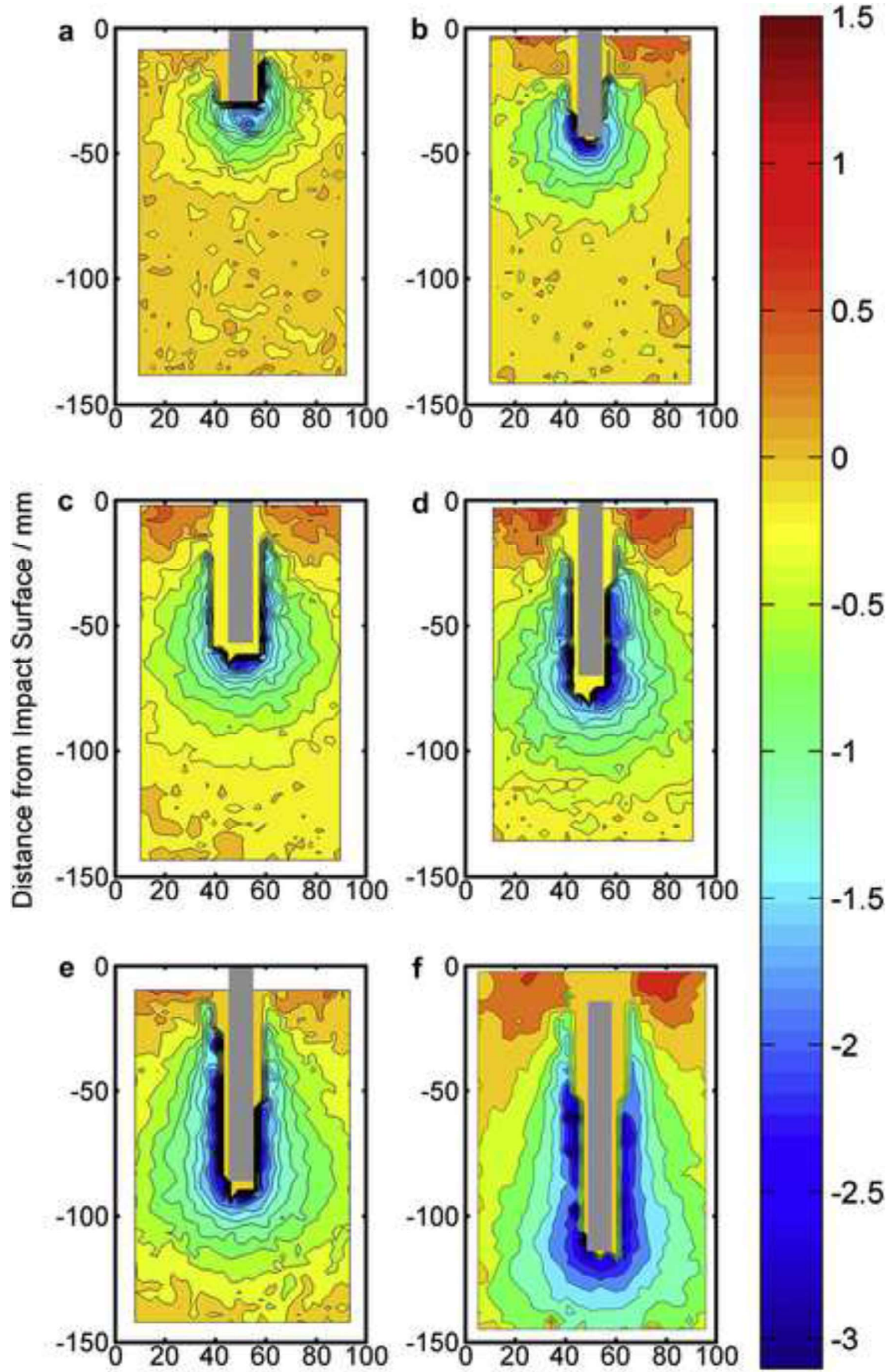

Distance from Edge of Sample / $\mathrm{mm}$ 

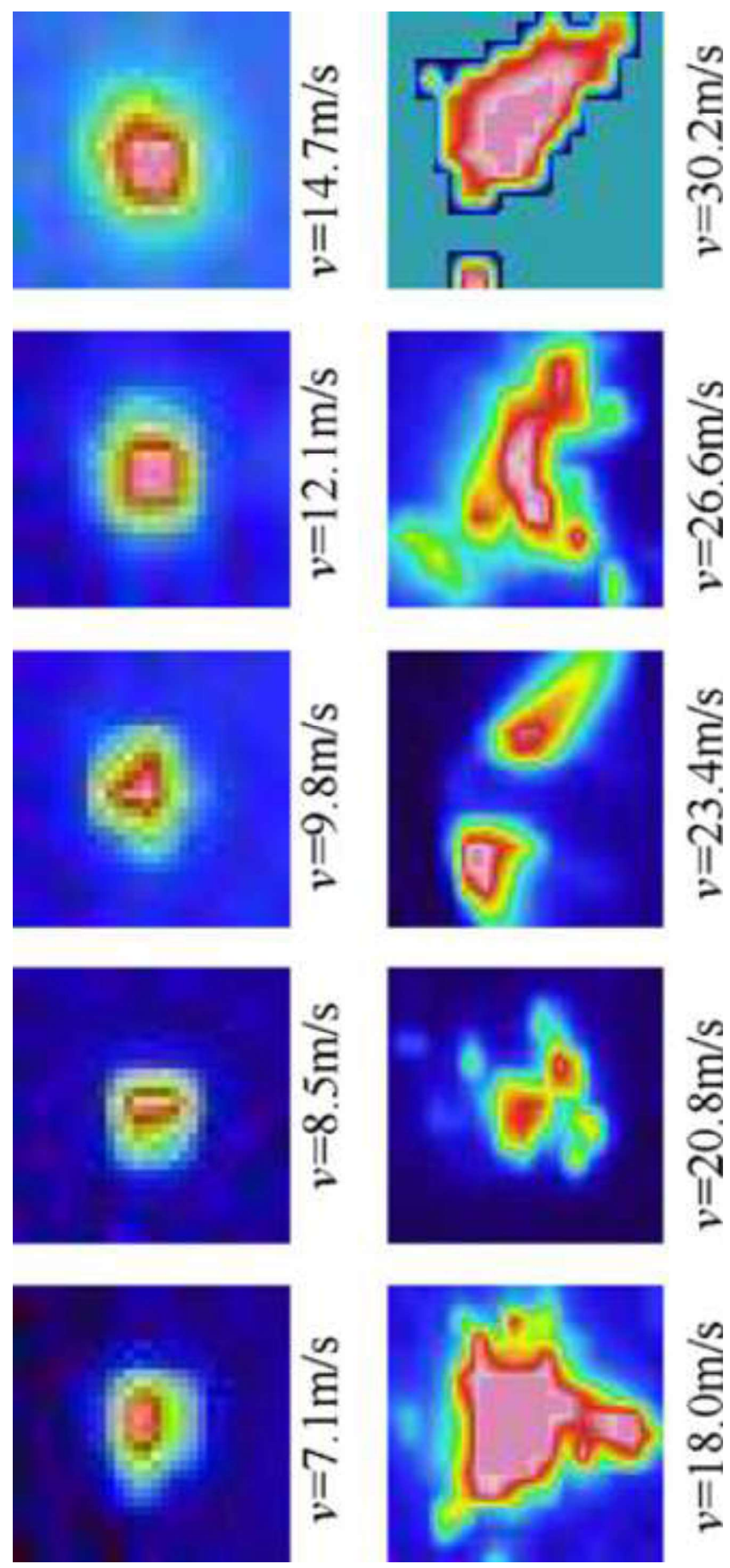

$\frac{\infty}{5}$ 